BRUNO HIDEKI NAKATA

Análise do Controle de Aerogeradores de Indução Duplamente Alimentados e do Perfil de Tensão em Redes de Subtransmissão

São Paulo 


\section{Análise do Controle de Aerogeradores de Indução Duplamente Alimentados e do Perfil de Tensão em Redes de Subtransmissão}

Dissertação apresentada à Escola Politécnica da Universidade de São Paulo para obtenção do título de Mestre em Ciências

Área de Concentração: Sistemas de Potência

Versão corrigida contendo as alterações solicitadas pela comissão julgadora em $01 \mathrm{de}$ Novembro de 2017

Orientador: Prof. Dr. Maurício Barbosa de Camargo Salles

São Paulo

2018 
Este exemplar foi revisado e corrigido em relação à versão original, sob responsabilidade única do autor e com a anuência de seu orientador.

São Paulo, 08 de Janeino de $20 / 8$

Assinatura do autor: Bundh/nakte.

Assinatura do orientador:

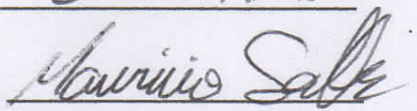

Catalogação-na-publicação

Nakata, Bruno Hideki

Análise do Controle de Aerogeradores de Indução Duplamente

Alimentados e do Perfil de Tensão em Redes de Subtransmissão / B. H.

Nakata -- versão corr. -- São Paulo, 2018.

$95 \mathrm{p}$.

Dissertação (Mestrado) - Escola Politécnica da Universidade de São

Paulo. Departamento de Engenharia de Energia e Automação Elétricas.

1.Energia Eólica 2. Energia Elétrica 3.Engenharia Elétrica 4.Sistemas Elétricos de Potência I. Universidade de São Paulo. Escola Politécnica.

Departamento de Engenharia de Energia e Automação Elétricas II.t. 
Dissertação de autoria de Bruno Hideki Nakata, sob o título "Análise do Controle de Aerogeradores de Indução Duplamente Alimentados e do Perfil de Tensão em Redes de Subtransmissão", apresentada à Escola Politécnica da Universidade de São Paulo, para obtenção do título de Mestre em Ciências, na área de concentração Sistemas de Potência, aprovada em 01 de Novembro de 2017 pela comissão julgadora constituída pelos doutores:

Prof. Dr. Maurício Barbosa de Camargo Salles

Presidente

Instituição: Escola Politécnica da Universidade de São Paulo (USP)

Prof. Dr. Ademir Pelizari

Instituição: Centro de Engenharia, Modelagem e Ciências Sociais Aplicadas - Universidade Federal do ABC (UFABC)

Prof. Dr. Ahda Pionkoski Grilo Pavani

Instituição: Centro de Engenharia, Modelagem e Ciências Sociais Aplicadas - Universidade Federal do ABC (UFABC) 


\section{Agradecimentos}

Ao professor Maurício Salles, pela orientação e apoio durante todo o desenvolvimento do trabalho, que foram fundamentais para a finalização desta dissertação.

Aos membros do laboratório de Eletromagnetismo Aplicado (LMAG) que contribuíram para o desenvolvimento deste trabalho: Cristian Torres Montenegro, David Joel Figueroa Cortés, Luís Felipe Normandia Lourenço, Luis Alejandro Gutierrez Gomez

Ao chefe e amigo Daniel Perez Duarte pelo apoio ao desenvolvimento deste trabalho.

Ao amigo Mateus Henrique Balan pela ajuda na revisão do texto final.

À minha família e amigos pelo apoio à minha formação acadêmica. 


\section{Resumo}

NAKATA, Bruno Hideki. Análise do Controle de Aerogeradores de Indução Duplamente Alimentados e do Perfil de Tensão em Redes de Subtransmissão. 2018. 95 f. Dissertação (Mestrado em Ciências) - Escola Politécnica, Universidade de São Paulo, São Paulo, 2018.

Com o aumento da penetração da energia eólica nos sistemas de potência, critérios cada vez mais rigorosos vem sendo estabelecidos ao longo do tempo para a conexão e operação das plantas eólicas nas redes elétricas. A evolução das tecnologias empregadas em turbinas possibilitou o atendimento a esses critérios, passando do conceito dinamarquês de turbinas de velocidade fixa para turbinas de velocidade variável, que possibilitam melhor aproveitamento da energia disponível nos ventos e maior capacidade de controle das grandezas envolvidas. Neste trabalho, foram analisados diferentes tipos de controle de um gerador de indução duplamente alimentado (DFIG) e a influência dessa máquina nos níveis de tensão de uma rede de subtransmissão à qual está conectada. Os resultados mostram que os tipos de controles indicados para a operação da planta eólica podem variar sensivelmente de acordo com o carregamento e a velocidade do vento em um determinado momento. $\mathrm{O}$ crescimento de carga esperado da rede também pode influenciar na estratégia de controle da planta.

Palavras-chave: Geração de Energia Eólica. Geradores de Indução de Dupla Alimentação. Sistemas Elétricos de Potência. Engenharia Elétrica. 


\begin{abstract}
NAKATA, Bruno Hideki. Analysis of the control of Doubly Fed induction Generators and the Voltage Profile in Subtransmission Networks. 2018. 95 p. Dissertation (Master of Science) - School of Arts, Sciences and Humanities, University of São Paulo, São Paulo, 2018.

With the increased penetration of wind energy in electrical power systems, increasingly stringent grid codes have been stablished over time for the connection and operation of wind power plants. The evolution of the technologies applied in wind turbines allowed meeting these criteria, moving from the Danish concept of fixed-speed turbines to variable-speed wind turbines, which enable better use of the available wind power and greater control of the variables involved. This study analyzes different control strategies of a doubly-fed induction generation (DFIG) and the influence of this machine in the voltage profile of a subtransmission system to which it is connected. The results show that the types of control suitable for the operation of the wind power plant may vary considerably according to the load and the wind speed at a given time. The expected load growth of the network can also influence in power plant control strategy.
\end{abstract}

Keywords: Wind Power Generation. Doubly-fed Induction Generator. Electrical Power Systems. Electrical Engineering. 


\section{Lista de figuras}

Figura 1: Previsão do mercado de energia eólica para o período 2016-2021.

Figura 2: Dados históricos e previsão da evolução da capacidade instalada de geração eólica no Brasil. 16

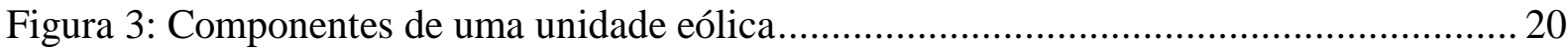

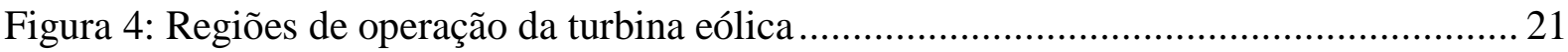

Figura 5: Comparação entre o desempenho de turbinas de velocidade fixa e variável ........... 23

Figura 6: Configuração de uma turbina eólica com gerador SCIG ..................................... 26

Figura 7: Configuração de uma turbina eólica com gerador DFIG .................................... 27

Figura 8: Configuração de uma turbina eólica com gerador PMSG …............................... 28

Figura 9: Circuito equivalente da máquina de indução duplamente alimentada .................... 32

Figura 10: Circuito equivalente da máquina DFIM com valores referidos no lado do estator 33

Figura 11: Quatro quadrantes de operação da máquina DFIM .......................................... 35

Figura 12: Diagrama de funcionamento do controlador RSC ......................................... 39

Figura 13: Diagrama de Funcionamento do controlador GSC ......................................... 39

Figura 14: Curva de capabilidade de corrente reativa para o gerador DFIG e para o conjunto DFIG \& conversor (Engelhardt, Erlich, Feltes, \& Kretschmann, 2011) ....

Figura 15: Curva de capabilidade de potência reativa para a turbina eólica (Engelhardt, Erlich, Feltes, \& Kretschmann, 2011)................................................................... 42

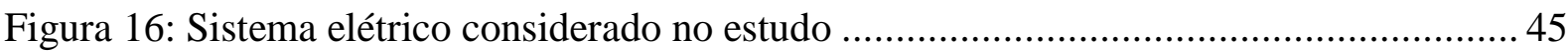

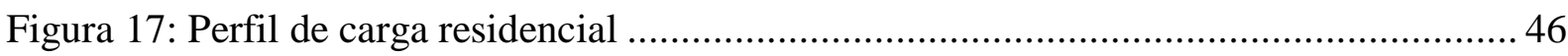

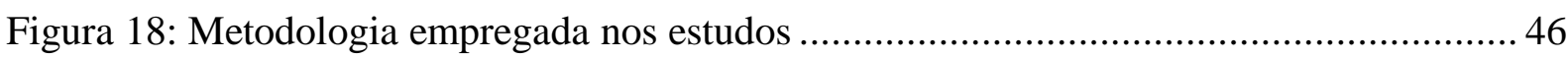

Figura 19: Tensão em função do horário do dia para cada barra do sistema (vento $=5 \mathrm{~m} / \mathrm{s}$ ) .49

Figura 20: Tensão em função do horário do dia para cada barra do sistema (vento $=16 \mathrm{~m} / \mathrm{s}$ ) 49

Figura 21: Potência reativa no ponto de conexão com a rede ............................................ 50

Figura 22: Potência ativa no ponto de conexão com a rede .............................................. 51

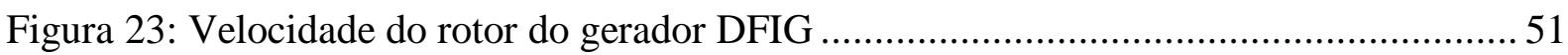

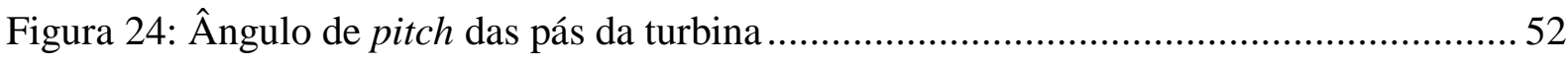

Figura 25: Tensão na barra B7 para todos os valores de carga e velocidade do vento............ 53

Figura 26: Mapa de operação da planta para controle de fator de potência unitário............... 54

Figura 27: Tensão em função do horário do dia para cada barra do sistema (vento $=5 \mathrm{~m} / \mathrm{s}$ ) .54

Figura 28: Tensão em função do horário do dia para cada barra do sistema (vento $=16 \mathrm{~m} / \mathrm{s}$ ). 55

Figura 29: Potência reativa no ponto de conexão com a rede. 
Figura 30: Tensão na barra B7 para todos os valores de carga e velocidade do vento. 56

Figura 31: Mapa de operação para controle de fator de potência 0,92 indutivo .56

Figura 32: Tensão em função do horário do dia para cada barra do sistema (vento $=5 \mathrm{~m} / \mathrm{s}$ ). .57

Figura 33: Tensão em função do horário do dia para cada barra do sistema (vento $=16 \mathrm{~m} / \mathrm{s}$ ) 58

Figura 34: Potência reativa no ponto de conexão com a rede 58

Figura 35: Tensão nas barras no horário de menor carga 59

Figura 36: Mapa de operação para controle de fator de potência em 0,92 capacitivo 60

Figura 37: Valores de tensão na barra B7 para todas as situações de carga e velocidade do vento

Figura 38: Mapa de operação para controle de tensão em 1p.u. 61

Figura 39: Tensão na barra B7 para todas as situações de carga e velocidade do vento 63

Figura 40: Primeira alternativa para mapa operativo geral da planta eólica..... 64

Figura 41: Rede elétrica e os novos valores das cargas

Figura 42: Tensão na barra B7 para todas as condições de carga e velocidade do vento controle de fator de potência unitário

Figura 43: Mapas operativos para controle de fator de potência unitário considerando diferentes cenários de carga

Figura 44: Tensão na barra B7 para todas as condições de carga e velocidade do vento controle de fator de potência 0,92 indutivo

Figura 45: Mapas operativos para controle de fator de potência 0,92 indutivo considerando diferentes cenários de carga

Figura 46: Mapa operativo para controle de fator de potência 0,98 indutivo considerando crescimento de carga.

Figura 47: Tensão na barra B7 para todas as condições de carga e velocidade do vento controle de fator de potência 0,92 capacitivo.

Figura 48: Mapas operativos para controle de fator de potência 0,92 capacitivo considerando diferentes cenários de carga

Figura 49: Mapa operativo geral para a planta eólica considerando rede com crescimento de carga....... 74

Figura 50: Perfil de carga comercial 75

Figura 51: Tensão na barra B7 para todas as condições de carga e velocidade do vento controle de fator de potência unitário ........................................................... 76

Figura 52: Mapa de operação para controle de fator de potência unitário. 76 
Figura 53: Tensão na barra B7 para todas as condições de carga e velocidade do vento controle de fator de potência 0,92 indutivo...................................................... 77

Figura 54: Mapa de operação para controle de fator de potência 0,92 indutivo ..................... 78

Figura 55: Tensão na barra B7 para todas as condições de carga e velocidade do vento controle de fator de potência 0,92 capacitivo....................................................... 79

Figura 56: Mapa de operação para controle de fator de potência 0,95 ................................. 79

Figura 57: Mapa de operação para controle de tensão em 1p.u. ............................................ 80

Figura 58: Tensão na barra B7 para todas as condições de carga e velocidade do vento controle de potência reativa em 0.03 p.u.

Figura 59: Mapa operativo geral da planta eólica para a rede com consumidores comerciais 82

Figura 60: Perfil de carga industrial

Figura 61: Tensões na barra B7 para todos os valores de carregamento e velocidade do vento controle de fp unitário 83

Figura 62: Mapa operativo para controle de fator de potência unitário..... 84

Figura 63: Tensões na barra B7 para todos os valores de carregamento e velocidade do vento - controle de fp 0,92 indutivo 85

Figura 64: Mapa operativo para controle de fator de potência 0,92 indutivo 86

Figura 65: Tensões na barra B7 para todas as condições de carregamento e velocidade do vento - Controle de fator de potência 0,92 capacitivo 87

Figura 66: Mapa operativo para controle de fator de potência 0,92 capacitivo 87

Figura 67: Mapa operativo geral da planta com consumidores industriais 88 


\section{Lista de abreviaturas e siglas}

ABEEólica

$\mathrm{AC}$

DC

DFIG

DFIG

DPC

DTC

GIDA

GIGE

GSC

GSIP

GWEC

HVRT

LVRT

MPPT

PI

PMSG

p.u.

RSC

SCIG
Associação Brasileira de Energia Eólica

Corrente alternada ou alternating current

Corrente contínua ou direct current

Doubly-fed induction generator

Doubly-fed induction machine

Direct power control

Direct torque control

Gerador de indução duplamente alimentado

Gerador de indução com rotor em gaiola de esquilo

Grid-side converter

Gerador síncrono de imã permanente

Global Wind Energy Council

High-voltage ride through

Low-voltage ride through

Maximum power point tracking

Proporcional-integral

Permanent-magnetic synchronous generator

Por unidade

Rotor-side converter

Squirrel-cage induction generator 


\section{Lista de símbolos}

\section{Lista de símbolos referentes à modelagem da máquina de indução duplamente alimentada (DFIM)}

\begin{tabular}{|c|c|}
\hline$\omega_{m}$ & Frequência angular do rotor \\
\hline$\omega_{r}$ & Frequência angular das correntes e tensões induzidas no rotor \\
\hline$\omega_{s}$ & Frequência angular das correntes e tensões induzidas no estator \\
\hline$\overline{E_{r s}}$ & Tensão induzida no rotor \\
\hline$E_{s}$ & Tensão induzida no estator \\
\hline$\overline{I_{r}}$ & Corrente induzida no rotor \\
\hline$\overline{I_{s}}$ & Corrente induzida no estator \\
\hline$N_{r}$ & Número de espiras por fase do rotor \\
\hline$N_{s}$ & Número de espiras por fase do estator \\
\hline$p$ & Número de pólos da máquina \\
\hline$P_{m e c}$ & Potência mecânica da máquina \\
\hline$P_{r}$ & Potência ativa no rotor \\
\hline$P_{s}$ & Potência ativa no estator \\
\hline Perdas ${ }_{C u \_r}$ & Perdas no cobre do rotor \\
\hline $\operatorname{Perdas}_{C u \_s}$ & Perdas no cobre do estator \\
\hline$R_{r}$ & Resistência do rotor \\
\hline$R_{s}$ & Resistência do estator \\
\hline$s$ & Escorregamento \\
\hline$T_{e m}$ & Torque eletromecânico no eixo da máquina \\
\hline$\overline{V_{s}}$ & Tensão fornecida ao estator pela rede \\
\hline$\overline{V_{r}}$ & Tensão fornecida ao rotor \\
\hline$X_{\sigma r}$ & Reatância de dispersão do rotor \\
\hline$X_{\sigma S}$ & Reatância de dispersão do estator \\
\hline
\end{tabular}

Lista de símbolos referentes ao controlador do conversor RSC

$I_{d r} \quad$ Componente de eixo direto da corrente medida no rotor

I dr_ref Componente de eixo direto da corrente de referência do rotor

$I_{q r} \quad$ Componente de eixo de quadratura da corrente medida no rotor 
$I_{\text {qr_ref }} \quad$ Componente de eixo de quadratura da corrente de referência no rotor

Potência ativa medida

$P_{\text {ref }} \quad$ Potência ativa de referência

Potência reativa medida

$Q_{\text {ref }}$

Potência reativa de referência no modo de regulação de potência reativa

V

Tensão medida

$V_{d r}$

Componente de eixo direto da tensão de referência no lado do rotor

$V_{q r}$

Componente de eixo de quadratura da tensão de referência no lado do rotor

$V_{\text {ref }}$

Tensão de referência no modo de regulação de tensão

\section{Lista de símbolos referentes ao controlador do conversor GSC}

I dgrid Componente de eixo direto da corrente medida na rede

Idgrid_ref

Componente de eixo direto da corrente de referência no lado da rede

$I_{\text {qgrid }}$

Componente de eixo de quadratura da corrente medida no lado da rede

Iqgrid_ref

Componente de eixo de quadratura da corrente de referência no lado da rede

$V_{d c}$

Tensão medida no link DC do conversor

$V_{d c \_r e f}$

Tensão de referência no link DC do conversor

$V_{d g r i d}$

Componente de eixo direto da tensão de referência no lado da rede

$V_{\text {qgrid }}$

Componente de eixo de quadratura da tensão de referência no lado da rede 


\section{Sumário}

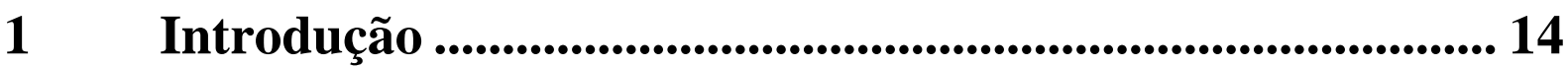

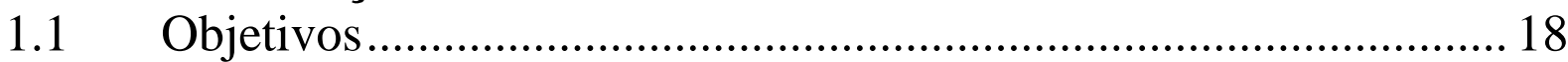

1.2 Organização da Dissertação ...................................................... 18

2 Turbinas Éólicas ....................................................................... 20

2.1 Modos de Operação de Turbinas Eólicas ....................................... 21

2.1.1 Operação em Velocidade Fixa ................................................................. 22

2.1.2 Operação em Velocidade Variável........................................................ 22

2.2 Sistemas de Controle Aerodinâmico para Limitação da Potência . 23

2.2.1 Controle por Perda Aerodinâmica passivo (Stall passivo) .................... 24

2.2.2 Controle de Ângulo de Passo (pitch) ..................................................... 24

2.2.3 Controle por Perda Aerodinâmica Ativo (stall ativo)........................... 24

2.3 Tipos de Turbinas ............................................................................ 24

2.3.1 Gerador de Indução em Gaiola de Esquilo (SCIG) ................................ 25

2.3.2 Gerador de Indução Duplamente Alimentado (DFIG) ......................... 27

2.3.3 Gerador Síncrono de imã Permanente (PMSG) ...................................... 28

2.4 Considerações Gerais ............................................................... 29

3 Modelagem, Operação e Controle do DFIG ....................... 31

3.1 Modelagem do DFIG ............................................................... 31

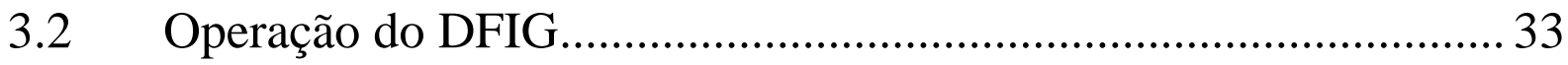

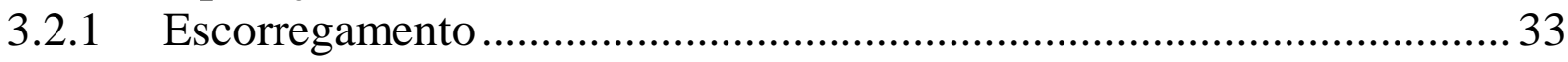

3.2.2 Operação em Quatro Quadrantes da DFIM .......................................... 34

3.2.3 Operação do DFIG nos Modos Subsíncrono e Supersíncrono ............... 36

3.3 Controle da Turbina com Gerador DFIG ...................................... 37

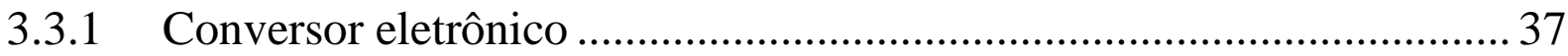

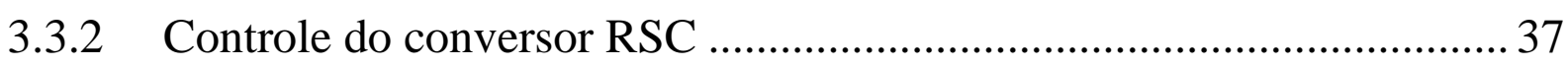

3.3.3 Controle do Conversor GSC …............................................................. 39

3.4 Capabilidade de Potência Reativa de Turbinas com Geradores

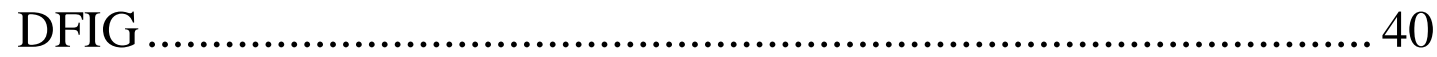

3.5 Considerações Gerais ......................................................... 42

4 Análise dos Níveis de Tensão da Rede e Tipos de Controle do Gerador DFIG Considerando Perfil de Carga

Residencial........................................................................ 44

4.1 Sistema Elétrico Considerado........................................................ 44

4.2 Limites de Tensão e Fator de Potência no Ponto de Conexão ....... 45

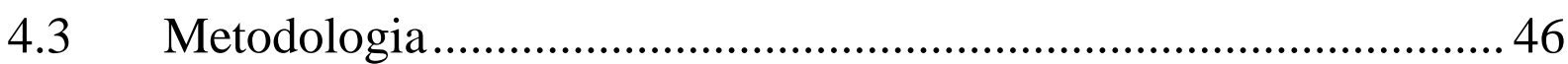

4.3.1 Limites de Tensão ........................................................................... 47 
4.3.2 Capabilidade de Potência Reativa ......................................................... 48

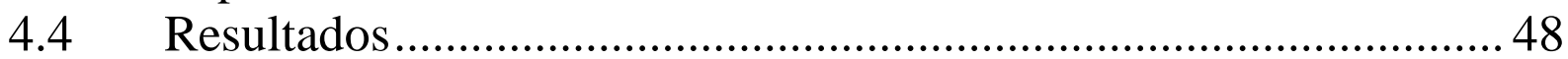

4.4.1 Controle de Fator de Potência Unitário................................................... 48

4.4.2 Controle de Fator de Potência 0,92 Indutivo .......................................... 54

4.4.3 Controle de Fator de Potência 0,92 Capacitivo .....................................5 57

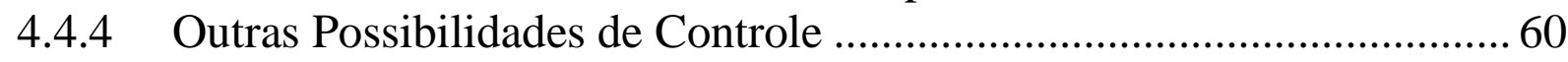

4.4.4.1 Controle de tensão em 1pu da planta eólica: ...................................................60

4.4.4.2 Injeção de valor fixo de potência reativa para velocidades reduzidas: ............62

4.4.5 Mapa Operativo Geral da Planta para a Rede com Consumidores

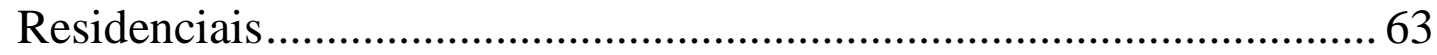

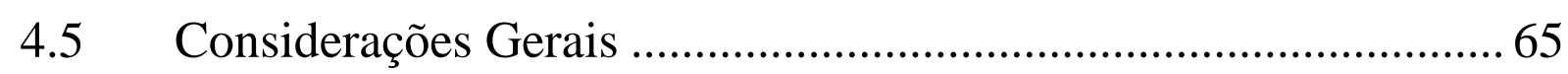

5 Análise da Influência do Crescimento de Carga da Rede e Análise Considerando Diferentes Tipos de Consumidores 67

5.1 Análise da Influência do Crescimento de Carga da Rede .............. 67

5.1.1 Controle de Fator de Potência Unitário......................................................67

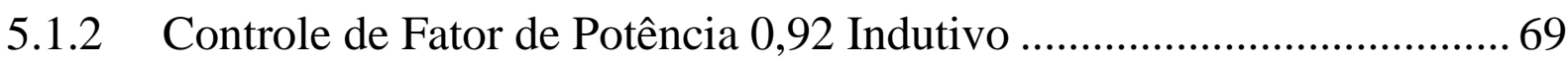

5.1.3 Controle de Fator de Potência em 0,98 indutivo.................................... 71

5.1.4 Controle de Fator de Potência 0,92 Capacitivo ...................................... 71

5.1.5 Mapa Operativo Geral para a Rede Considerando Crescimento de Carga

5.2 Análise Considerando Perfil de Carga Comercial......................... 74

5.2.1 Controle de Fator de Potência Unitário.................................................... 75

5.2.2 Controle de Fator de Potência 0,92 indutivo............................................. 77

5.2.3 Controle de Fator de Potência 0,92 capacitivo ...................................... 78

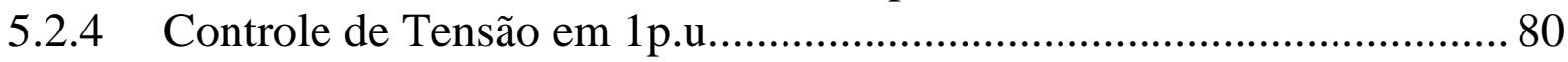

5.2.5 Controle de Potência Reativa em 0.03p.u............................................ 80

5.2.6 Mapa Operativo Geral da Planta Eólica Considerando Consumidores

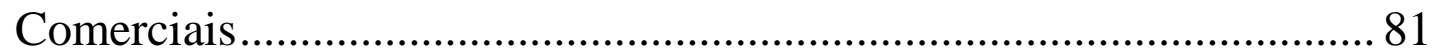

5.3 Análise Considerando Perfil de Carga Industrial ......................... 82

5.3.1 Controle de Fator de Potência Unitário.................................................. 83

5.3.2 Controle de Fator de Potência 0,92 Indutivo .......................................... 84

5.3.3 Controle de Fator de Potência 0,92 capacitivo ....................................... 86

5.3.4 Mapa Operativo Geral da Planta Eólica para a Rede com Consumidores

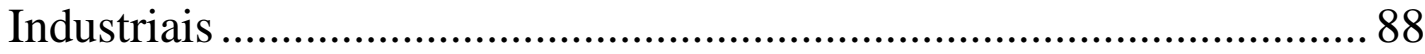

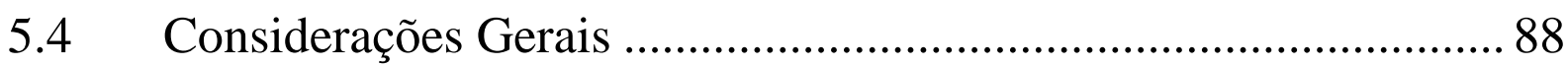

6 Conclusões e Trabalhos Futuros ........................................... 90

Referências.............................................................................................. 93 


\section{Introdução}

A energia eólica, ou energia contida nos ventos, é utilizada há muito tempo pelo homem em diversas atividades, como movimentar moinhos, impulsionar veleiros e gerar eletricidade. A utilização da energia eólica para geração de eletricidade teve início no fim do século XIX, com diversos avanços tecnológicos sendo obtidos até a década de 1990, quando se tornou uma das principais fontes utilizadas para produção de energia elétrica (Sohn, 2014).

Entre as vantagens da energia eólica em relação a outras fontes para geração de energia elétrica, podem ser citadas (Pinto, 2013), (Muller, Deicke, \& Doncker, 2002), (Salles, 2009), (Sohn, 2014):

- Tempo reduzido para implantação do parque eólico, construção modular e manutenção reduzida;

- Energia limpa e renovável, com baixo impacto ambiental. Não provoca danos ao solo, como plantas de geração que utilizam carvão, e não produze lixo radioativo com os riscos de contaminação relacionados à energia nuclear;

- Em relação à energia hidráulica, não necessita de grandes espaços para construção de reservatórios, e o espaço utilizado pode ser empregado para outras atividades (agricultura e pecuária, por exemplo);

- Independência e diversificação da fonte energética, não dependendo da variação dos preços dos combustíveis fósseis;

- Possibilidade de operação em regime complementar em relação a outras fontes de energia, por exemplo, intensificando o uso da energia eólica e armazenando água durante o período de poucas chuvas.

Entre as desvantagens, são listadas (Pinto, 2013), (Salles, 2009), (Sohn, 2014):

- Poluição visual;

- Instalação em rotas de pássaros;

- Cintilação luminosa;

- Ruído;

- Influência no regime de ventos e na temperatura do clima local;

- Dificuldade para previsão do vento (Schubert, 2012);

- Perda de inércia mecânica do sistema elétrico (Hansen, Altin, \& Iov, 2016), (Mohseni \& Islam, 2012) e (Vyver, Kooning, Meersman, Vandevelde, \& Vandoorn, 2015); 
- Oscilações de potência ativa e reativa, decorrentes da variação estocástica do vento, com impacto nos níveis de tensão e frequência no ponto de conexão com a rede elétrica (Hansen, Altin, \& Iov, Provision of enhanced ancillary services from wind power plants-Examples and challenges, 2016), (Mohseni \& Islam, 2012).

As características positivas apresentadas, os incentivos governamentais para maior utilização de energias limpas e a busca por redução de custos justificam o crescimento da utilização da geração eólica como fonte de energia elétrica (Sohn, 2014).

A capacidade instalada global de energia eólica chegou a 486,8 GW em 2016, com perspectiva de atingir 741,7 GW até 2021. A Figura 1 apresenta dados de capacidade acumulada, capacidade instalada no ano e crescimento esperado da capacidade acumulada para o período de 2016 a 2021 (GWEC, 2016).

Figura 1: Previsão do mercado de energia eólica para o período 2016-2021.

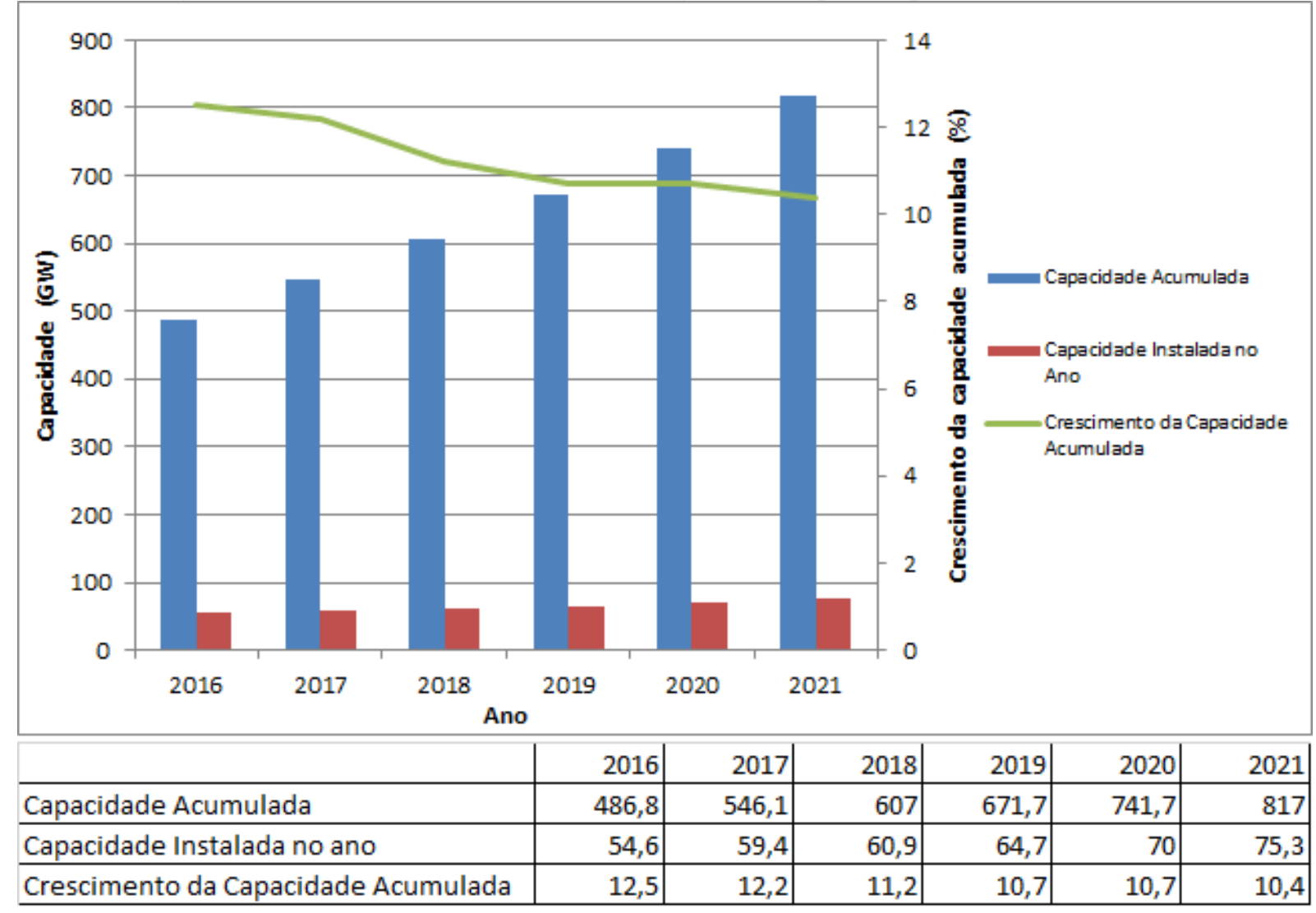

Em 2016, o Brasil atingiu a marca de 10,75 GW de capacidade acumulada, sendo o nono país com maior capacidade instalada acumulada no mundo. A perspectiva é que a capacidade chegue a 17,3 GW em 2020, conforme apresentado na Figura 2 (ABEEólica, 2016). 
Com o crescimento da penetração da geração eólica, as desvantagens citadas anteriormente tornam-se mais críticas. Em relação à operação dos sistemas elétricos, a perda de inércia mecânica faz com que o sistema elétrico esteja mais susceptível à perda de estabilidade após uma contingência. Além disso, as variações nos valores de potência ativa e reativa geradas, devido às variações existentes na velocidade do vento, causam variações nos valores de tensão e frequência no ponto de conexão da planta eólica com o sistema elétrico.

Figura 2: Dados históricos e previsão da evolução da capacidade instalada de geração eólica no Brasil.

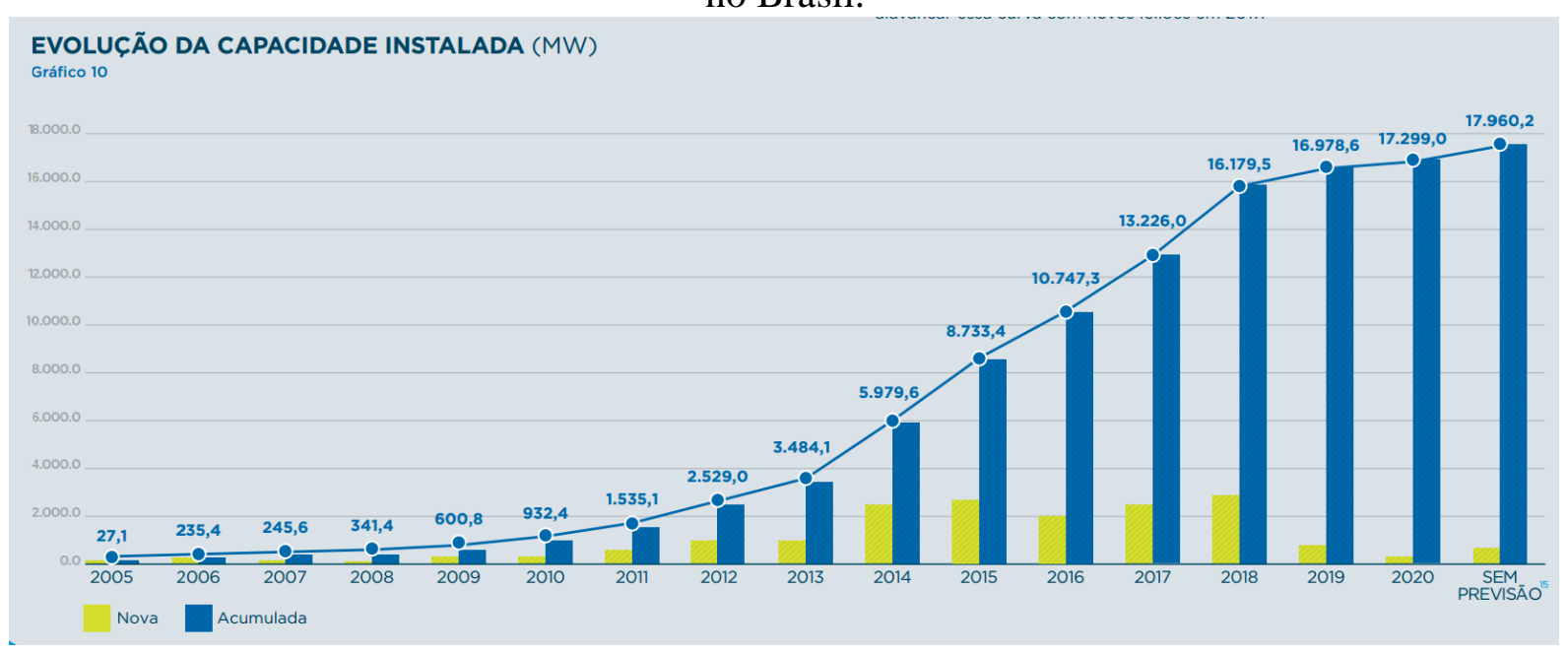

Fonte: ABEEólica.

Para mitigar esses problemas, foram estabelecidos ao longo dos anos requisitos cada vez mais exigentes para a operação das plantas eólicas, com a tarefa de manter a estabilidade do sistema durante condições normais de operação e de contingência não recaindo apenas sobre as plantas de fontes convencionais de energia. Os principais requisitos vigentes para operação das plantas eólicas nos sistemas elétricos, especialmente em sistemas com alta penetração dessa tecnologia, são listados a seguir (MacDowell, Dutta, Richwine, Achilles, \& Miller, 2015), (Mohseni \& Islam, 2012):

- Operação contínua durante distúrbios de tensão causados por contingências - low voltage ride-through (LVRT) e high voltage ride-through (HVRT);

- Requisitos de potência ativa e reativa para resposta a distúrbios na rede;

- Operação das plantas eólicas em extensas faixas de variação de frequência e tensão;

- Controle de potência ativa para resposta a variações de frequência no ponto de conexão com a rede;

- Controle de potência reativa para resposta a variações de tensão no ponto de conexão com a rede. 
Os dois primeiros requisitos referem-se à operação após uma contingência da rede, enquanto os três seguintes estão relacionados à operação em condições normais (estado permanente).

Naturalmente, para viabilizar o aumento da penetração nos sistemas elétricos e atender aos requisitos estabelecidos para conexão e operação das plantas eólicas nesses sistemas, as tecnologias empregadas nas turbinas eólicas evoluíram ao longo do tempo.

No início da década de 1990, as turbinas utilizavam predominantemente o conceito de operação em velocidade fixa (Hansen, Iov, Blaabjerg, \& Hansen, 2004). Essas turbinas são compostas por um gerador de indução conectado diretamente à rede, projetadas para obter eficiência máxima para um valor de velocidade do vento, por isso são conhecidas como turbinas de velocidade fixa. Possuem como principais vantagens serem simples, robustas e com baixo custo em relação a outras tecnologias. Entretanto, por operarem em apenas velocidade única (mais precisamente em uma faixa bastante restrita de velocidade), não possibilitam o aproveitamento máximo da energia disponível nos ventos. Além disso, variações na velocidade do vento, que resultam em variações na potência ativa gerada pela turbina, podem causar variações significativas de tensão em sistemas elétricos com baixo momento de inércia. Outra desvantagem dessa tecnologia está no fato de não permitir o controle de potência reativa absorvida ou injetada na rede. O gerador de indução em gaiola de esquilo (GIGE), ou squirrel cage induction generator (SCIG), é a principal tecnologia utilizada nas turbinas de velocidade fixa (Hansen, Iov, Blaabjerg, \& Hansen, 2004), (Marques, 2004), (Sohn, 2014).

Posteriormente, passaram a ser utilizadas as chamadas turbinas de velocidade variável, que permitem variar a velocidade rotacional da turbina de acordo com a velocidade do vento, obtendo assim máxima eficiência aerodinâmica para uma faixa grande de velocidades do vento. Nessas turbinas podem ser utilizados tanto geradores de indução quanto geradores síncronos, conectados à rede através de conversores de potência.

Com o desenvolvimento e aperfeiçoamento das turbinas de velocidade variável e dos conversores de potência, além do melhor aproveitamento da energia disponível nos ventos, tornou-se possível realizar o controle de potência ativa e reativa (controle de tensão e frequência no ponto de conexão com o sistema elétrico), assim como melhorar a resposta a surtos causados por contingências na rede. O gerador síncrono de imã permanente (GSIP), ou permanentemagnetic synchronous generator (PMSG), e o gerador de indução duplamente alimentado (GIDA), ou doubly-fed induction generation (DFIG), são duas das tecnologias mais utilizadas nas turbinas de velocidade variável (Hansen, Iov, Blaabjerg, \& Hansen, 2004), (MacDowell, Dutta, Richwine, Achilles, \& Miller, 2015), (Marques, 2004), (Salles, 2009), (Sohn, 2014). 
Tanto o gerador PMSG quanto o gerador DFIG utilizam conversores de potência para realizar a conexão com a rede. O estator do gerador PMSG é conectado à rede através de um conversor projetado para transmitir $100 \%$ da potência elétrica de saída do gerador. Já no gerador DFIG, enquanto o estator é conectado diretamente à rede elétrica, um conversor é utilizado para conectar o rotor da máquina à rede. Dessa maneira, a potência elétrica transmitida pelo conversor é menor em relação ao conversor do gerador WRSG, o que resulta em custos reduzidos desse equipamento. Esse é um dos motivos pelo qual o gerador DFIG é a tecnologia mais utilizada em turbinas eólicas atualmente (Marques, 2004), (Sohn, 2014).

Com a evolução desses conversores e das demais tecnologias empregadas nas turbinas, as unidades eólicas atualmente tem capacidade para cumprir de maneira satisfatória os requisitos estabelecidos para operação nos sistemas elétricos mesmo em casos com alta penetração desse tipo de geração (MacDowell, Dutta, Richwine, Achilles, \& Miller, 2015).

\subsection{Objetivos}

O objetivo principal deste trabalho é analisar os níveis de tensão de uma rede de subtransmissão de energia em condições normais de operação (sem contingências), além dos tipos de controle das turbinas de uma planta eólica conectada a essa rede. A partir dessas análises, espera-se obter os seguintes resultados:

- Determinação dos tipos de controle adequados para cada ponto de operação da rede, mantendo os valores de tensão e potência reativa no ponto de conexão da planta eólica com a rede dentro dos limites operativos. Um ponto de operação é representado por um valor de carga e uma determinada velocidade do vento. Foram estudados três perfis de carga: residencial, comercial e industrial.

- Verificação da influência do crescimento de carga nos níveis de tensão da rede e nos tipos de controle utilizados para cada ponto de operação.

O sistema de distribuição considerado nos estudos, que será detalhado mais adiante, foi conectado a uma planta eólica com capacidade 30 MW, composta por 20 geradores DFIG de $1,5 \mathrm{MW}$.

\subsection{Organização da Dissertação}

Após o capítulo introdutório, esta dissertação está organizada da seguinte maneira: 
No capítulo 2 são apresentados conceitos sobre turbinas eólicas que serão explorados durante o trabalho. O capítulo inicia-se com informações sobre os componentes de uma unidade eólica, seguido dos modos de operação e dos tipos de controle para limitação da potência elétrica gerada. Por fim, são apresentados os principais tipos de geradores empregados nas turbinas.

O capítulo 3 aborda o gerador de indução duplamente alimentado (DFIG), que foi o gerador empregado nas turbinas da planta eólica conectada à rede do estudo. São apresentados detalhes sobre o funcionamento, operação e controle do gerador DFIG.

O capítulo 4 apresenta o sistema elétrico considerado nos estudos, a metodologia e os resultados obtidos para a rede considerando consumidores residências. São apresentados os valores de tensão no ponto de conexão com a rede utilizando diferentes estratégias de controle, para diferentes condições de carregamento e velocidade do vento. Por fim, são propostas estratégias operativas, combinando os tipos de controle analisados, para que seja possível operar a planta eólica sem violação dos critérios de tensão e potência reativa em todas as condições de carregamento e velocidade do vento observadas.

No capítulo 5, são apresentados os resultados do estudo considerando consumidores com diferentes perfis de carga (comercial e industrial), além de analisar a influência do crescimento de carga esperado para a rede nos níveis de tensão.

O capítulo 6 apresenta as conclusões obtidas e sugestões de trabalhos futuros. 


\section{Turbinas Eólicas}

Os componentes básicos de uma unidade eólica são apresentados na Figura 3.

Figura 3: Componentes de uma unidade eólica

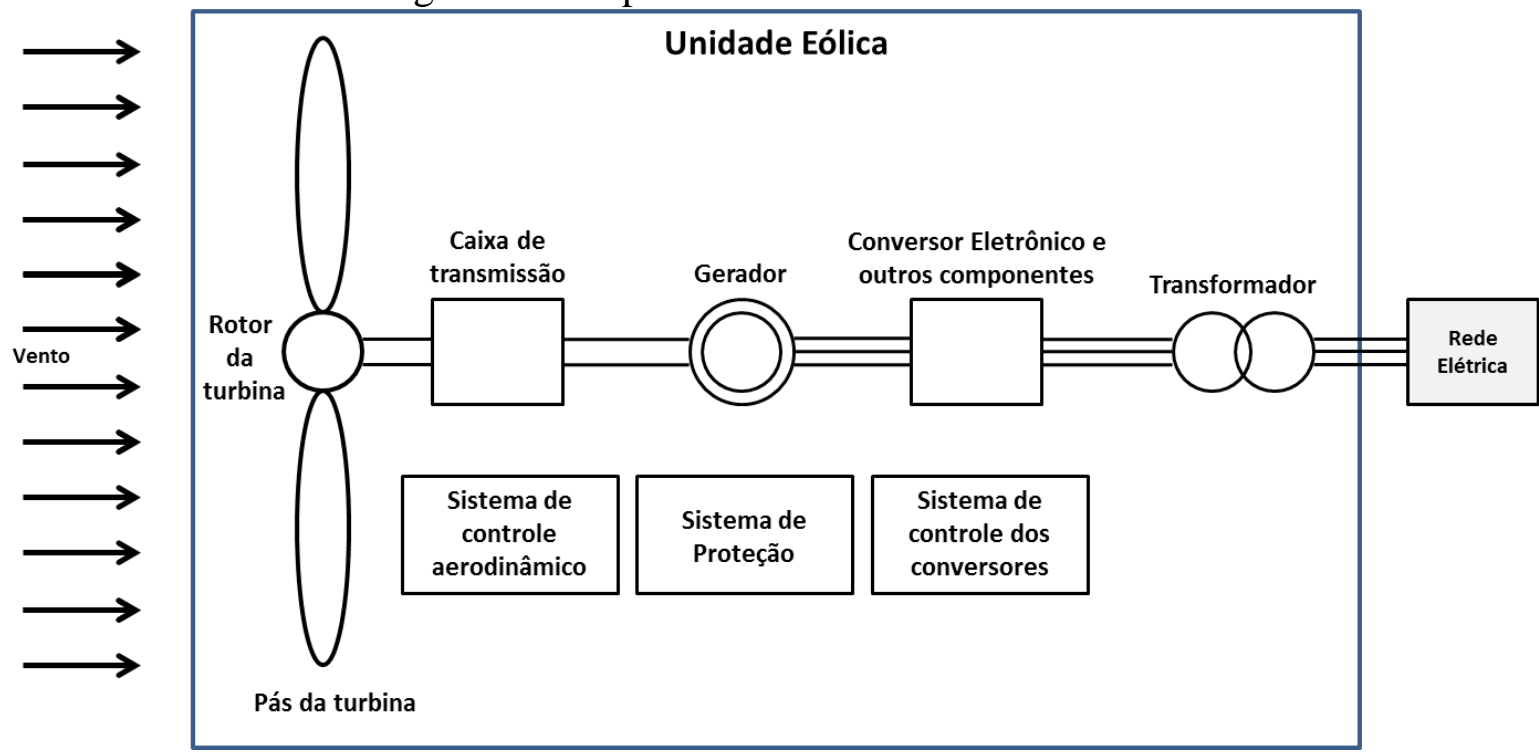

As turbinas eólicas ou aerogeradores são utilizadas para conversão da energia eólica contida nos ventos em energia mecânica, através da rotação das pás da turbina. Essa energia mecânica movimenta o rotor da turbina, sendo transmitida ao rotor do gerador normalmente através de uma caixa de transmissão. O gerador elétrico, que pode ser tanto um gerador síncrono como um gerador de indução, converte a energia mecânica em energia elétrica, transmitindo-a para a rede elétrica através de um transformador aumentador (Abad, López, Rodriguez, Marroyo, \& Iwanski, 2011), (Sohn, 2014).

Dependendo da tecnologia utilizada, a transmissão da energia do gerador para a rede elétrica pode ser feita de maneira direta ou utilizando-se conversores eletrônicos. Para os casos em que a conexão é feita sem conversores, geralmente são utilizados soft-starters para iniciar a operação do gerador e bancos de capacitores para realizar a compensação da potência reativa consumida pela máquina (Abad, López, Rodriguez, Marroyo, \& Iwanski, 2011), (Hansen, Iov, Blaabjerg, \& Hansen, 2004), (Marques, 2004), (Sohn, 2014), (Tripathy \& Rourkela, 2014).

As turbinas possuem um sistema de controle aerodinâmico que permite limitar a potência ativa gerada pela máquina, sistema de controle associado ao conversor de potência para controle das potências ativa e reativa injetada/consumida, além de um sistema de proteção (Abad, López, Rodriguez, Marroyo, \& Iwanski, 2011), (Sohn, 2014). 


\subsection{Modos de Operação de Turbinas Eólicas}

Para melhor entendimento dos modos de operação das turbinas eólicas, será apresentado inicialmente o conceito de regiões de operação da turbina eólica. Conforme gráfico da potência gerada pela turbina de acordo com a velocidade do vento, ilustrado na Figura 4, a operação de uma turbina pode ser dividida em quatro regiões (Abad, López, Rodriguez, Marroyo, \& Iwanski, 2011), (Marques, 2004), (Novak, 1995):

- Região I ou região de partida: Região delimitada pelo valor de velocidade do vento que causa a partida da máquina.

- Região II ou região de operação normal: Região de operação normal da turbina, que pode ser feita tanto em velocidade fixa quanto em velocidade variável. Nessa região, a turbina pode funcionar tanto no modo sub-síncrono (abaixo da velocidade síncrona do gerador) como em modo super-síncrono (acima da velocidade síncrona).

- Região III ou região de limitação de potência: região em que ocorre limitação da potência ativa da turbina através do sistema de controle aerodinâmico, devido aos valores elevados da velocidade do vento.

- Região IV ou região de desligamento: região determinada pelo valor de velocidade do vento a partir do qual ocorre o desligamento da máquina, para evitar possíveis danos aos componentes da mesma.

Figura 4: Regiões de operação da turbina eólica

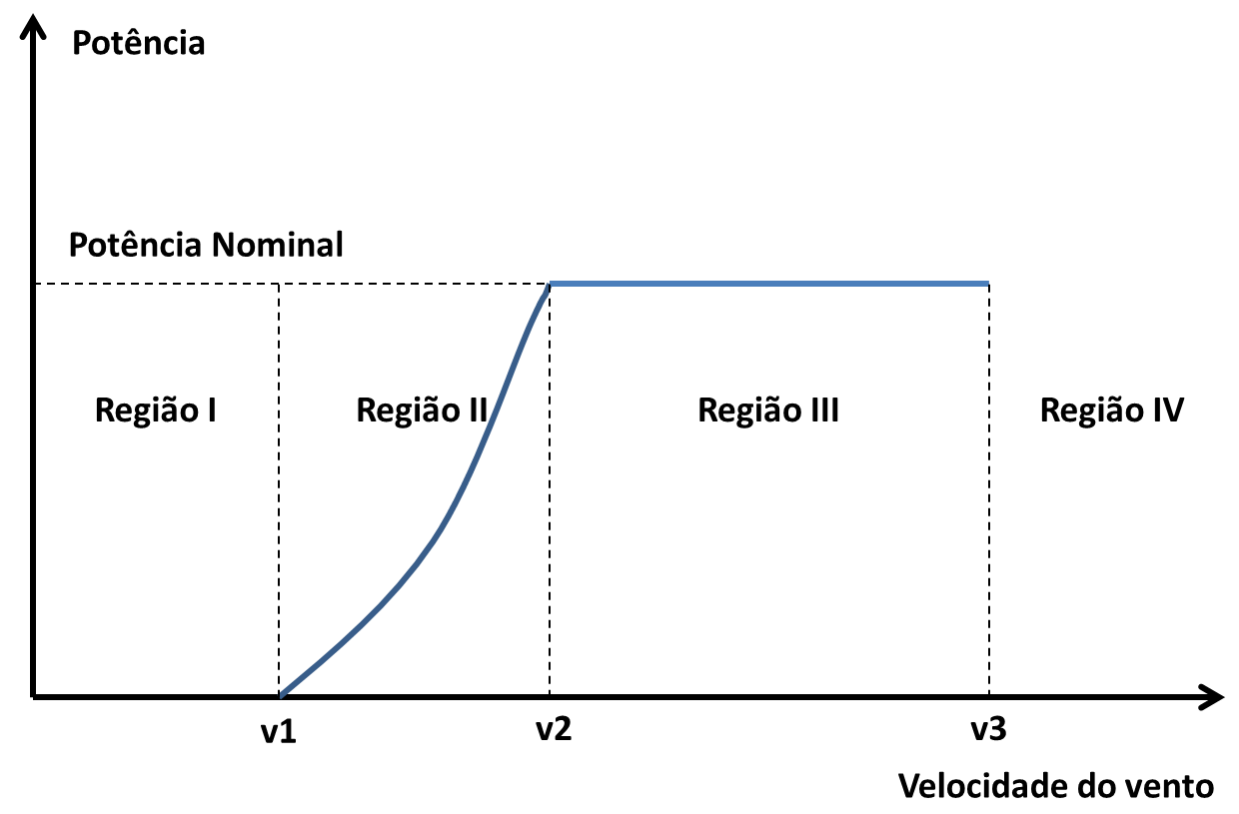


Assim, na região de operação normal, podem ser utilizados dois modos de operação das turbinas: velocidade fixa e velocidade variável.

\subsubsection{Operação em Velocidade Fixa}

Turbinas de velocidade fixa possuem o estator conectado diretamente à rede elétrica. Dessa maneira, a velocidade do rotor é determinada pela frequência da rede e pelo número de

pólos do gerador, permanecendo praticamente constante (fixa). O escorregamento do gerador dessas turbinas é bastante reduzido, por volta de 1-2\% (Marques, 2004), (Sohn, 2014).

As turbinas de velocidade fixa são projetadas para obter máximo aproveitamento aerodinâmico para uma determinada velocidade do vento. As principais vantagens dessa tecnologia em relação às turbinas de velocidade variável referem-se à robustez, simplicidade e baixo custo, sendo que o custo reduzido se deve em grande parte pela não utilização de conversores eletrônicos para conectar o gerador à rede elétrica (Marques, 2004), (Sohn, 2014).

\subsubsection{Operação em Velocidade Variável}

As turbinas de velocidade variável caracterizam-se pela variação da velocidade do rotor do gerador de acordo com a velocidade do vento, buscando máximo aproveitamento da energia eólica disponível. Essa variação é obtida com a utilização de conversores eletrônicos ao invés da conexão direta entre gerador e rede elétrica, que resulta no desacoplamento entre a velocidade do rotor e a frequência da rede (Marques, 2004) (Salles, 2009), (Sohn, 2014).

A Figura 5 apresenta uma comparação entre uma turbina de velocidade fixa e outra de velocidade variável, em relação aos valores de potência gerada para diferentes velocidades do vento. É possível observar que a turbina de velocidade variável apresenta valores superiores de geração de energia para ampla faixa de velocidades do vento, enquanto que a turbina de velocidade fixa apresenta desempenho semelhante apenas para velocidades próximas da velocidade síncrona do gerador. 
Figura 5: Comparação entre o desempenho de turbinas de velocidade fixa e variável

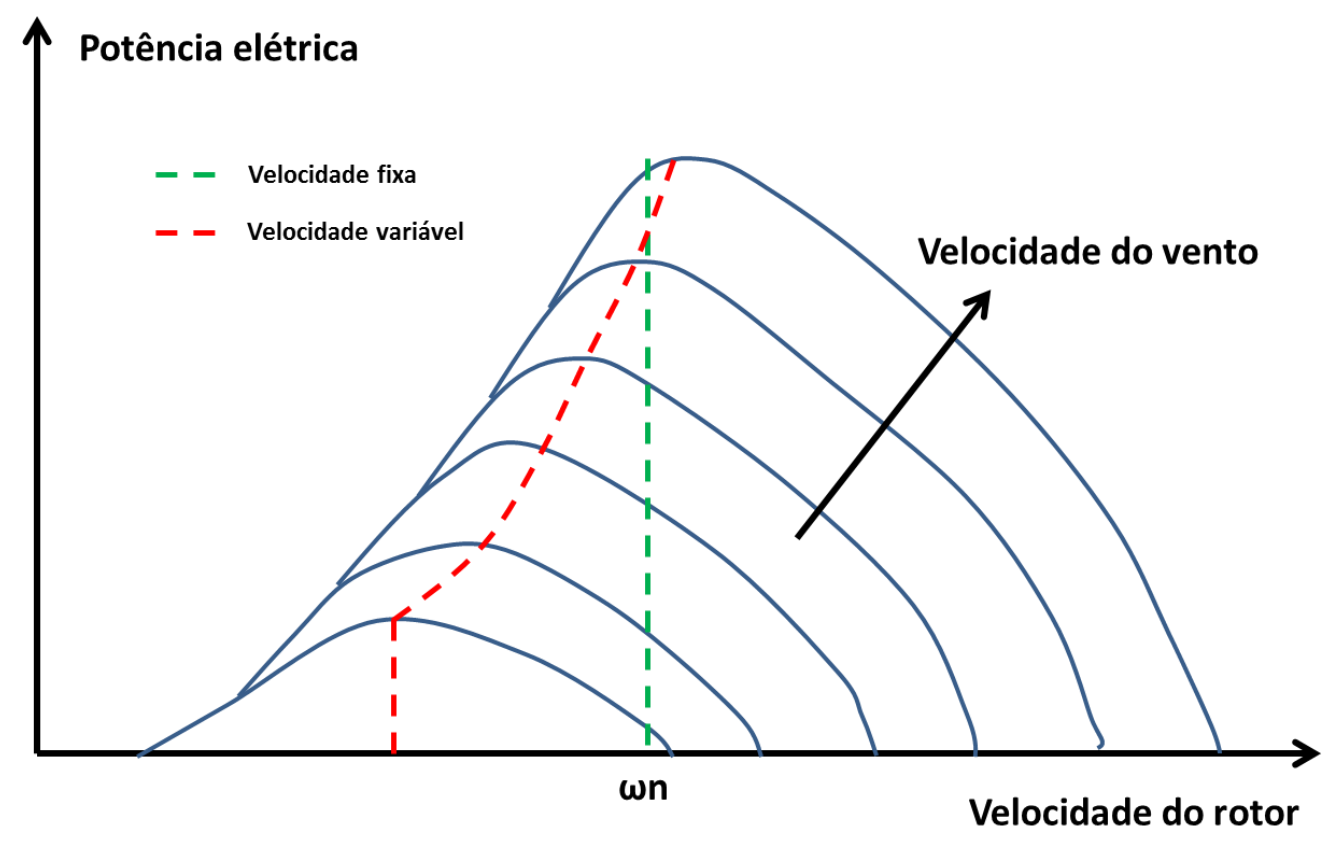

\subsection{Sistemas de Controle Aerodinâmico para Limitação da Potência}

Para valores elevados de velocidade do vento, pode ser necessário limitar a velocidade do rotor (e os valores gerados de potência mecânica) para que não ultrapasse a velocidade máxima permitida, a partir da qual podem ser causados danos aos componentes da turbina. A seguir, são apresentados os sistemas de controle aerodinâmico empregados nas turbinas eólicas para limitação da potência mecânica quando se encontram na região III de operação. Para mais detalhes sobre esses sistemas, podem ser consultados os trabalhos de (Abad, López, Rodriguez, Marroyo, \& Iwanski, 2011), (Ackermann, 2005), (Silva, 2006), (Hansen, Iov, Blaabjerg, \& Hansen, 2004) e (Sohn, 2014).

Os métodos de controle aerodinâmico podem ser classificados em métodos passivos, como o controle por perda aerodinâmica passiva (stall passivo), e métodos ativos, como o controle de ângulo de passo (pitch) e o controle por perda aerodinâmica ativa (stall ativo).

Nas turbinas de velocidade fixa, podem ser utilizados os três métodos de controle citados, enquanto que nas turbinas de velocidade variável é utilizado predominantemente o controle de pitch. 


\subsubsection{Controle por Perda Aerodinâmica passivo (Stall passivo)}

O controle por perda aerodinâmica passiva é baseado no aumento da força de arrasto e da turbulência sobre as pás com o aumento das velocidades do vento. Quando a velocidade do vento ultrapassa a velocidade nominal (velocidade $v_{2}$ na Figura 4 ), a força de arrasto passa a frear as pás da turbina, limitando assim os valores de potência mecânica gerados.

A robustez, simplicidade e baixo custo são as principais vantagens do controle stall passivo. Entre as desvantagens, podem ser citadas a incapacidade de auxiliar na partida das turbinas, instabilidade nos valores de potência gerados para valores elevados de velocidade do vento e desgaste nos equipamentos devido à turbulência geradas na turbina.

\subsubsection{Controle de Ângulo de Passo (pitch)}

O controle de ângulo de passo é um método ativo que consiste em rotacionar as pás da turbina para aumentar o ângulo de passo e, consequentemente, diminuir a velocidade de rotação das pás e os valores de potência gerados.

Comparado ao controle stall, esse método ativo permite controlar mais precisamente os valores de potência gerados, aumentar a eficiência do processo de geração de energia e reduzir os esforços mecânicos sobre as pás das turbinas.

\subsubsection{Controle por Perda Aerodinâmica Ativo (stall ativo)}

O controle stall ativo é uma combinação dos dois métodos citados anteriormente. Ao invés de aumentar o ângulo de passo para reduzir a potência gerada pela turbina, como no controle de pitch, nesse método o ângulo de passo é reduzido, visando aumentar a força de arrasto e a turbulência nas pás da turbina.

\subsection{Tipos de Turbinas}

As turbinas eólicas podem ser classificadas em quatro tipos (Hansen, Iov, Blaabjerg, \& Hansen, 2004), (Sohn, 2014):

- Tipo A: Turbinas de velocidade fixa, com o estator do gerador conectado diretamente à rede elétrica e o rotor em curto-circuito; 
- Tipo B: Turbinas de velocidade fixa com o estator conectado diretamente à rede elétrica e o rotor conectado a uma resistência variável;

- Tipo C: Turbinas de velocidade variável, sendo que a conexão do rotor com a rede é realizada através de um conversor eletrônico cuja potência nominal é reduzida em relação à potência nominal do gerador;

- Tipo D: Turbinas de velocidade variável utilizando conversor eletrônico que deve suportar a potência nominal do gerador.

A seguir serão apresentadas três configurações utilizadas comumente em turbinas eólicas:

- Gerador de indução em gaiola de esquilo (SCIG) conectado diretamente à rede elétrica (tipo A);

- Gerador de indução duplamente alimentado (DFIG) com conversor eletrônico (tipo C);

- Gerador síncrono a imã permanente (PMSG) conectado à rede através de conversores eletrônicos (tipo D).

Para maiores detalhes sobre os tipos de turbinas, podem ser consultados os trabalhos de (Abad, López, Rodriguez, Marroyo, \& Iwanski, 2011), (Pinto, 2013), (Marques, 2004) e (Sohn, 2014).

\subsubsection{Gerador de Indução em Gaiola de Esquilo (SCIG)}

A turbina com o chamado conceito dinamarquês, que utiliza um gerador de indução em gaiola de esquilo (SCIG), é ilustrada na Figura 6.

O estator do gerador SCIG é conectado diretamente à rede elétrica, enquanto o rotor é colocado em curto-circuito. Normalmente, a turbina é composta também por um soft-starter para auxiliar na partida do motor e um banco de capacitor para realizar a compensação de potência reativa consumida pela máquina.

A turbina com gerador SCIG opera em velocidade fixa, conforme ilustrado na Figura 6, obtendo máximo aproveitamento para uma determinada velocidade do vento. Como alternativa para aumentar a eficiência aerodinâmica desse tipo de tecnologia, algumas turbinas são projetadas para funcionar em duas velocidades, utilizando-se dois tipos de geradores diferentes na turbina ou variando-se o número de pólos de um mesmo gerador. Dessa maneira, é possível 
operar a turbina com uma determinada velocidade para valores baixos de velocidade do vento e outro valor para velocidades médias e elevadas de vento (Marques, 2004).

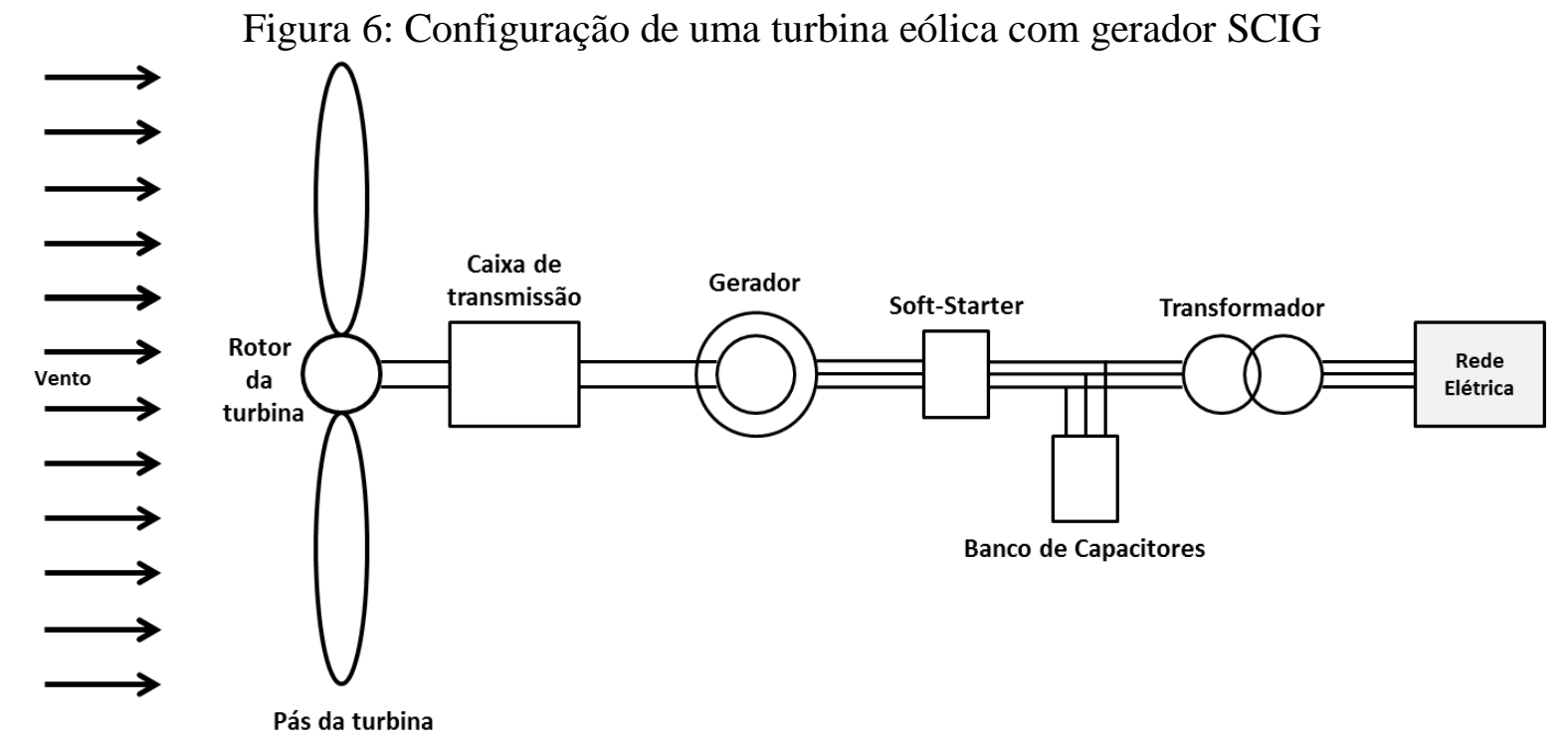

Entre as vantagens dessa configuração, podem ser citadas (Marques, 2004), (Sohn, 2014), (Tripathy \& Rourkela, 2014):

- Sistema simples, robusto e com custo reduzido em relação a outras tecnologias;

- Manutenção reduzida;

- Modelagem mais simples;

- Não produz harmônicos de corrente porque não realiza conversão de frequência.

As desvantagens desse tipo de turbina são elencadas a seguir (Marques, 2004), (Sohn, 2014), (Tripathy \& Rourkela, 2014):

- Menor eficiência em relação às turbinas de velocidade variável;

- Variações na velocidade do vento resultam em variações no torque elétrico, afetando a qualidade da energia gerada;

- Flutuações na rede elétrica provocam oscilações mecânicas nas turbinas, causando desgaste nos equipamentos;

- Não permite controle de potência reativa gerada e, consequentemente, não permite controle de tensão no ponto de conexão com a rede elétrica;

- Necessita de caixa de transmissão, o que provoca ruídos e manutenção adicional. 


\subsubsection{Gerador de Indução Duplamente Alimentado (DFIG)}

O gerador DFIG é atualmente o modelo mais utilizado em turbinas eólicas, correspondendo a cerca de 50\% de todos os modelos implantados no mundo (Cárdenas, Peña, Alepuz, \& Fellow, 2013). A Figura 7 apresenta a configuração usual de uma turbina que utiliza gerador DFIG.

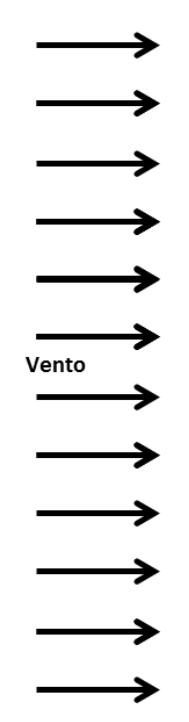

Figura 7: Configuração de uma turbina eólica com gerador DFIG

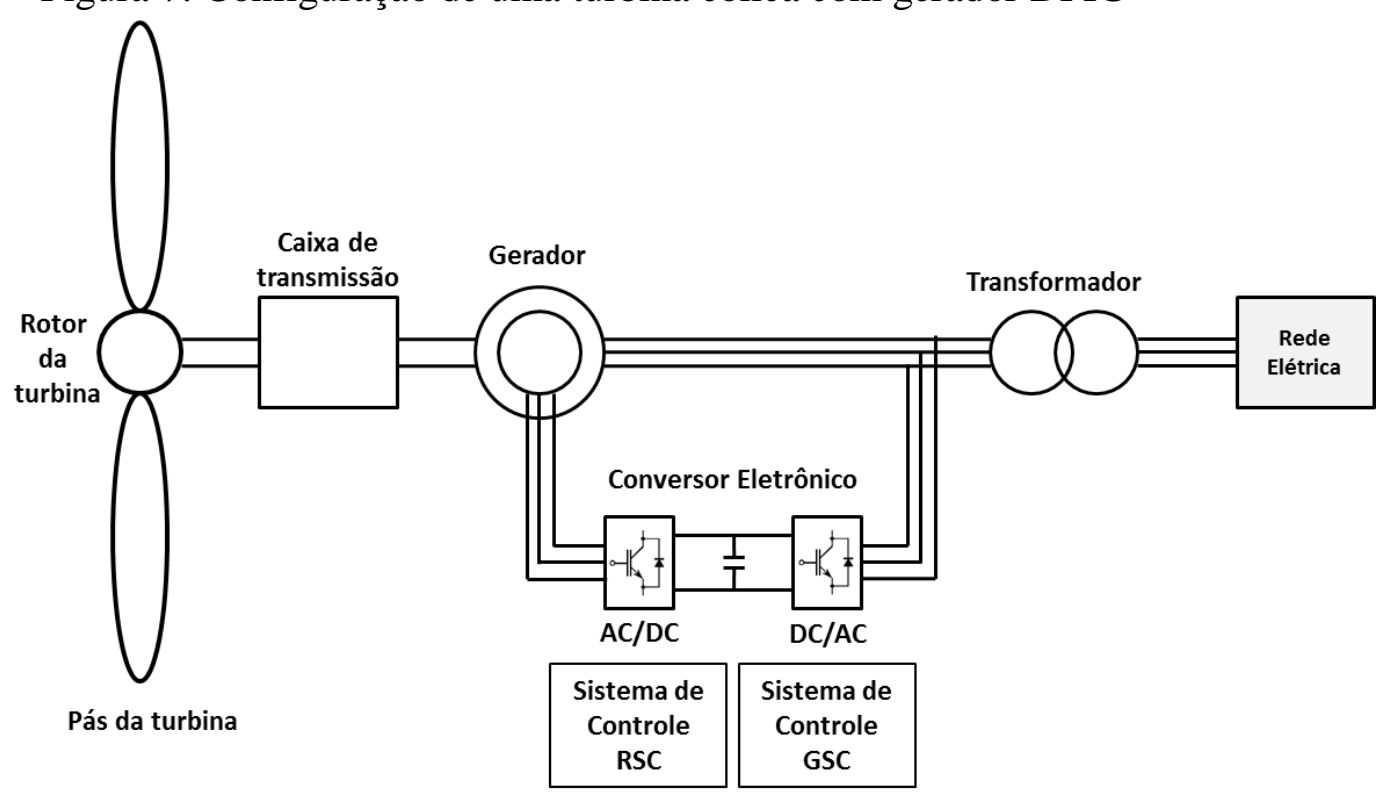

O estator do gerador é conectado diretamente à rede elétrica, enquanto o rotor é conectado através de um conversor eletrônico. Com essa configuração, apenas parte da potência gerada (cerca de 30\%) passa pelo rotor, o que permite dimensionar o conversor eletrônico para valores reduzidos de potência, acarretando em custos menores em relação a conversores dimensionados para suportar a potência nominal da turbina. O funcionamento do gerador DFIG e do controle da turbina através dos conversores eletrônicos serão detalhados no capítulo 3.

Em relação às principais vantagens das turbinas com gerador DFIG, podem ser citadas (Marques, 2004), (Sohn, 2014), (Tripathy \& Rourkela, 2014):

- Operação em velocidade variável, com a velocidade do rotor podendo variar entre $\pm 30 \%$ em relação à velocidade síncrona do gerador. Assim, é possível obter melhor aproveitamento da energia eólica disponível em relação às tecnologias de velocidade fixa;

- Controle independente das potências ativa e reativa, que é possível pela utilização de conversores eletrônicos; 
- Desacoplamento da frequência angular do gerador em relação à frequência da rede, o que possibilita melhor controle das frequências fornecidas à rede elétrica e diminuição do estresse mecânico na turbina;

- Maior suportabilidade a afundamentos de tensão em relação às turbinas de velocidade fixa;

- Conversor eletrônico não é dimensionado para a potência nominal do gerador, o que proporciona custos reduzidos em relação a outras tecnologias de velocidade variável.

Em relação às desvantagens dessa tecnologia, podem ser citadas (Marques, 2004), (Sohn, 2014), (Tripathy \& Rourkela, 2014):

- A utilização do conversor eletrônico e de um sistema de proteção associado traz custos adicionais em relação às turbinas de velocidade fixa;

- Modelagem mais complexa em relação às turbinas de velocidade fixa;

- Operação numa faixa de velocidades menor em relação às turbinas com gerador PMSG.

\subsubsection{Gerador Síncrono de imã Permanente (PMSG)}

A configuração usual de uma turbina utilizando o gerador PMSG é apresentada na Figura 8.

Figura 8: Configuração de uma turbina eólica com gerador PMSG
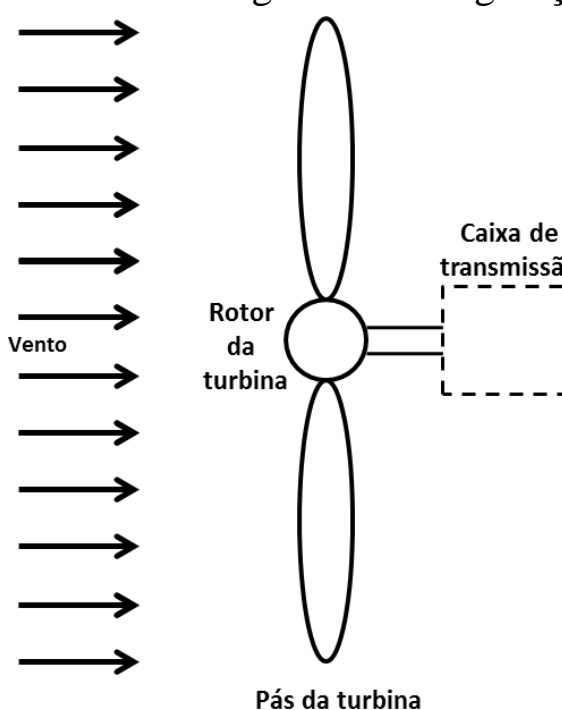

AC/DC

DC/AC

\begin{tabular}{|c|c|c|c|c|c|c|c|}
\hline $\begin{array}{c}\text { Sistema de } \\
\text { Controle } \\
\text { Controle }\end{array}$ &
\end{tabular} MSC GSC

A conexão do rotor do gerador PMSG pode ser feita através de uma caixa de transmissão ou através de acoplamento direto ( "gearless" ou "direct drive”). A conexão do estator com a 
rede é feita através de um conversor eletrônico que deve ser dimensionado para suportar a potência nominal do gerador, o que acarreta em custo elevado desse equipamento em relação às turbinas com gerador DFIG. Por outro lado, por ser um conversor que desacopla totalmente o gerador da rede, permite obter maior suportabilidade a variações de velocidade do vento e afundamentos de tensão, além de maior controle de potência reativa trocada com a rede.

As principais vantagens desse tipo de turbina são listadas abaixo (Marques, 2004), (Sohn, 2014), (Tripathy \& Rourkela, 2014):

- Não necessita de caixa de transmissão para geradores de baixa velocidade;

- Maior suportabilidade a variações na velocidade do vento e afundamentos de tensão na rede elétrica em relação às tecnologias apresentadas anteriormente;

- Operação em velocidade variável numa faixa de velocidades superior ao gerador DFIG, o que permite aumentar a potência extraída do vento.

- Maior confiabilidade em relação a geradores excitados eletricamente;

Desvantagens dessa tecnologia (Marques, 2004), (Sohn, 2014), (Tripathy \& Rourkela, 2014):

- Custo elevado do conversor de alta potência, que deve ser dimensionado para transmitir a potência nominal do gerador;

- Custo e variação de preços de imãs permanentes e desmagnetização desse material em altas temperaturas.

\subsection{Considerações Gerais}

Comentários sobre os tópicos apresentados no capítulo 2:

- Em relação ao modo de operação, as turbinas eólicas podem ser classificadas em dois tipos: turbinas de velocidade fixa e turbinas de velocidade variável. A tecnologia de velocidade fixa foi a primeira empregada nas turbinas eólicas, apresentando como vantagens a simplicidade, robustez e baixo custo. Entretanto, com o aumento da penetração da geração eólica nos sistemas elétricos e os requisitos cada vez mais exigentes para conexão e operação das plantas eólicas no sistema elétrico, as tecnologias evoluíram ao longo do tempo para atender a esses requisitos.

- As turbinas de velocidade variável possibilitam melhor aproveitamento da energia eólica disponível, pois são projetadas para buscar máximo 
aproveitamento para ampla faixa de velocidades do vento. Além disso, com a utilização de conversores eletrônicos para conexão do gerador com a rede elétrica, é possível controlar os valores de tensão e frequência no ponto de conexão com a rede, o que permite atender de maneira mais adequada aos critérios de operação no sistema elétrico.

- Por possibilitar melhor desempenho em relação às tecnologias de velocidade fixa, o gerador DFIG passou a ser cada vez mais utilizado e hoje é a tecnologia mais empregada em turbinas eólicas. Outro fator que contribuiu para a ampla utilização dessa tecnologia é o custo reduzido dos conversores, que devem suportar apenas parte da potência nominal do gerador, em relação a outras tecnologias de turbinas com velocidade variável cujos conversores devem suportar a potência nominal do gerador.

- As turbinas com gerador síncrono de imã permanente passaram a ser mais utilizadas recentemente devido à queda dos preços dos imãs de terras raras utilizadas para a construção do gerador. A participação no mercado dessa tecnologia cresceu de 1,9\% em 2008 a 18,3\% em 2013 (Smith, 2014). Entretanto, riscos associados à disponibilidade e variabilidade nos preços para compra desses metais fazem com que o gerador DFIG continue sendo a tecnologia mais utilizada em turbinas eólicas. 


\section{Modelagem, Operação e Controle do DFIG}

\subsection{Modelagem do DFIG}

O gerador DFIG pode ser representado tanto por modelos em estado estacionário, como também por modelos dinâmicos, que possibilitam tanto análises em estado permanente como análises do período de transição entre dois estados. Os modelos dinâmicos são importantes nas análises de contingências e de outras instabilidades na rede, que podem causar variações significativas nos parâmetros do gerador.

Os trabalhos de (Abad, López, Rodriguez, Marroyo, \& Iwanski, 2011), (Akhmatov, 2002), (Alkandari, Soliman, \& Abdel-Rahman, 2011) apresentam modelagens do DFIG em estado estacionário. Para modelos dinâmicos, podem ser consultados os trabalhos de (Abad, López, Rodriguez, Marroyo, \& Iwanski, 2011), (Ackermann, 2005), (Akhmatov, 2002), (Petersson, 2005), (Salles, 2009) e (Sohn, 2014).

Nesta seção é apresentado um modelo para representação em estado estacionário da máquina de indução duplamente alimentada (DFIM), que pode funcionar nos modos gerador e motor. A modelagem é baseada no trabalho de (Abad, López, Rodriguez, Marroyo, \& Iwanski, 2011).

A Figura 9 apresenta o circuito equivalente utilizado para representar uma máquina de indução duplamente alimentada. São adotadas as seguintes premissas:

- Representação de apenas uma das fases dos enrolamentos do rotor e do estator, considerando que ambos utilizam conexão em estrela.

- Estator alimentado por tensão trifásica constante e equilibrada através da rede elétrica.

- Rotor alimentado por tensão trifásica constante e equilibrada através de um conversor back-to-back. 
Figura 9: Circuito equivalente da máquina de indução duplamente alimentada

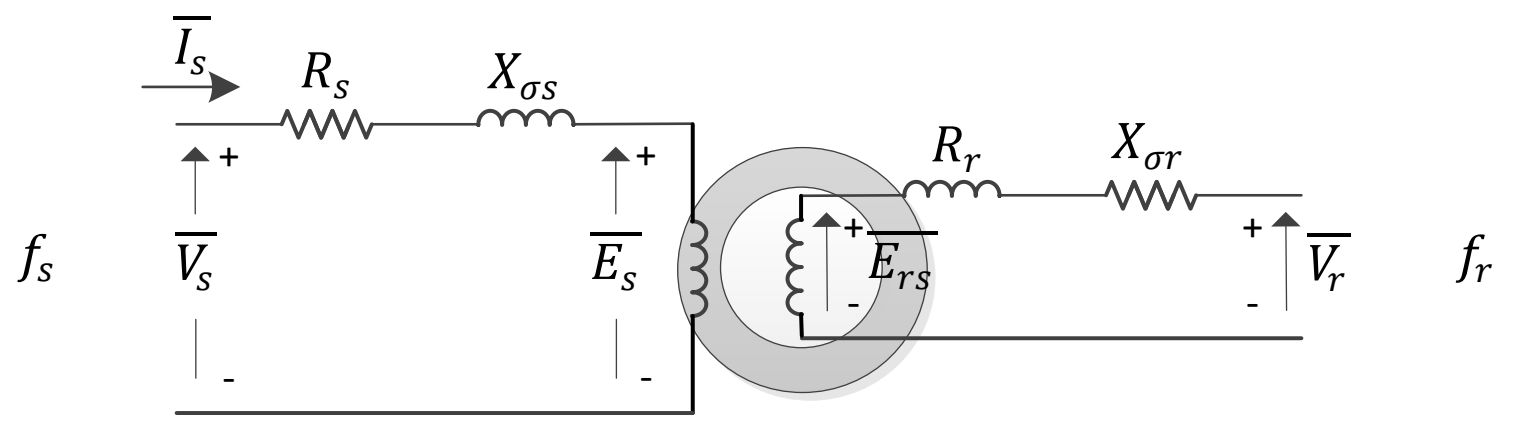

Sendo:

- $\bar{V}_{s}$ : Tensão fornecida ao estator pela rede, com frequência $f_{s}$.

- $\bar{V}_{r}$ : Tensão fornecida no rotor, com frequência $f_{r}$.

- $\overline{I_{s}}$ : Corrente induzida no estator, com frequência $f_{s}$.

- $\overline{I_{r}}$ : Corrente induzida no rotor, com frequência $f_{r}$.

- $\overline{E_{S}}$ : Tensão induzida nos enrolamentos do estator, com frequência $f_{s}$.

- $\overline{E_{r s}}$ : Tensão induzida no rotor (frequência $f_{r}$ ) devido ao escorregamento existente entre os campos induzidos no rotor e no estator.

- $R_{s}$ : Resistência do estator.

- $R_{r}$ : Resistência do rotor.

- $X_{\sigma S}$ : Reatância de dispersão do estator.

- $X_{\sigma r}$ : Reatância de dispersão do rotor.

- $N_{s}$ : Número de espiras por fase do estator.

- $N_{r}$ : Número de espiras por fase do rotor.

A frequência das correntes do estator $\left(f_{s}\right)$ e do rotor $\left(f_{r}\right)$ possuem valores distintos. Enquanto a frequência do estator depende da frequência da rede pela qual é alimentada, a frequência do rotor e sua reatância de dispersão são influenciadas pela velocidade da máquina de indução (Abad, López, Rodriguez, Marroyo, \& Iwanski, 2011).

Assim, podem ser obtidas as equações (1) e (2) para os circuitos do estator e do rotor:

$$
\begin{aligned}
& \overline{V_{s}}-\overline{E_{s}}=\left(R_{s}+X_{\sigma s}\right) \cdot \overline{I_{s}} \\
& \overline{V_{r}}-\overline{E_{r s}}=\left(R_{r}+X_{\sigma r}\right) \cdot \overline{I_{r}}
\end{aligned}
$$

Referenciando os valores de corrente, tensão e impedâncias para o estator da máquina, obtém-se o circuito representado na Figura 10. 
Figura 10: Circuito equivalente da máquina DFIM com valores referidos no lado do estator

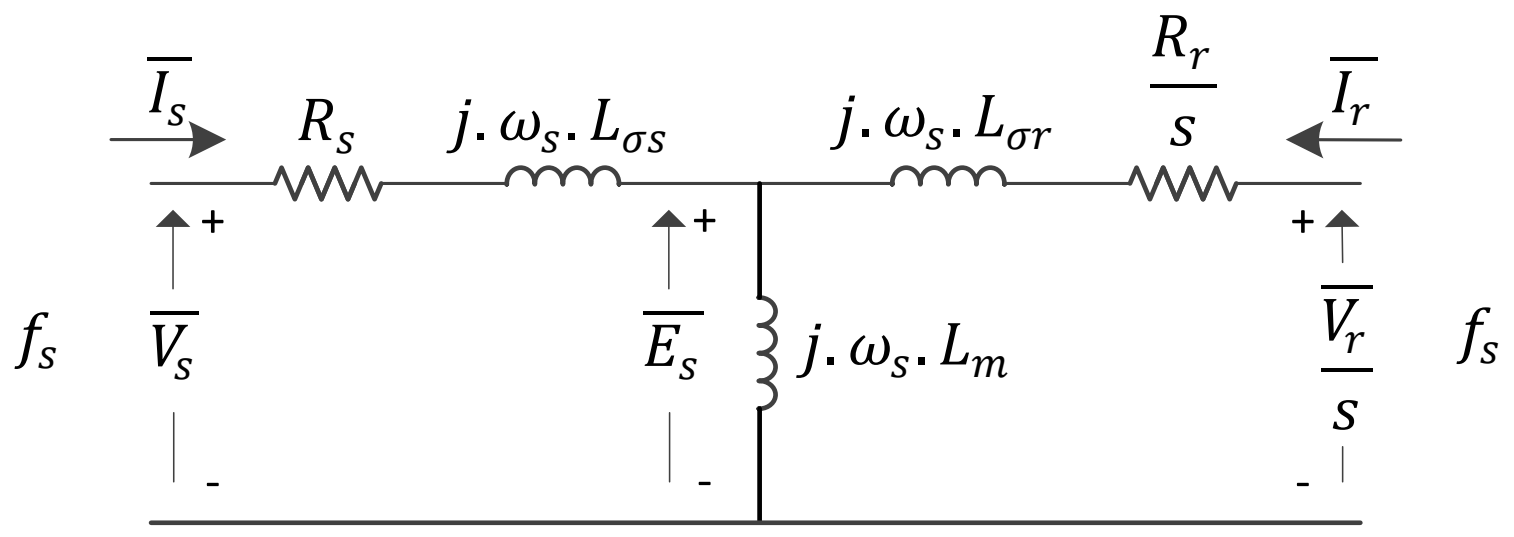

Desse circuito, resulta a seguinte equação para relacionar as tensões e correntes do estator e do rotor da máquina:

$$
\bar{V}_{s}-\frac{\overline{V_{r}}}{s}-\left(R_{s}+j \cdot \omega_{s} \cdot L_{\sigma s}\right) \cdot \bar{I}_{s}+\left(\frac{R_{r}}{s}+j \cdot \omega_{s} \cdot L_{\sigma s}\right) \cdot \overline{I_{r}}=0
$$

A tensão induzida no estator da máquina de indução é dada pela equação (4):

$$
\overline{E_{s}}=j \cdot \omega_{s} \cdot L_{m} \cdot\left(\overline{I_{s}}+\overline{I_{r}}\right)
$$

\subsection{Operação do DFIG}

\subsubsection{Escorregamento}

A frequência da tensão induzida no rotor da máquina de indução duplamente alimentada depende da frequência do fluxo rotacional no estator e da velocidade rotacional do rotor, conforme equação descrita em (5):

$$
\omega_{r}=\omega_{s}-\omega_{m}
$$

Sendo:

- $\omega_{r}$ : frequência angular das correntes e tensões nos enrolamentos do rotor.

- $\omega_{s}$ : frequência angular das correntes e tensões nos enrolamentos do estator.

- $\omega_{m}$ : frequência angular do rotor.

O escorregamento de uma máquina é definido pela relação entre a frequência angular do rotor e a frequência do estator, conforme equação (6).

$$
s=\frac{\omega_{r}}{\omega_{s}}
$$


A equação do escorregamento pode também ser descrita pela equação (7), substituindo o valor de $\omega_{r}$ encontrado em (5) na equação (6):

$$
s=\frac{\omega_{s}-\omega_{m}}{\omega_{s}}
$$

De acordo com o valor do escorregamento, podem ser definidos três modos de operação para a máquina de indução (Abad, López, Rodriguez, Marroyo, \& Iwanski, 2011):

- $\quad s>0$ : Operação em modo subsíncrono, com velocidade do rotor da máquina inferior à velocidade do estator.

- $s=0$ : Operação em modo síncrono. Velocidade do rotor igual à velocidade estatórica.

- $s<0$ : Operação em modo supersíncrono. Velocidade do rotor superior à velocidade das correntes e tensões no estator da máquina.

\subsubsection{Operação em Quatro Quadrantes da DFIM}

Em uma máquina de indução, o balanço das potências ativas existentes pode ser representado pela equação (8) (Abad, López, Rodriguez, Marroyo, \& Iwanski, 2011):

$$
P_{s}+P_{r}=P_{e r d a s_{C u \_s}}+P_{e r d a s_{C u \_r}}+P_{m e c}
$$

Sendo:

- $P_{S}$ : Potência ativa no estator.

- $P_{r}$ : Potência ativa no rotor.

- $\operatorname{Perdas}_{C u_{-} s}$ : Perdas no cobre no estator.

- Perdas ${ }_{C u \_r}$ : Perdas no cobre no rotor.

- $P_{m e c}$ : Potência mecânica da máquina.

Para valores positivos de $P_{S}$, a máquina está recebendo potência ativa através do estator. Para valores negativos de $P_{S}$, a máquina está fornecendo potência através do estator. Análise semelhança pode ser feita para o rotor da máquina.

Em relação aos valores da potência mecânica, $P_{m e c}>0$ define a operação da máquina como motor. Valores negativos representam a operação como gerador, com a máquina recebendo potência mecânica.

Desconsiderando as perdas no cobre e no ferro da máquina, podem ser obtidas as seguintes equações relacionando, potência, torque e velocidades. 


$$
\begin{aligned}
P_{r} & \cong-s \cdot P_{s} \\
P_{m e c} & \cong(1-s) \cdot P_{s} \\
P_{m e c} & \cong T_{e m} \cdot \frac{\omega_{m}}{p} \\
P_{s} & \cong T_{e m} \cdot \frac{\omega_{s}}{p} \\
P_{r} & =T_{e m} \cdot \frac{\omega_{r}}{p}
\end{aligned}
$$

Sendo:

- $T_{e m}$ : torque eletromagnético no eixo da máquina.

- $\quad p$ : número de pólos da máquina.

De acordo com as relações obtidas nas equações (9)-(13), podem ser definidos quatro modos de operação para a máquina de indução duplamente alimentada, conforme os quatro quadrantes ilustrados na Figura 11 e detalhados a seguir (Abad, López, Rodriguez, Marroyo, \& Iwanski, 2011).

Figura 11: Quatro quadrantes de operação da máquina DFIM

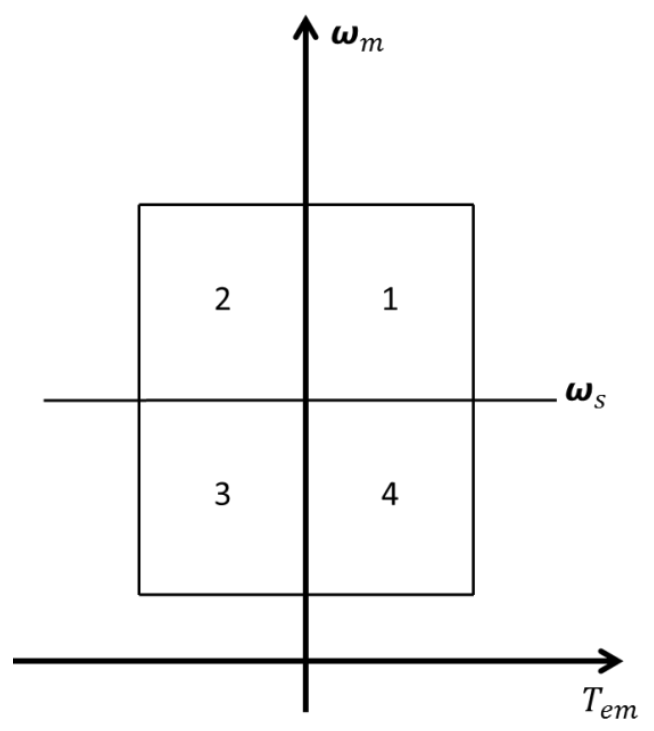

- Quadrante 1: máquina operando em modo motor $\left(P_{m e c}>0\right.$ e $\left.T_{e m}>0\right)$ e supersíncrono $(s<0)$. As potências ativas $P_{s}$ e $P_{r}$ são positivas, ou seja, a máquina recebe potência através do rotor e do estator.

- Quadrante 2: máquina operando em modo gerador $\left(P_{m e c}<0\right.$ e $\left.T_{e m}<0\right)$ e super-síncrono $(s<0)$. As potências ativas $P_{s}$ e $P_{r}$ são negativas, ou seja, a máquina fornece potência através do rotor e do estator. 
- Quadrante 3: máquina operando em modo gerador $\left(P_{m e c}<0\right.$ e $\left.T_{e m}<0\right)$ e subsíncrono $(s>0)$. A potência ativa $P_{S}$ é negativa (máquina fornece potência ativa através do estator), enquanto a potência ativa $P_{r}$ é positiva (máquina recebe potência ativa através do rotor).

- Quadrante 4: máquina operando em modo motor $\left(P_{m e c}>0\right.$ e $\left.T_{e m}>0\right)$ e subsíncrono $(s>0)$ ). A potência ativa $P_{S}$ é positiva (máquina recebe potência ativa através do estator), enquanto a potência ativa $P_{r}$ é negativa (máquina fornece potência ativa através do rotor).

\subsubsection{Operação do DFIG nos Modos Subsíncrono e Supersíncrono}

Para a operação do gerador DFIG em turbinas eólicas, são utilizados os modos de operação sub-síncrono (quadrante 3) e super-síncrono (quadrante 2).

O modo de operação sub-síncrono, em que a velocidade do rotor é inferior à velocidade síncrona do estator, é utilizado nas turbinas eólicas quando a velocidade do vento é inferior à velocidade nominal. As turbinas são controladas para extrair a máxima energia possível para cada valor de velocidade do vento, através do controle da tensão e da frequência aplicada nos enrolamentos do rotor. São controlados também os valores de potência ativa e reativa trocados com a rede elétrica (Salles, 2009). Conforme ilustrado na Figura 5, a energia gerada pelas turbinas de velocidade variável é superior em relação às turbinas de velocidade fixa para velocidades de vento reduzidas. Os conversores são utilizados também para garantir que a turbina não entrará em modo motor durante a operação sub-síncrona (Sohn, 2014).

No modo de operação super-síncrono, em que a velocidade rotórica é superior à velocidade síncrona do gerador, a turbina também é controlada para extrair a máxima energia possível. Quando a velocidade do vento ultrapassa a velocidade nominal, o sistema de controle de pitch é utilizado para limitar a potência ativa gerada. A velocidade do gerador é mantida constante através dos valores de tensão e frequência aplicados ao rotor, e os valores de potência trocados entre gerador e rede também são controlados (Salles, 2009).

Para obter as características operativas descritas anteriormente, são utilizados diversos sistemas de controle através dos conversores eletrônicos que conectam o rotor do DFIG à rede elétrica. 


\subsection{Controle da Turbina com Gerador DFIG}

\subsubsection{Conversor eletrônico}

O controle da turbina com gerador DFIG é realizado através de um conversor eletrônico que conecta o rotor do gerador à rede elétrica. Conforme ilustrado na Figura 7, o conversor é composto por um conversor do lado do rotor (rotor side converter - RSC) e um conversor do lado da rede (grid side converter - GSC), interligados por um link DC. Esse conversor é chamado de back-to-back, pois permite o fluxo bidirecional de potência ativa e reativa tanto do lado do rotor quanto da rede (Sohn, 2014).

O conversor RSC é utilizado para controlar o torque do gerador (ou a potência ativa) e a potência reativa trocada entre o estator do gerador e a rede elétrica. Através desse controlador, pode ser implementado, por exemplo, o método MPPT (maximum power point tracking) para otimizar o aproveitamento da energia eólica disponível (Gontijo, 2016), (Phan \& Yamamoto, 2015). Além disso, o RSC é utilizado para implementar as estratégias de controle da tensão ou da potência reativa no ponto de conexão coma rede elétrica. Já o conversor GSC é responsável por transmitir a potência ativa gerada pelo gerador ao manter a constante a tensão do link DC.

Para mais detalhes sobre o modelamento e funcionamento dos conversores back-toback, podem ser consultados os trabalhos de (Abad, López, Rodriguez, Marroyo, \& Iwanski, 2011) e (Petersson, 2005).

\subsubsection{Controle do conversor RSC}

Os trabalhos de (Ávila, 2014), (Cárdenas, Peña, Alepuz, \& Fellow, 2013), (Jacob, 2013), (Ashwani Kumar, 2013), (Rêgo, 2015), (Salles, 2009) e (Voltolini, 2007) apresentam uma revisão dos principais métodos de controle do conversor RSC. Em (Abad, López, Rodriguez, Marroyo, \& Iwanski, 2011), são descritos detalhadamente os dois principais métodos utilizados: controle vetorial e controle direto.

$\mathrm{O}$ método vetorial consiste basicamente em controlar de maneira independente os valores das correntes do eixo direto e do eixo de quadratura do rotor para obter os valores desejados de potência ativa e reativa no estator. O método direto consiste em controlar diretamente determinados parâmetros da turbina e possui dois tipos principais (Abad, López, Rodriguez, Marroyo, \& Iwanski, 2011): 
- Controle de torque ou DTC (direct torque control), que atua nos valores de torque e de fluxo rotórico.

- Controle de potência ou DPC (direct power control), que atua nos valores de potência ativa e reativa.

Uma comparação de desempenho entre os métodos DTC e DPC é apresentada em (Wu \& Yang, 2016).

O trabalho de (Veerasathian, Ongsakul, \& Mitra) apresenta uma comparação entre as estratégias de controle de tensão e de fator de potência, implementadas nos controladores RSC.

Neste trabalho, será utilizado o controlador do RSC disponível no software SimPowerSystems, que utiliza o método vetorial e funciona da seguinte maneira:

- Em relação ao controle de potência ativa, buscando o máximo aproveitamento da energia disponível, inicialmente os valores de potência $(P)$ medidos na saída da turbina, somados às perdas $\left(\operatorname{Perdas}_{C u_{-} s}+\operatorname{Perdas}_{C u_{\_} r}\right)$, são comparados com os valores correspondentes na curva característica da turbina, que busca obter máximo aproveitamento da energia eólica disponível para cada velocidade do vento. O valor dessa comparação é processado por um regulador PI, que fornece a corrente no eixo de quadratura $\left(I_{q r_{-} r e f}\right)$ desejada para o rotor. Esse valor é comparado com a corrente de quadratura medida $\left(I_{q r}\right)$ e depois é processada por um segundo regulador PI, que fornece a componente do eixo de quadratura $\left(V_{q r}\right)$ da tensão a ser fornecida ao rotor.

- O controle do fluxo de potência reativa pode ser feito de duas maneiras distintas: regulação de tensão ou regulação de potência reativa no ponto de conexão com a rede. No modo de regulação de tensão, o valor de tensão medido $(V)$ é comparado com o valor de referência escolhido $\left(V_{\text {ref }}\right)$, sendo processado por um regulador PI para obter a corrente de referência no eixo direto do rotor $\left(I_{d r \_r e f}\right)$. De maneira semelhante, no modo de regulação de potência reativa, as mesmas etapas são realizadas com a potência reativa medida $(Q)$ e o valor de referência $\left(Q_{\text {ref }}\right)$, sendo obtido o valor $I_{d r_{-} r e f}$ de referência. Dessa maneira, com a corrente de referência $I_{d r_{-} r e f}$ resultante do tipo de regulação utilizada, é feita a comparação com a corrente medida $\left(I_{d r}\right)$ e o valor do erro é processado por um regulador PI, resultando na componente do eixo direto $\left(V_{d r}\right)$ da tensão de referência. A Figura 12 apresenta o diagrama esquemático de funcionamento do controlador do conversor RSC. 
Figura 12: Diagrama de funcionamento do controlador RSC

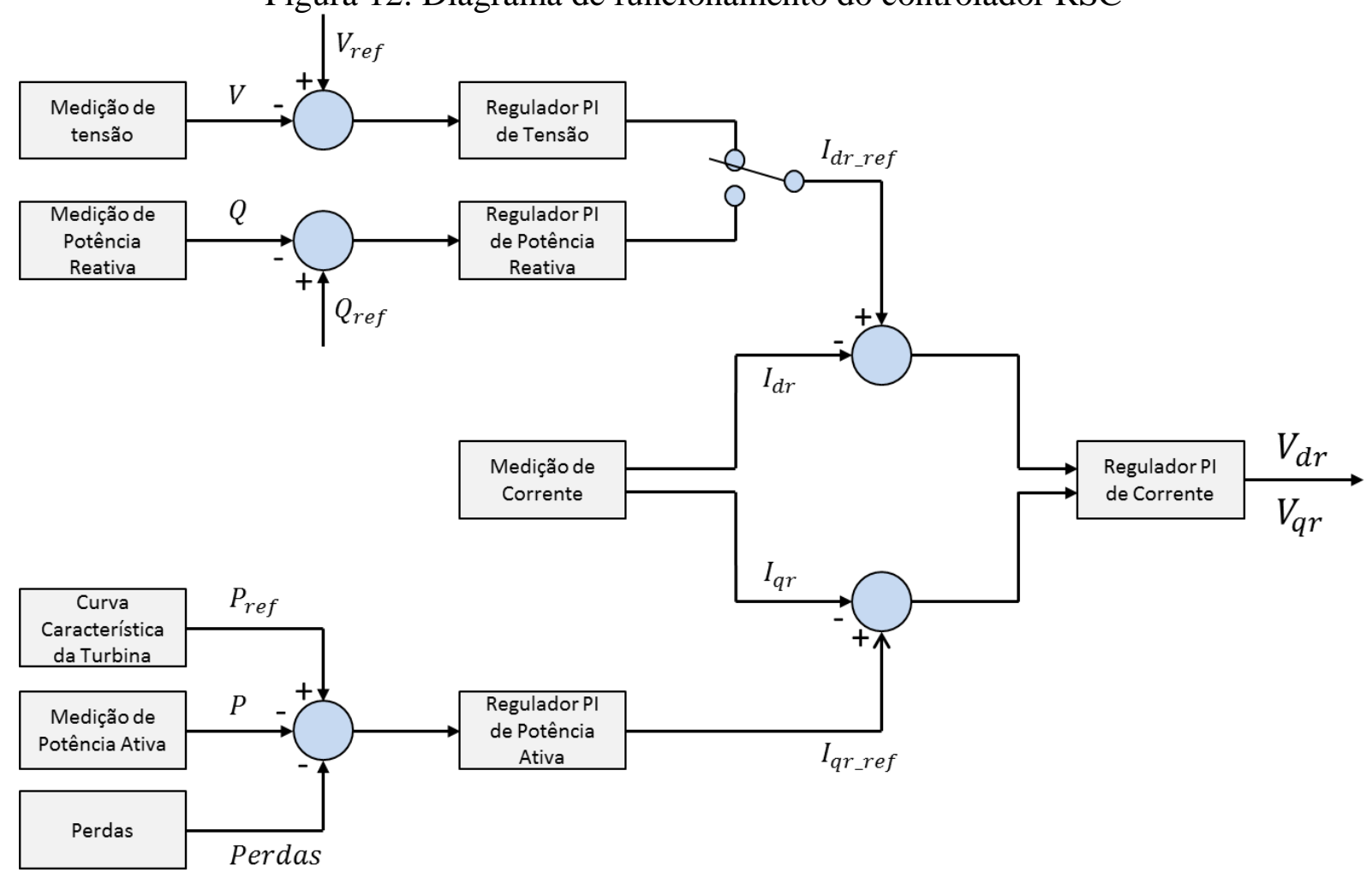

\subsubsection{Controle do Conversor GSC}

O controle do conversor GSC é utilizado para manter constante a tensão no link DC entre os conversores RSC e GSC, além de controlar os valores de potência reativa trocados coma rede.

Para manter constante a tensão no link DC, a tensão medida $\left(V_{d c}\right)$ é comparada com o valor de referência $\left(V_{d c_{-} \text {ref }}\right)$, e o valor resultante é processado por um regulador PI, obtendose assim a corrente de referência no eixo direto $\left(I_{\text {dgrid_ref }}\right)$. Essa corrente é comparada com a corrente medida $\left(I_{\text {dgrid }}\right)$ e o resultado é processado por outro regulador PI, que fornece a tensão de referência no eixo direto $\left(V_{\text {dgrid }}\right)$

Para o controle da potência reativa trocada com a rede, a corrente desejada para o eixo de quadratura ( $I_{\text {qgrid_ref }}$ ) é comparada com o valor medido $\left(I_{\text {qgrid }}\right)$, com o erro sendo processado pelo regulador PI que fornece a tensão de referência no eixo de quadratura $\left(V_{\text {qgrid }}\right)$. A Figura 13 apresentada o diagrama de funcionamento do controlador do conversor GSC.

Figura 13: Diagrama de Funcionamento do controlador GSC 


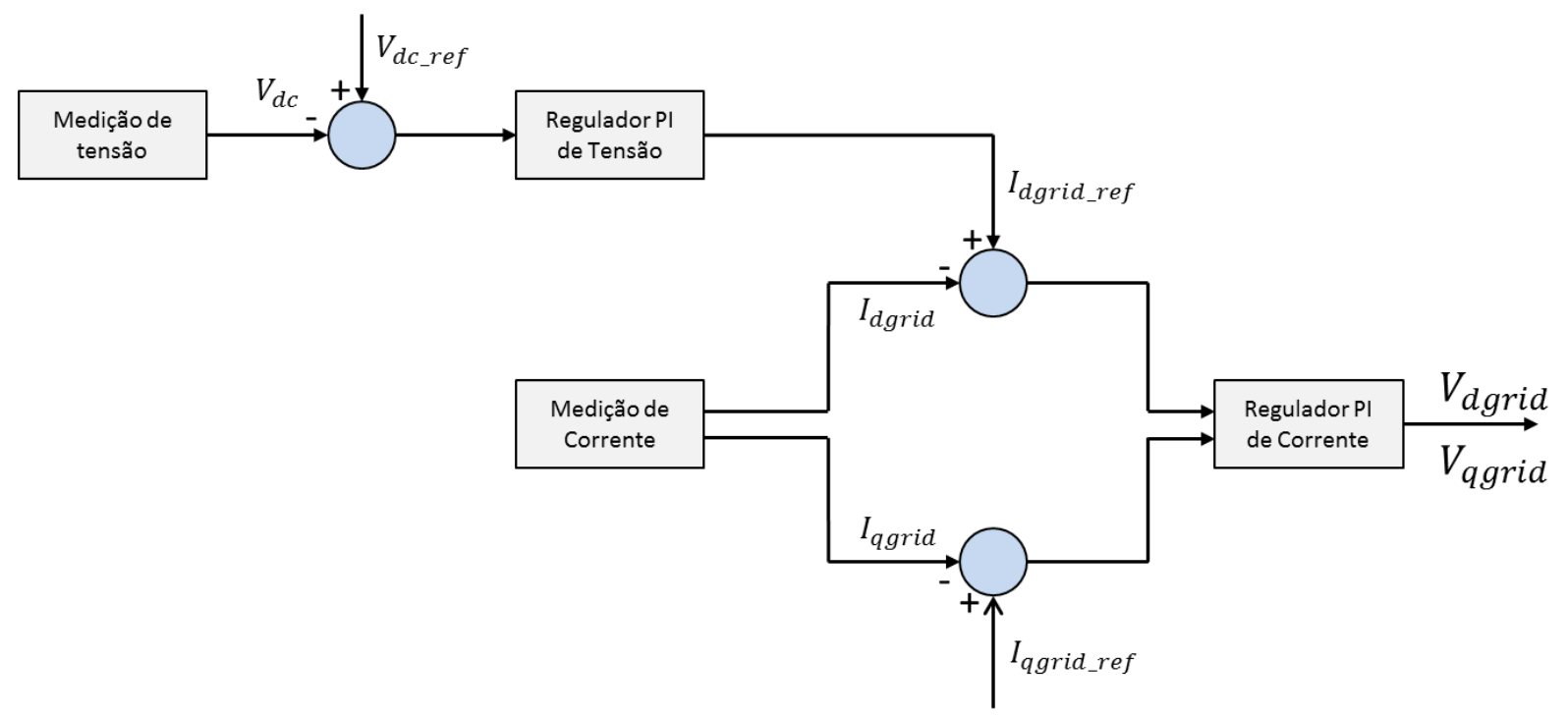

\subsection{Capabilidade de Potência Reativa de Turbinas com Geradores DFIG}

Em regime permanente, enquanto o valor de potência ativa produzido pelas turbinas eólicas está associado basicamente às condições de velocidade do vento, o valor de potência reativa gerada ou consumida pela turbina eólica planta eólica é limitado pelas características do gerador e do conversor utilizado e depende de diversos fatores, como perdas na máquina e nos conversores, influência da variação de velocidade nos valores de corrente nominal, filtros utilizados nos conversores, saturação do fluxo na máquina e limitação da tensão de saída do conversor (Engelhardt, Erlich, Feltes, \& Kretschmann, 2011).

A potência ativa fornecida no ponto de conexão da turbina éolica com a rede elétrica é composta pela potência do estator do gerador DFIG e pela potência que passa pelo conversor do lado da rede (GSC). Vale ressaltar que o estator do gerador DFIG não é projetado para fornecer 1p.u. de potência ativa entregue no ponto de conexão. O trabalho de (Engelhardt, Erlich, Feltes, \& Kretschmann, 2011) apresenta os seguintes valores de potência suprido por cada componente da turbina: estator supre 0,83 p.u. da potência ativa, enquanto o conversor GSC fornece 0,17p.u.

A partir de parâmetros típicos de turbinas eólicas, podem ser obtidos os valores nominais de corrente em cada um dos componentes da turbina eólica. De posse desses valores, são obtidas curvas de capabilidade tanto para o conversor GSC quando para o gerador DFIG, que representam os valores limite de corrente reativa que podem ser fornecidos por esses equipamentos para um determinado valor de corrente ativa, de maneira que a corrente resultante 
não ultrapasse seu valor nominal. A Figura 14 apresenta a curva de capabilidade de corrente reativa tanto para o gerador DFIG quando para o conjunto gerador DFIG mais conversor GSC.

Figura 14: Curva de capabilidade de corrente reativa para o gerador DFIG e para o conjunto DFIG \& conversor (Engelhardt, Erlich, Feltes, \& Kretschmann, 2011)

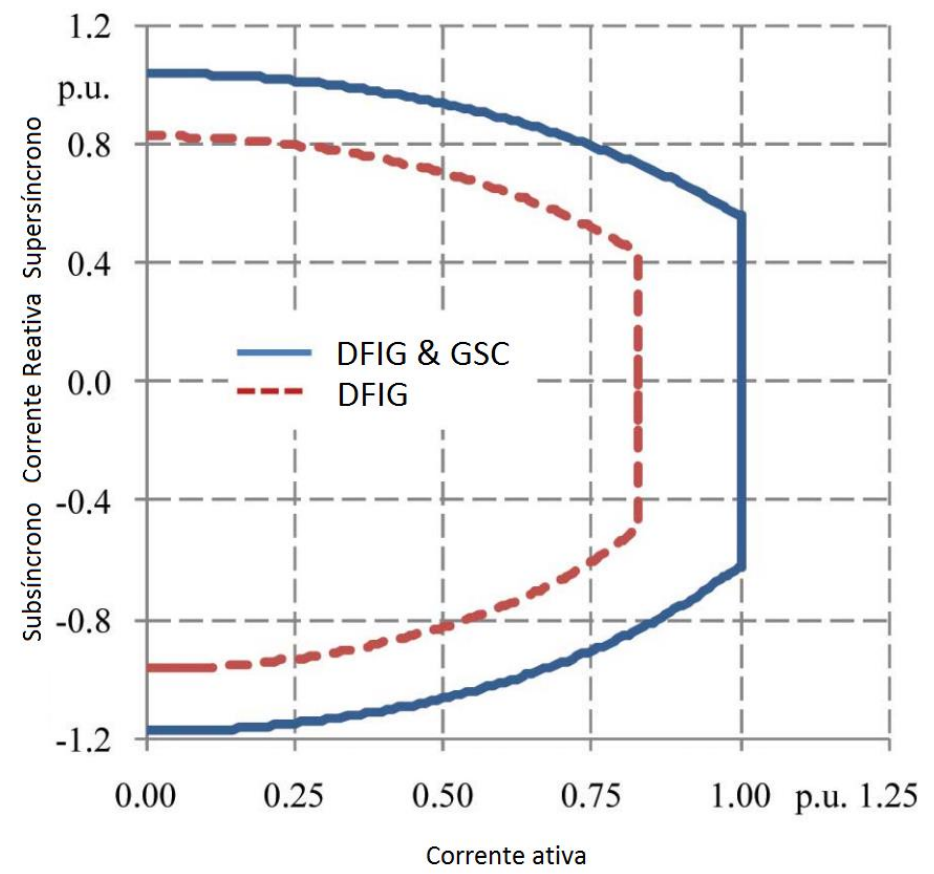

De maneira análoga, considerando os parâmetros típicos das turbinas e os valores de potência ativa, obtém-se a curva de capabilidade de potência reativa para a turbina eólica, conforma ilustrado na Figura 15. O desnível na curva de capabilidade deve-se à impedância transitória do circuito de resfriamento de conversores PWM (Engelhardt, Erlich, Feltes, \& Kretschmann, 2011). 
Figura 15: Curva de capabilidade de potência reativa para a turbina eólica (Engelhardt, Erlich, Feltes, \& Kretschmann, 2011)

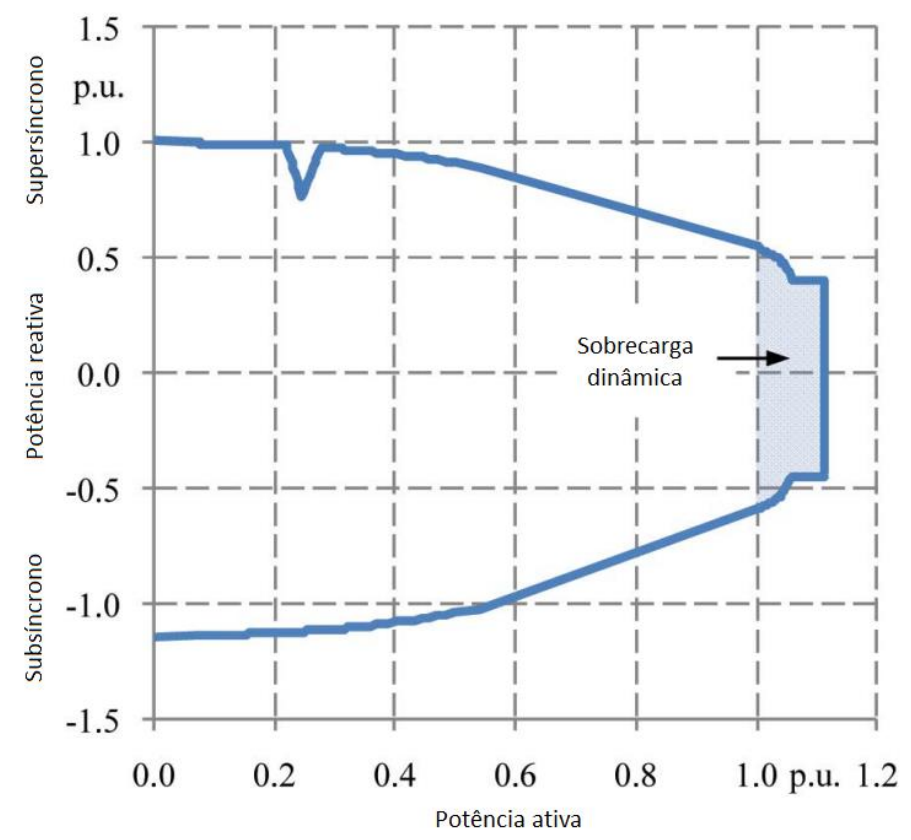

\subsection{Considerações Gerais}

Neste capítulo foram abordados o funcionamento, operação e controle do gerador DFIG. Com a possibilidade de operar tanto em modo sub-síncrono quanto em modo super-síncrono, o gerador DFIG, assim como outras tecnologias de turbinas de velocidade variável, permite melhor aproveitamento da energia eólica disponível em relação às tecnologias de velocidade fixa.

Para controlar os valores de potência ativa e reativa trocados com a rede e, consequentemente, controlar os valores de tensão e frequência no ponto de conexão com o sistema elétrico, são utilizados controladores associados ao conversor eletrônico back-to-back (composto pelos conversores RSC e GSC) da turbina.

Através do conversor RSC, são controlados os valores de torque ou potência ativa do gerador, o que possibilita implementar métodos para maximizar o aproveitamento da energia eólica disponível. O conversor RSC permite também o controle de potência reativa trocada entre o estator do gerador e a rede elétrica, utilizando ou a estratégia de controle de tensão ou de controle de potência reativa (fator de potência). Já o conversor GSC é utilizado para manter constante a tensão no link DC e controlar os valores de potência reativa trocados entre o conversor e a rede elétrica. 
Enquanto o valor de potência ativa gerado pela turbina eólica depende basicamente das condições do vento, a potência reativa suprida é limitada pelas características do gerador e do conversor utilizado. Através das curvas de capabilidade, é possível determinar os valores limite de potência reativa que podem ser supridos pela turbina para um determinado valor de potência ativa (e condição de vento). Nos modelos utilizados nas simulações, os valores de potência reativa supridos pela turbina não são limitados de acordo com sua curva de capabilidade, porém essa limitação foi considerada nos estudos. 


\section{Análise dos Níveis de Tensão da Rede e Tipos de Controle do Gerador DFIG Considerando Perfil de Carga Residencial}

Neste capítulo, será realizada a análise dos níveis de tensão em uma rede de subtransmissão, com a presença de uma planta eólica conectada a uma das barras do sistema. A planta eólica é composta por turbinas com geradores DFIG.

Considerando uma determinada estratégia de controle para a planta eólica e consumidores residenciais conectados à rede, foram obtidos os valores de tensão nas barras do sistema para cada ponto operativo da rede, representado pelo valor da carga em um horário do dia e pela velocidade do vento. Assim, considerando uma faixa de tensões admissíveis no ponto de conexão da planta eólica com a rede, foi determinada a viabilidade de cada tipo de controle para cada ponto operativo.

\subsection{Sistema Elétrico Considerado}

O sistema elétrico considerado nos estudos é apresentado na Figura 16. A rede é alimentada por um sistema de subtransmissão de $132 \mathrm{kV}$ com dois transformadores de 132/33kV. A planta eólica, cuja capacidade de geração é de 30MW, é conectada à barra B7 da rede através de um transformador $33 \mathrm{kV} / 575 \mathrm{~V}$. Existem quatro cargas no circuito, conectadas às barras B2, B3, B4 e B5, com valores de demanda que variam de acordo com o patamar horário. Os valores de potência ativa e reativa de cada carga são apresentados a seguir:

- Carga 1: $\mathrm{P}=50 \mathrm{MW}$ e $\mathrm{Q}=12 \mathrm{MVar}$;

- Carga 2: $\mathrm{P}=6 \mathrm{MW}$ e $\mathrm{Q}=2 \mathrm{MVar}$;

- Carga 3: $\mathrm{P}=24 \mathrm{MW}$ e $\mathrm{Q}=5 \mathrm{MVar}$;

- Carga 4: $\mathrm{P}=12 \mathrm{MW}$ e $\mathrm{Q}=3 \mathrm{MVar}$;

A planta eólica considerada é composta por geradores DFIG, com o rotor conectado à rede através de um conversor eletrônico back-to-back AC/DC/AC, enquanto o estator é conectado diretamente ao sistema de $60 \mathrm{~Hz}$.

As simulações foram feitas utilizando o software SimPowerSystems do Matlab. 
Figura 16: Sistema elétrico considerado no estudo

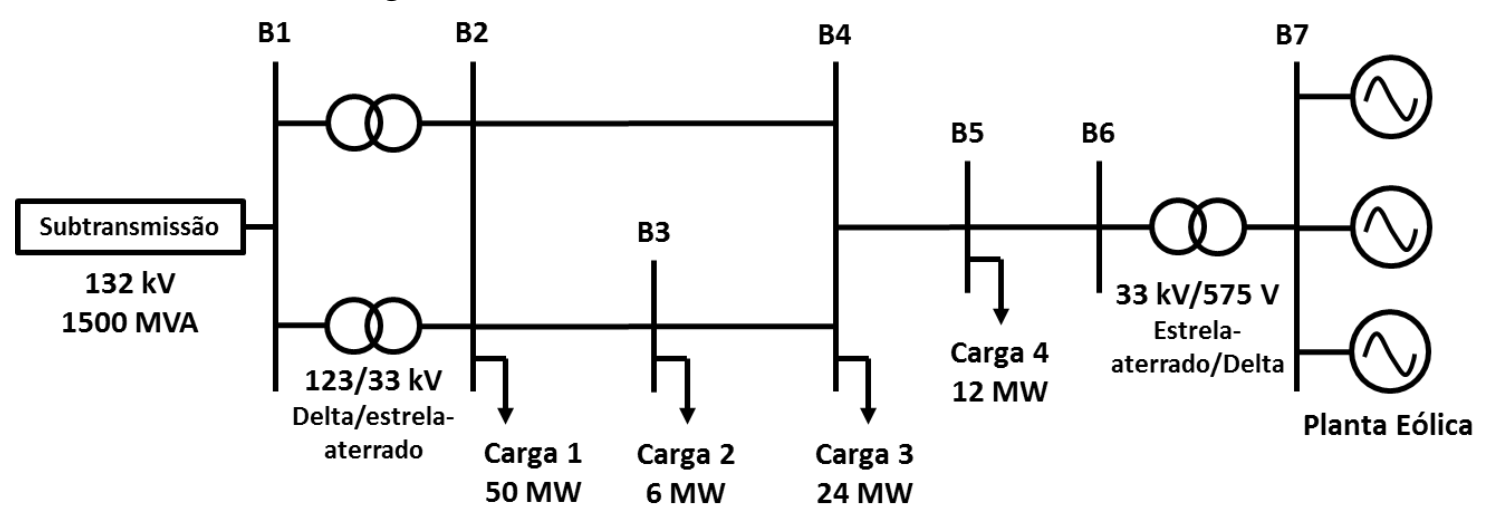

\subsection{Limites de Tensão e Fator de Potência no Ponto de Conexão}

Os valores limite de tensão e fator de potência no ponto de conexão de uma unidade geradora à rede elétrica são definidos no módulo 8 (Qualidade de Energia) dos Procedimentos de Distribuição de Energia Elétrica no Sistema Elétrico Nacional - PRODIST.

Em relação aos limites de tensão, a partir de um determinado valor de referência $T_{R}$, são definidas três faixas de tensão apresentadas na Tabela 1:

Tabela 1: Faixas de tensão em pontos de conexão em tensão nominal superior a $1 \mathrm{kV}$ e inferior a $69 \mathrm{kV}$

\begin{tabular}{|c|c|}
\hline Tensão de Atendimento (TA) & $\begin{array}{c}\text { Faixa de Variação da Tensão de Leitura } \\
\boldsymbol{T}_{\boldsymbol{L}} \text { em relação à tensão de referência } \boldsymbol{T}_{\boldsymbol{R}}\end{array}$ \\
\hline Adequada & $0,93 T_{R} \leq T_{L} \leq 1,05 T_{R}$ \\
\hline Precária & $0,90 T_{R} \leq T_{L} \leq 0,93 T_{R}$ \\
\hline Crítica & $T_{L} \leq 0,90 T_{R}$ ou $T_{L} \geq 1,05 T_{R}$ \\
\hline
\end{tabular}

É desejável que a tensão no ponto de conexão permaneça na faixa de tensão adequada. Entretanto, é permitido que a tensão esteja nas faixas precária e crítica durante pequenos intervalos de tempo (definidos no módulo 8 do PRODIST).

Em relação aos limites de fator de potência no ponto de conexão, para unidade consumidora ou conexão entre distribuidoras com tensão inferior a $230 \mathrm{kV}$, o fator de potência no ponto de conexão deve estar compreendido entre 0,92 indutivo e 0,92 capacitivo.

Os limites de tensão e fator de potência apresentados foram considerados nas simulações para determinar os parâmetros de controle a serem utilizados e quais controles são adequados para cada ponto operativo. 


\subsection{Metodologia}

O perfil de carga residencial é apresentado na Figura 17. Em cada caso simulado, considerou-se a existência de apenas um tipo de consumidor para as quatro cargas existentes no circuito.

Figura 17: Perfil de carga residencial

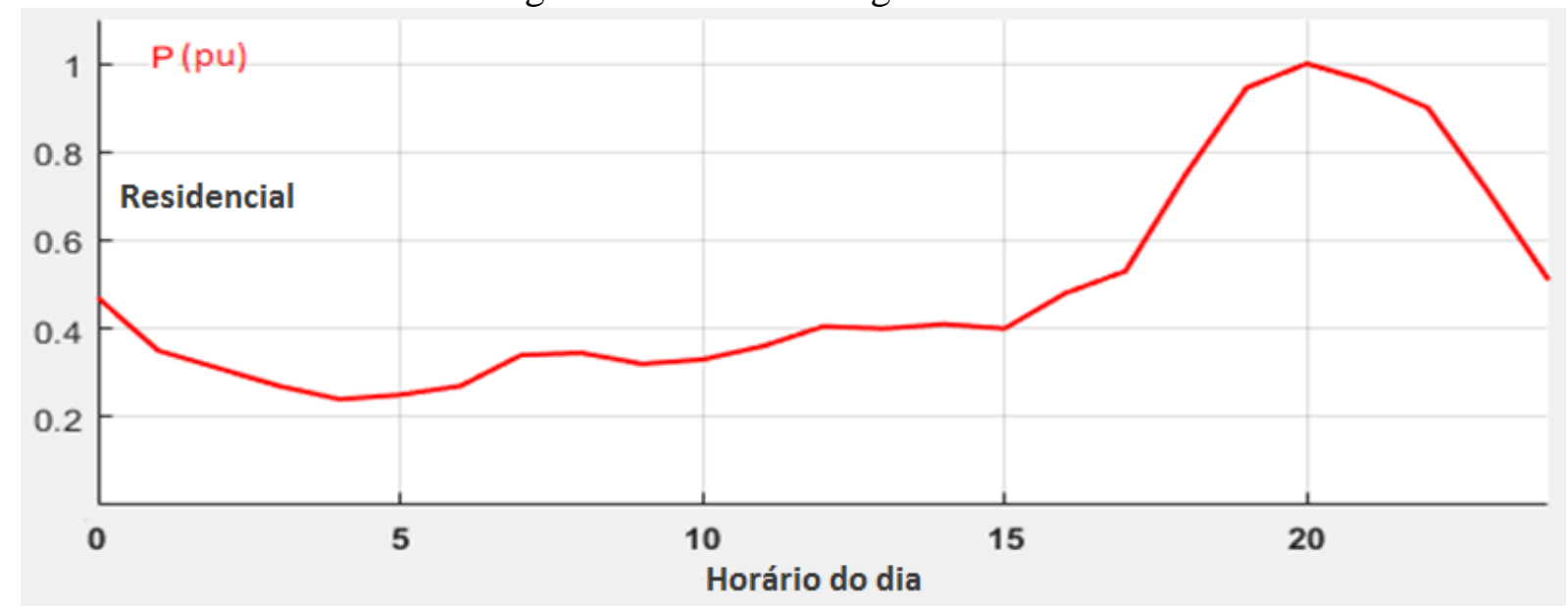

Em relação ao controle das turbinas com gerador DFIG, foram consideradas três estratégias de controle no ponto de conexão com a rede elétrica:

- Controle de fator de potência unitário;

- Controle de fator de potência 0,92 indutivo;

- Controle de fator de potência 0,92 capacitivo;

- Controle de tensão em 1p.u;

- Controle de potência reativa;

A metodologia utilizada no estudo é descrita na Figura 18.

Figura 18: Metodologia empregada nos estudos

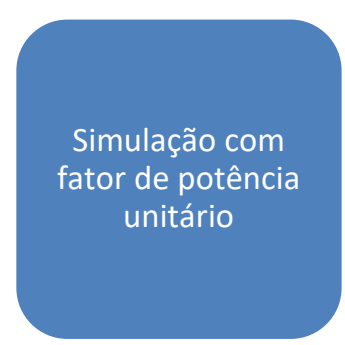

Verificação das

situações em que esse controle não é

suficiente para

manter o valor da

tensão no ponto de

conexão dentro da

faixa adequada
Caso haja situações

em que não é

Simulação com

controle 0,92

indutivo e 0,92

capacitivo

possível manter a

tensão dentro da

faixa adequada,

levantar outras

possibildiades de 
Inicialmente, realiza-se a simulação da rede com a planta eólica utilizando controle de fator de potência unitário, analisando-se o valor de tensão no ponto de conexão para diferentes condições de carga (cada patamar horário do dia) e velocidade do vento (considerando velocidades de $5 \mathrm{~m} / \mathrm{s}$ a $16 \mathrm{~m} / \mathrm{s}$ ). O intervalo de velocidades de vento foi escolhido para observar o funcionamento da turbina em todos os modos de operação (Figura 4).

Para determinar a viabilidade desse controle para cada situação de carga e velocidade do vento, foram analisados os limites de tensão no ponto de conexão com a rede (barra B7). Além disso, foram considerados os limites de potência reativa que podem ser supridos pela turbina eólica, determinados pela curva de capabilidade da mesma, considerando os resultados apenas para os valores de velocidade do vento que mantém a potência reativa dentro desses limites.

Após a verificação dos pontos operativos em que o controle de fator de potência unitário não é suficiente para manter a tensão dentro da faixa adequada, realizam-se novas simulações considerando controle de fator de potência 0,92 indutivo e 0,92 capacitivo, observando-se o comportamento desses pontos para os diferentes tipos de controle. Caso ainda existam pontos operativos com violação dos critérios de tensão, buscou-se estratégias de controle que permitam a operação adequada do sistema nessas situações, como o controle de tensão em 1p.u. no ponto de conexão e o controle de potência reativa em um valor fixo.

O controle de valor fixo de potência reativa foi abordado como uma possível alternativa ser utilizada em poucas situações de velocidade do vento e carregamento, já que faz com que o fator de potência no ponto de conexão com a rede ultrapasse os limites admissíveis.

\subsubsection{Limites de Tensão}

Apesar do módulo 8 do PRODIST determinar pequenos intervalos em que a tensão no ponto de conexão pode situar-se nas faixas precária e crítica, foram considerados como pontos operativos viáveis neste estudo apenas aqueles cuja tensão situa-se na faixa adequada. Esta premissa foi adotada porque, por um lado, o presente estudo obtém como resultados apenas os valores de tensão em cada hora do dia para um dia típico. Entretanto, para definir os intervalos de tempo em que a tensão pode situar-se nas faixas precária e crítica, são utilizados indicadores calculados a partir de grande número de registros (1008) realizados em intervalos consecutivos de tempo (10 minutos) inferiores aos valores por hora obtidos no estudo. 


\subsubsection{Capabilidade de Potência Reativa}

Conforme explicitado no item 3.4, os valores de potência reativa trocados entre a planta eólica e a rede elétrica são limitados pelos parâmetros da turbina e pelos valores de potência ativa obtidos de acordo com a velocidade do vento disponível.

O modelo de turbina eólica utilizado neste estudo não considera os limites da curva de capabilidade para determinar os valores de potência reativa trocados com a rede. Dessa maneira, nas simulações realizadas, devem ser analisados quais valores de velocidade do vento mantém os valores de potência reativa dentro dos limites da curva de capabilidade.

Inicialmente, foram realizadas simulações com velocidade do vento variando de $5 \mathrm{~m} / \mathrm{s}$ a $16 \mathrm{~m} / \mathrm{s}$, para observar o comportamento do sistema elétrico para todos os modos de operação da turbina eólica (Figura 4). Posteriormente, ao analisar os valores limite de potência reativa de acordo com a curva de capabilidade apresentada em (Engelhardt, Erlich, Feltes, \& Kretschmann, 2011), determinou-se que a potência reativa permanece dentro dos limites estabelecidos para velocidades do vento menores ou iguais a $12 \mathrm{~m} / \mathrm{s}$.

\subsection{Resultados}

A seguir são apresentados os resultados obtidos para a rede com consumidores residenciais. Conforme apresentado na Figura 17, a rede com consumidores residências apresenta valores de carga reduzidos no período da madrugada, com o menor valor sendo registrado às $4 \mathrm{~h}$. A carga cresce durante o dia e atinge os maiores valores no final da tarde e no período da noite, com o maior valor sendo registrado às $20 \mathrm{~h}$.

\subsubsection{Controle de Fator de Potência Unitário}

Na Figura 19 são apresentados os valores das tensões em função do horário do dia para cada barra do sistema, considerando velocidade do vento de $5 \mathrm{~m} / \mathrm{s}$, que foi o menor valor de velocidade considerado na simulação.

Observa-se que as tensões na barra B7, barra de conexão com o sistema elétrico, apresentam valores abaixo do limite de 0,93 p.u. nos dois patamares horários com maior carga (entre 20h e 21h), o que inviabiliza o uso do controle de fator de potência unitário nesses casos. 
Figura 19: Tensão em função do horário do dia para cada barra do sistema (vento $=5 \mathrm{~m} / \mathrm{s}$ )

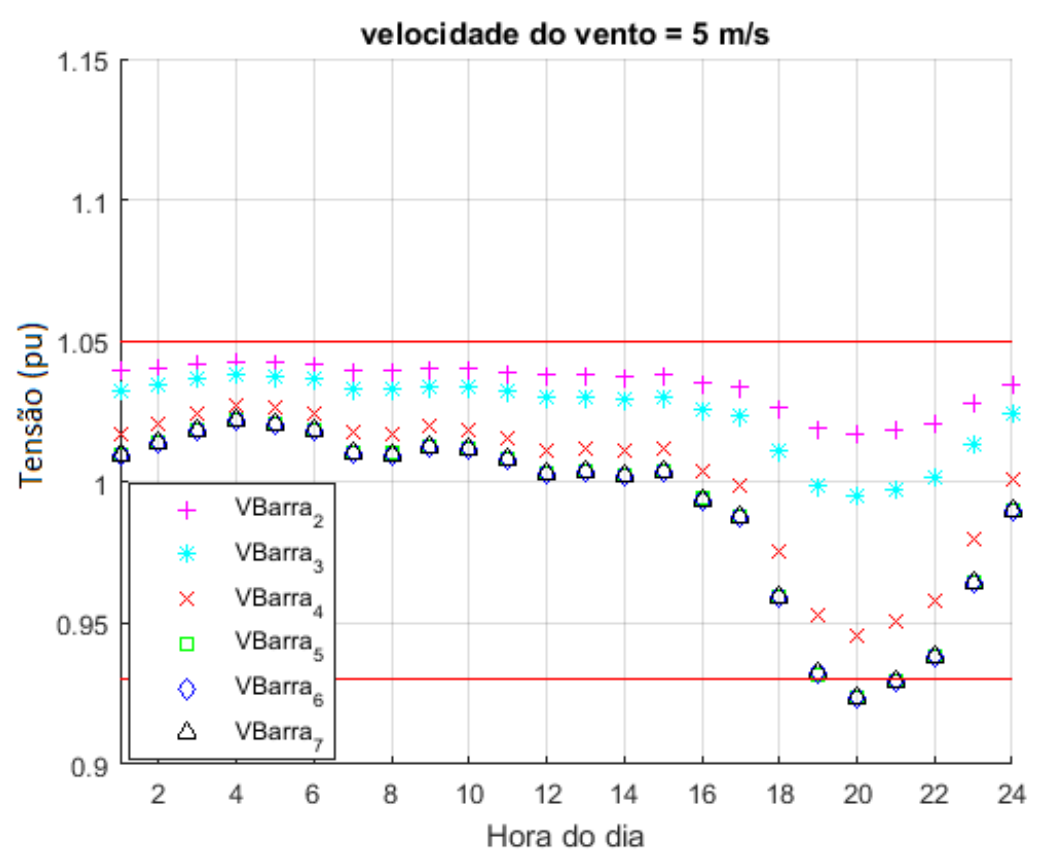

Para a velocidade do vento em 16 m/s, conforme ilustrado na Figura 20, os valores de tensão na barra B7 apresentam valores superiores ao limite de 1,05 p.u. durante grande parte do dia, permanecendo dentro dos limites estabelecidos apenas em horários com carga elevada (entre $18 \mathrm{~h}$ e $22 \mathrm{~h}$ ).

Figura 20: Tensão em função do horário do dia para cada barra do sistema (vento $=16 \mathrm{~m} / \mathrm{s}$ )

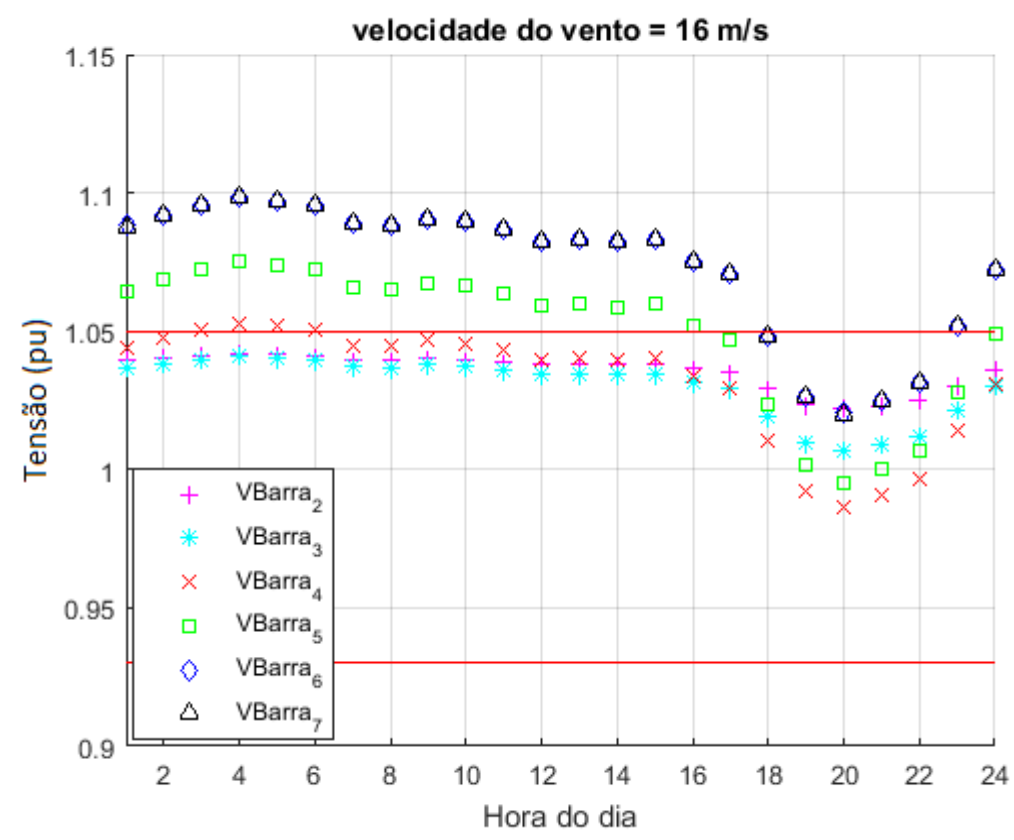

Em relação aos valores de potência reativa injetada ou absorvida pela rede, observa-se na Figura 21 que os valores são nulos, devido ao controle utilizado de fator de potência unitário. 
Figura 21: Potência reativa no ponto de conexão com a rede

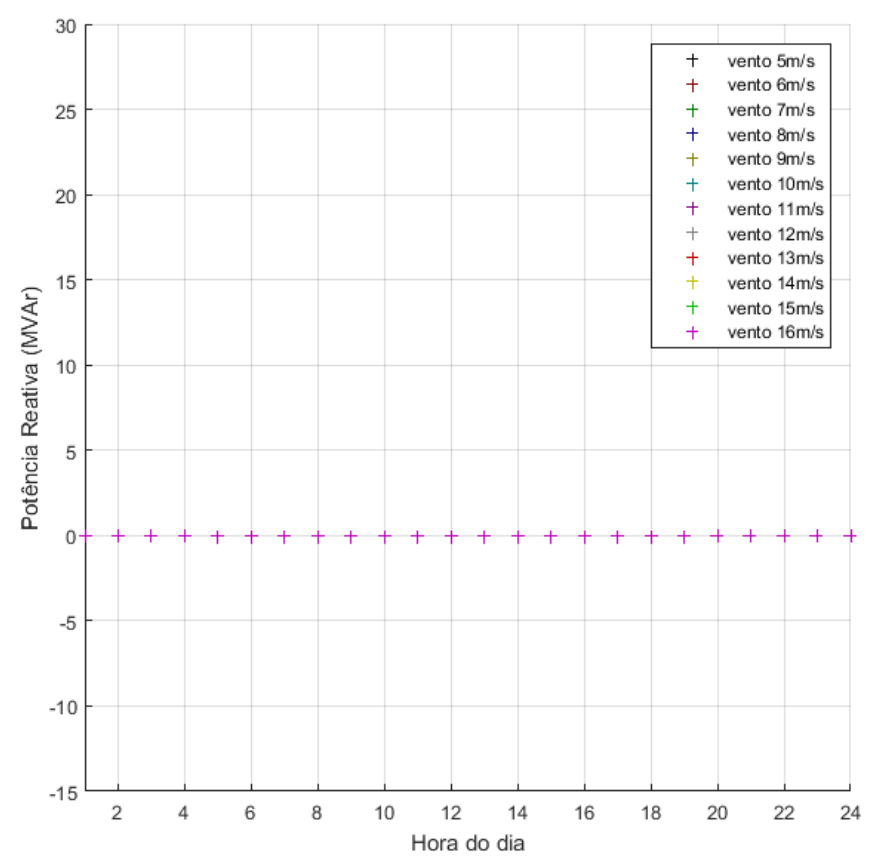

A Figura 22 apresenta os valores de potência ativa medidos no ponto de conexão com a rede para diferentes horários. Observa-se que, para valores do vento menores ou iguais a 13 $\mathrm{m} / \mathrm{s}$, os valores de potência ativa variam de acordo com a velocidade do vento, visando o máximo aproveitamento da energia eólica disponível. Para velocidades acima de $13 \mathrm{~m} / \mathrm{s}$, a potência ativa é limitada através do sistema de controle de pitch pelo valor da potência nominal das turbinas (30 MW).

O sistema elétrico considerado nos estudos é capaz de absorver potência ativa gerada pela turbina e transferir para outro trecho do sistema (não representado no estudo) através da subestação de subtransmissão. Dessa maneira, mesmo para valores reduzidos de carga, o gerador continua produzindo potência ativa de acordo com a velocidade do vento correspondente. Logo, os resultados obtidos para potência ativa, velocidade do rotor e ângulo de pitch não mudam de acordo com o tipo de controle escolhido, sendo apresentados apenas nesta subseção. 
Figura 22: Potência ativa no ponto de conexão com a rede

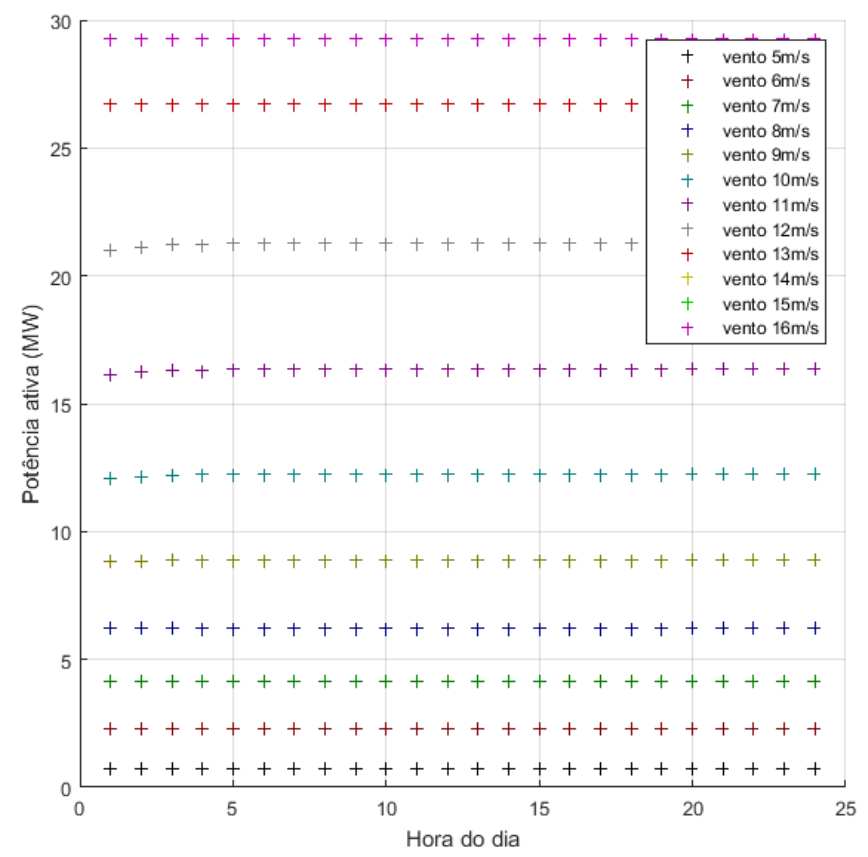

Em relação à velocidade do rotor do gerador, observa-se que, para velocidades do vento reduzidas, a operação ocorre no modo sub-síncrono, com velocidades abaixo de 1pu. Para velocidades superiores a $10 \mathrm{~m} / \mathrm{s}$, ocorre operação no modo super-síncrono e as velocidades superam o valor de 1 p.u. Os resultados são apresentados na Figura 23.

Figura 23: Velocidade do rotor do gerador DFIG

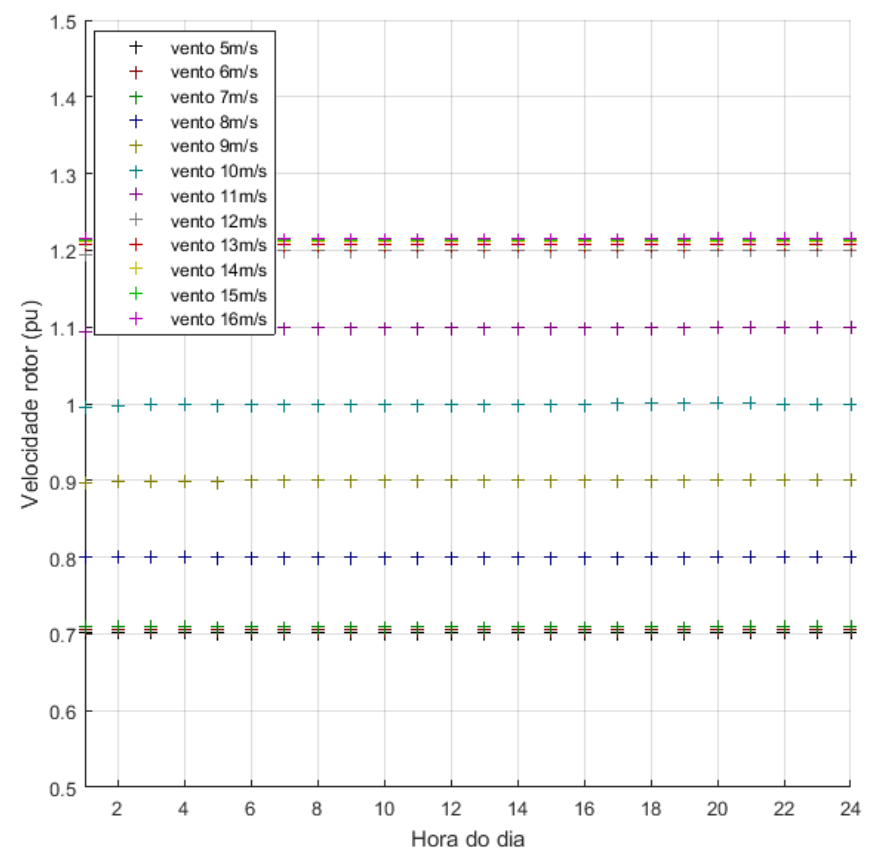


Na Figura 24, são apresentados os valores de ângulo de pitch para diferentes patamares horários. Observa-se que, para velocidades elevadas (acima de $13 \mathrm{~m} / \mathrm{s}$ ), o sistema passa a ser acionado para limitar a potência ativa gerada pela turbina ao valor nominal.

Figura 24: Ângulo de pitch das pás da turbina

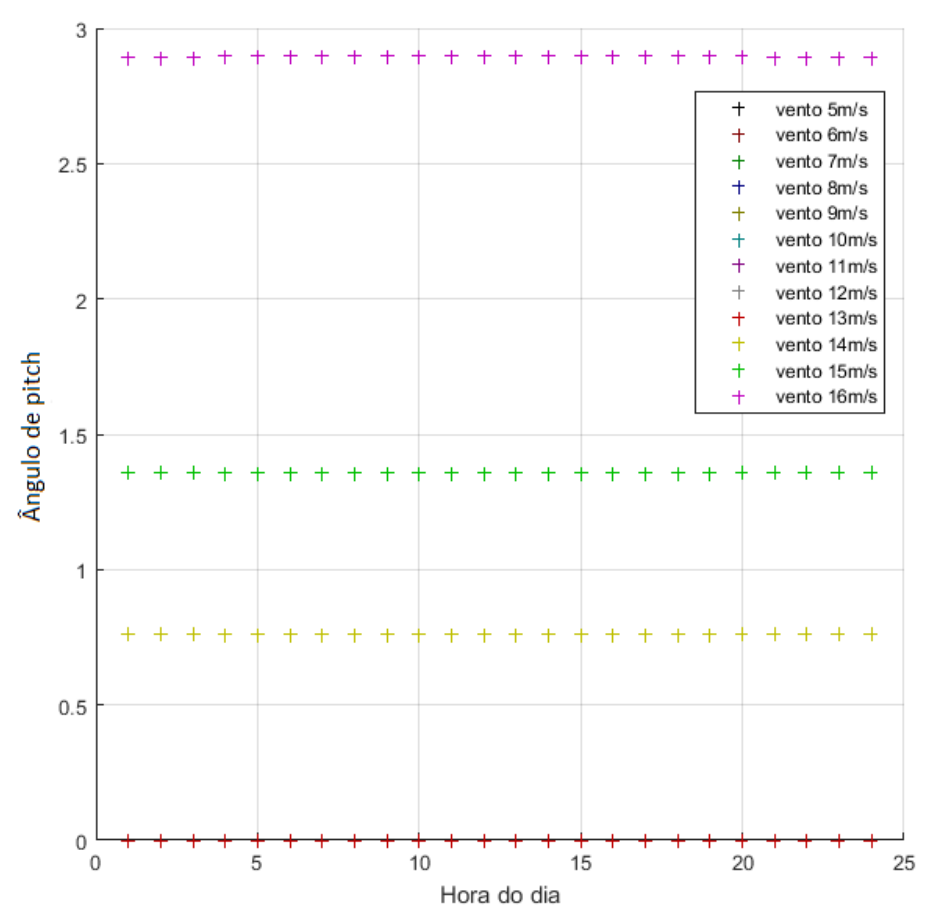

Para determinar a viabilidade de utilizar o controle de fator de potência unitário, foram analisados os valores de tensão na barra B7 de conexão com o sistema para todos os patamares de carga e velocidades do vento, conforme ilustrado na Figura 25. Observa-se que, para velocidades do vento entre $6 \mathrm{~m} / \mathrm{s}$ e $9 \mathrm{~m} / \mathrm{s}$, não há violação de tensão em nenhuma situação de carga. Já para o menor valor de velocidade do vento $(5 \mathrm{~m} / \mathrm{s})$, ocorre violação de tensão para os patamares com maior carga (entre 20h e 21h). Por fim, para velocidades do vento maiores ou iguais a $10 \mathrm{~m} / \mathrm{s}$, ocorrem violações de tensão para os patamares de menor carga.

Outro ponto a ser considerado é a capabilidade de potência reativa trocada com a rede no ponto de conexão. De acordo com os limites da curva de capabilidade apresentada em (Engelhardt, Erlich, Feltes, \& Kretschmann, 2011), a potência aparente no ponto de conexão com a rede não deve ultrapassar 1.1p.u. Isso ocorre para velocidades do vento superiores a 12 $\mathrm{m} / \mathrm{s}$.

Considerando os resultados das simulações e a curva de capabilidade de potência reativa da turbina eólica, obteve-se o mapa operativo apresentado na Figura 26. Os pontos representados em azul mostram as condições de carga e velocidade do vento em que é possível operar o sistema com o controle de fator de potência unitário. Os pontos em vermelho 
representam condições em que a tensão no ponto de operação extrapola os limites da faixa de tensão adequada.

Figura 25: Tensão na barra B7 para todos os valores de carga e velocidade do vento

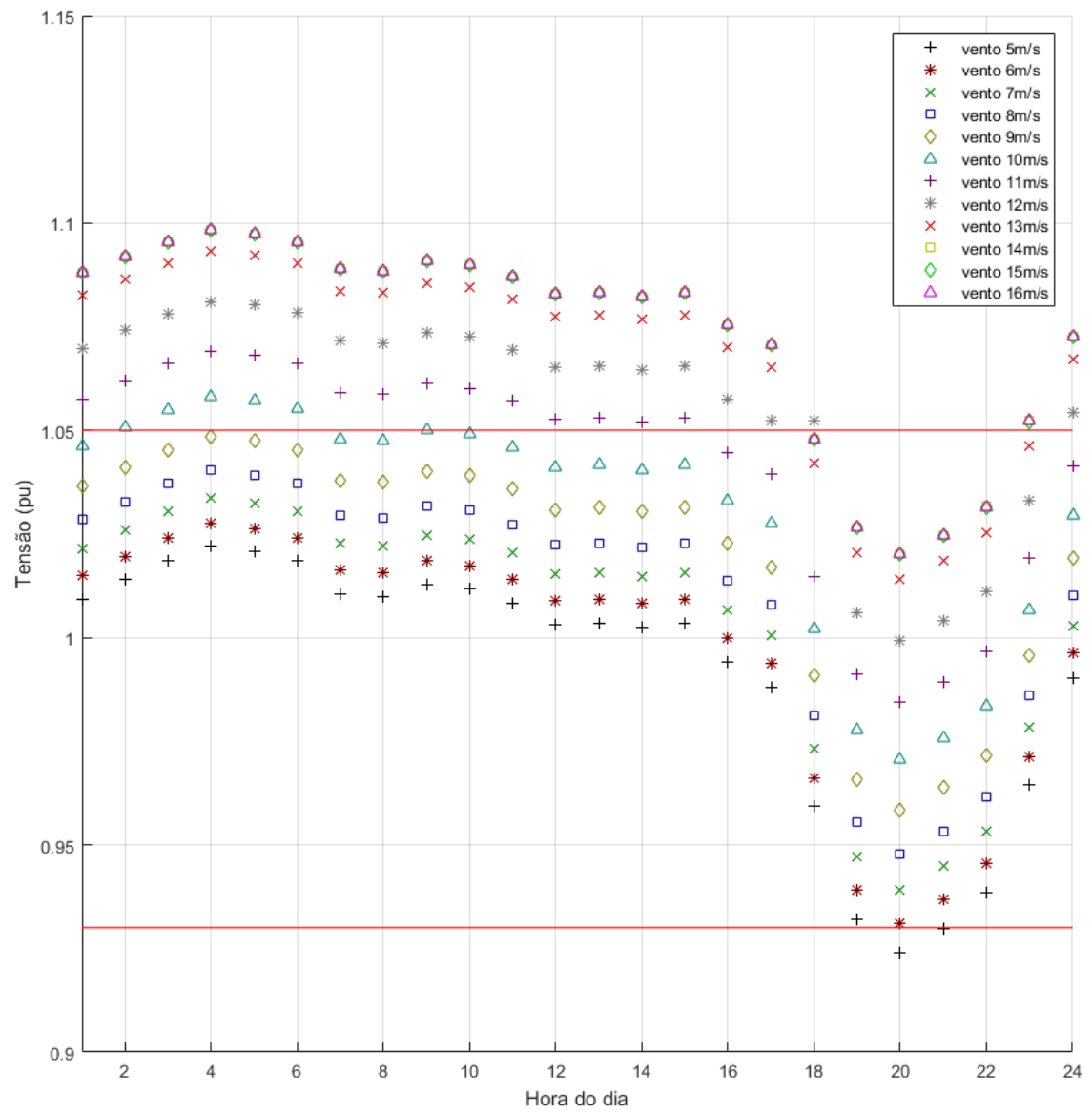

Observa-se que esse controle é adequado em duas condições:

- Carga elevada e velocidade do vento elevada;

- Carga reduzida e velocidade do vento baixa. 
Figura 26: Mapa de operação da planta para controle de fator de potência unitário

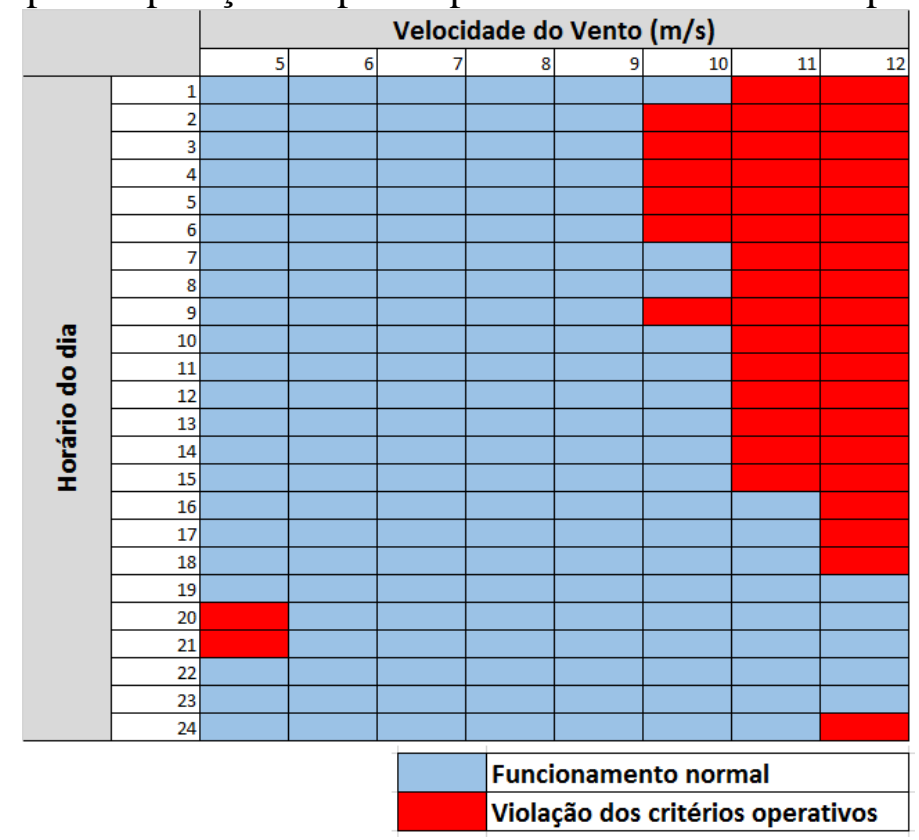

\subsubsection{Controle de Fator de Potência 0,92 Indutivo}

Os valores das tensões em função dos horários do dia em cada uma das barras do sistema, para a velocidade de $5 \mathrm{~m} / \mathrm{s}$, são apresentados na Figura 27. Observa-se que a tensão na barra B7 ultrapassa o limite inferior de 0,93p.u. da faixa admissível de tensão para os patamares horários com maior carga (entre 20h e 21h). Para a velocidade do vento de $16 \mathrm{~m} / \mathrm{s}$, observa-se que não há violação dos valores de tensão independente da carga do sistema (Figura 28).

Figura 27: Tensão em função do horário do dia para cada barra do sistema (vento $=5 \mathrm{~m} / \mathrm{s}$ )

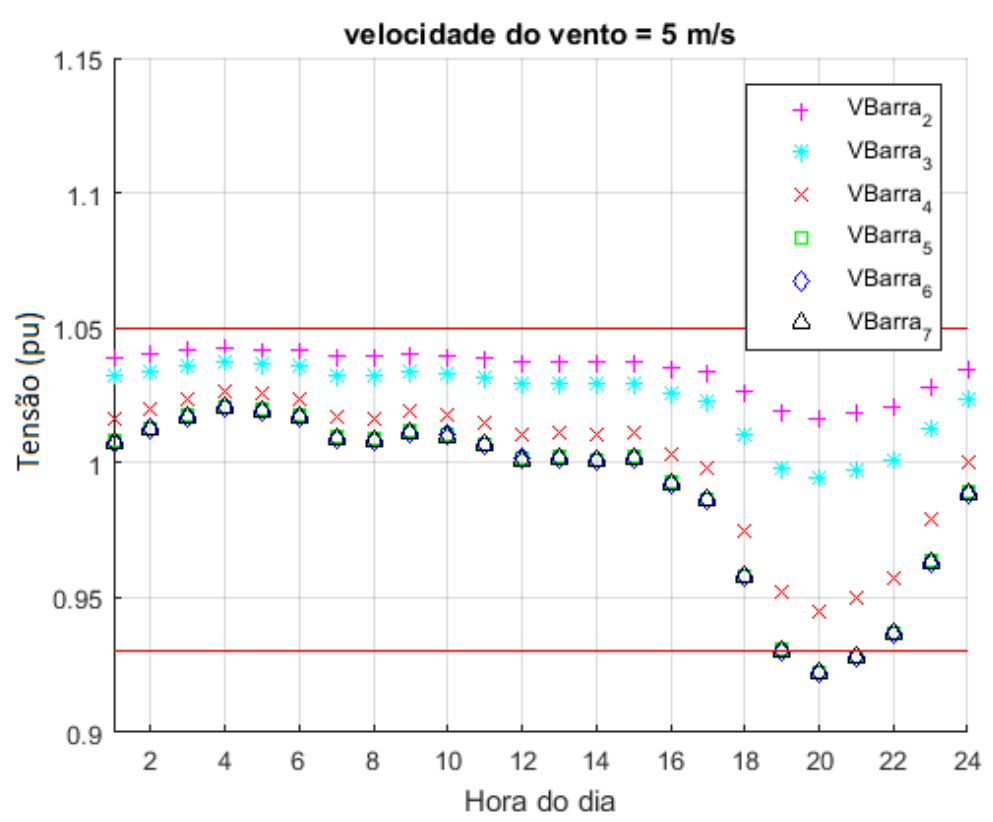


Figura 28: Tensão em função do horário do dia para cada barra do sistema (vento $=16 \mathrm{~m} / \mathrm{s}$ )

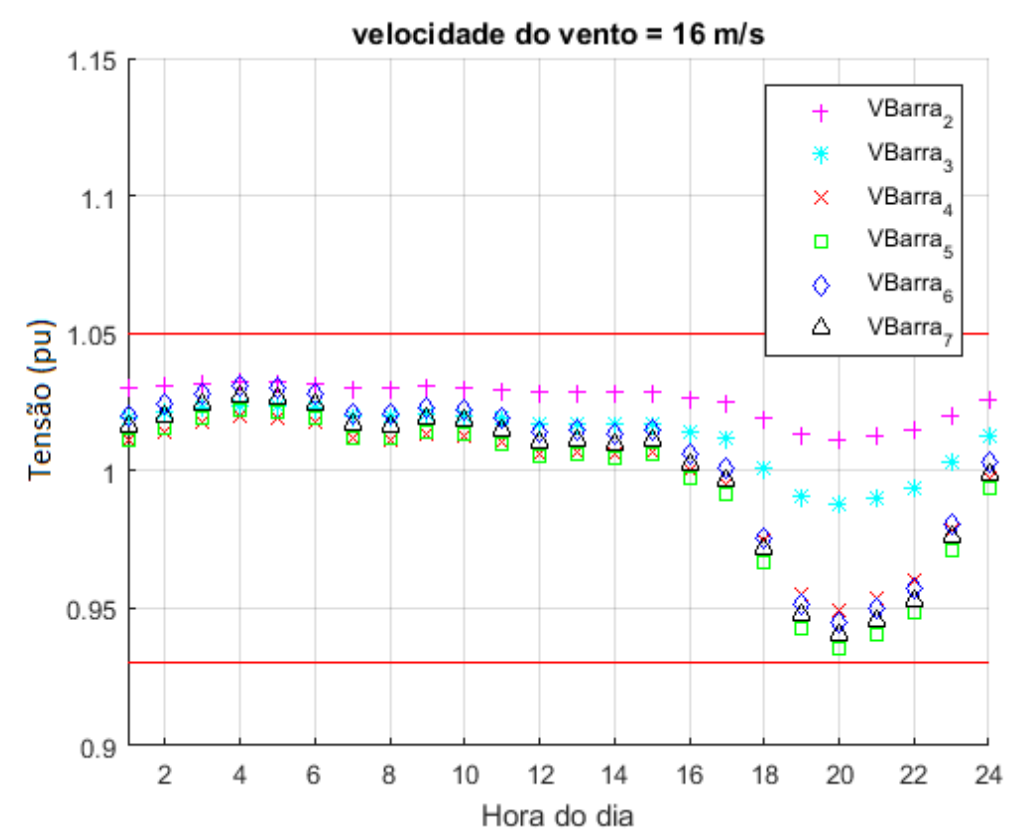

A Figura 29 mostra que, quanto maior a velocidade do vento, maior será o valor de potência reativa injetada na rede com o controle de fator de potência 0,92 indutivo.

Figura 29: Potência reativa no ponto de conexão com a rede.

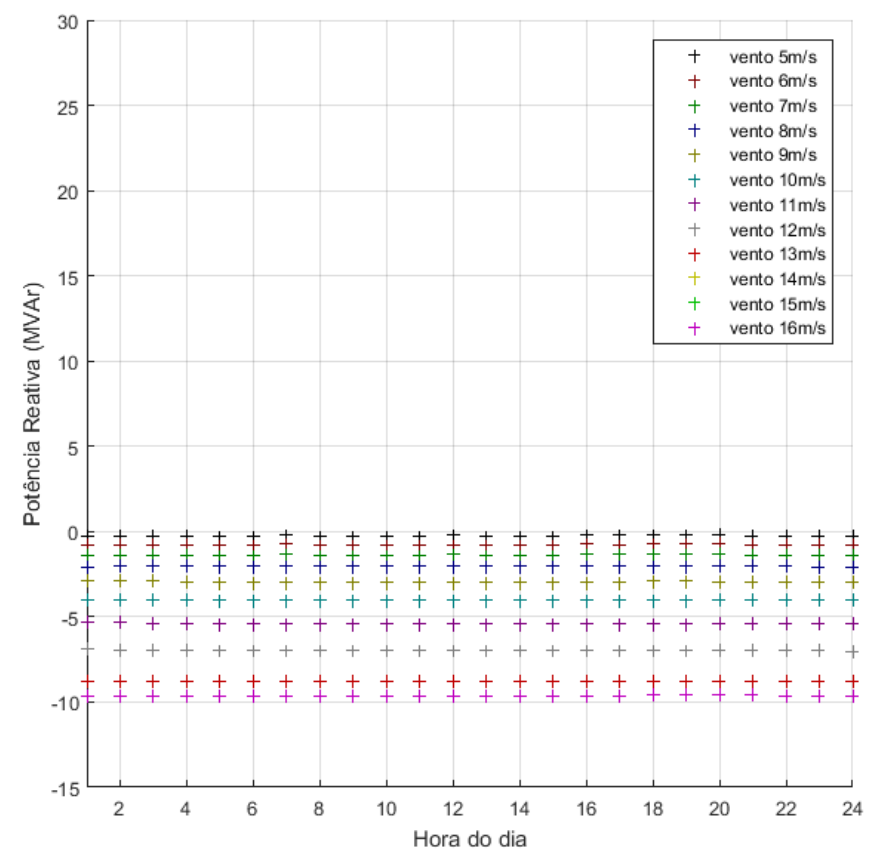

Para determinar o mapa operativo da planta eólica com controle de fator de potência 0,92 indutivo, foram analisados os valores de tensão para cada patamar de carga e velocidade do vento, conforme apresentado na Figura 30. Observa-se que, para tensões superiores a $7 \mathrm{~m} / \mathrm{s}$, não ocorre violação de tensão na barra B7 em qualquer situação de carga. 
Considerando os resultados obtidos e os limites de capabilidade de potência reativa, obteve-se o mapa operativo representado na Figura 31. Em relação ao controle de fator de potência unitário, o controle 0,92 indutivo permite operação mais ampla em situações de velocidade do vento elevada, porém acentua os problemas de tensão em condições de carga elevada e velocidade do vento reduzida.

Figura 30: Tensão na barra B7 para todos os valores de carga e velocidade do vento

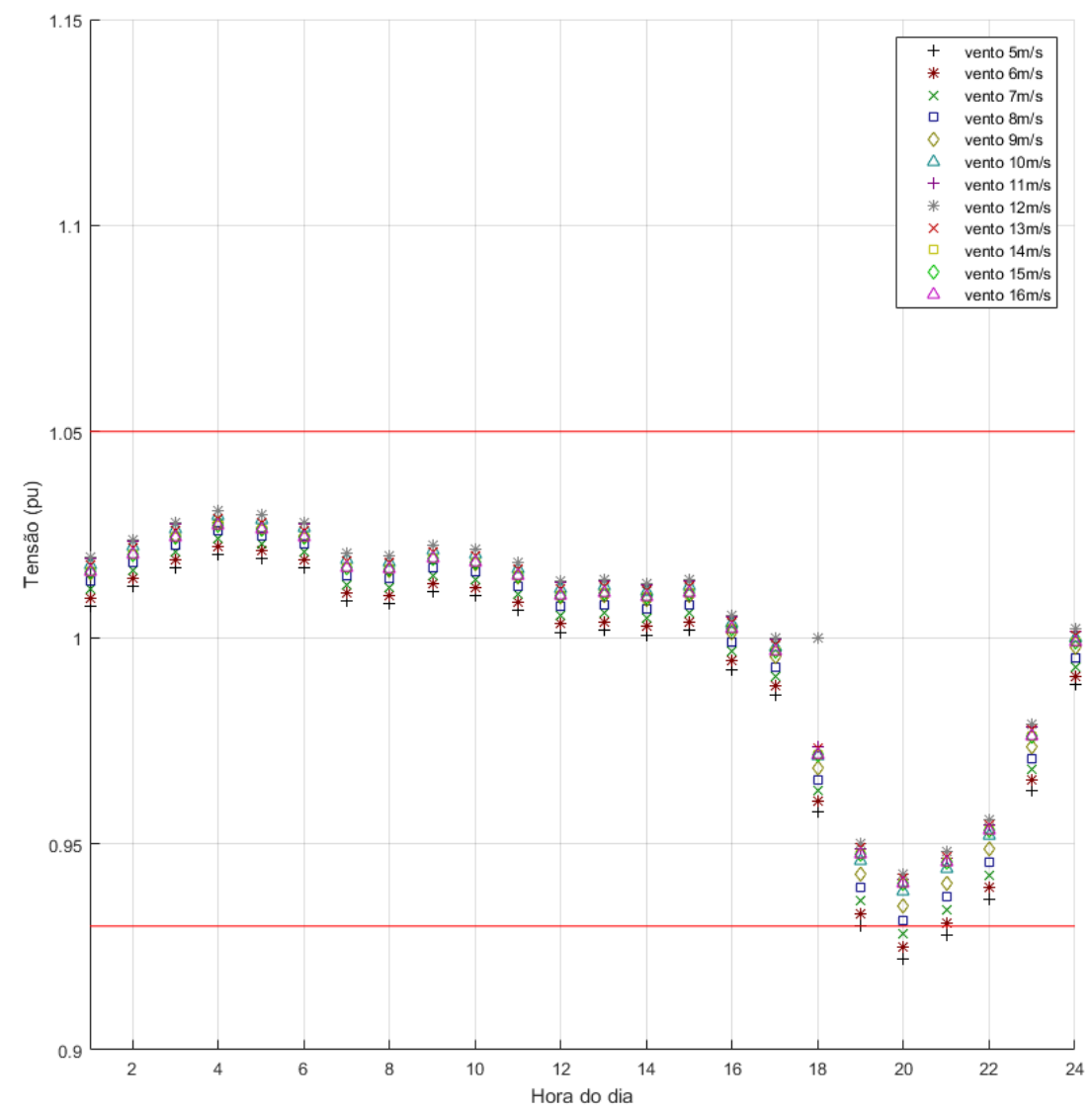

Figura 31: Mapa de operação para controle de fator de potência 0,92 indutivo 


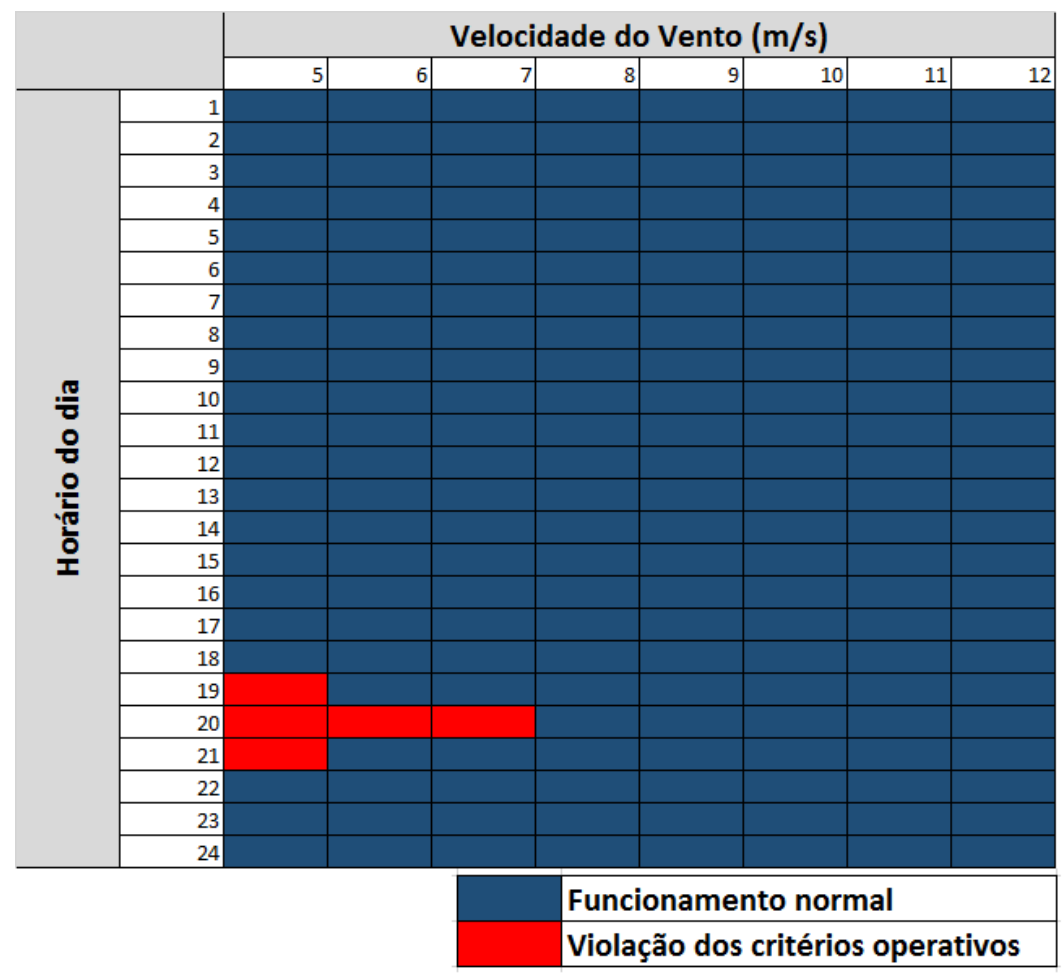

\subsubsection{Controle de Fator de Potência 0,92 Capacitivo}

A Figura 32 apresenta os valores de tensão em cada horário do dia para cada barra do sistema, com velocidade do vento de $5 \mathrm{~m} / \mathrm{s}$. É possível observar que, para o horários com maior carga (20h), a tensão na barra de conexão com a rede elétrica apresenta valores abaixo do limite de 0,93 p.u.

Figura 32: Tensão em função do horário do dia para cada barra do sistema (vento $=5 \mathrm{~m} / \mathrm{s}$ )

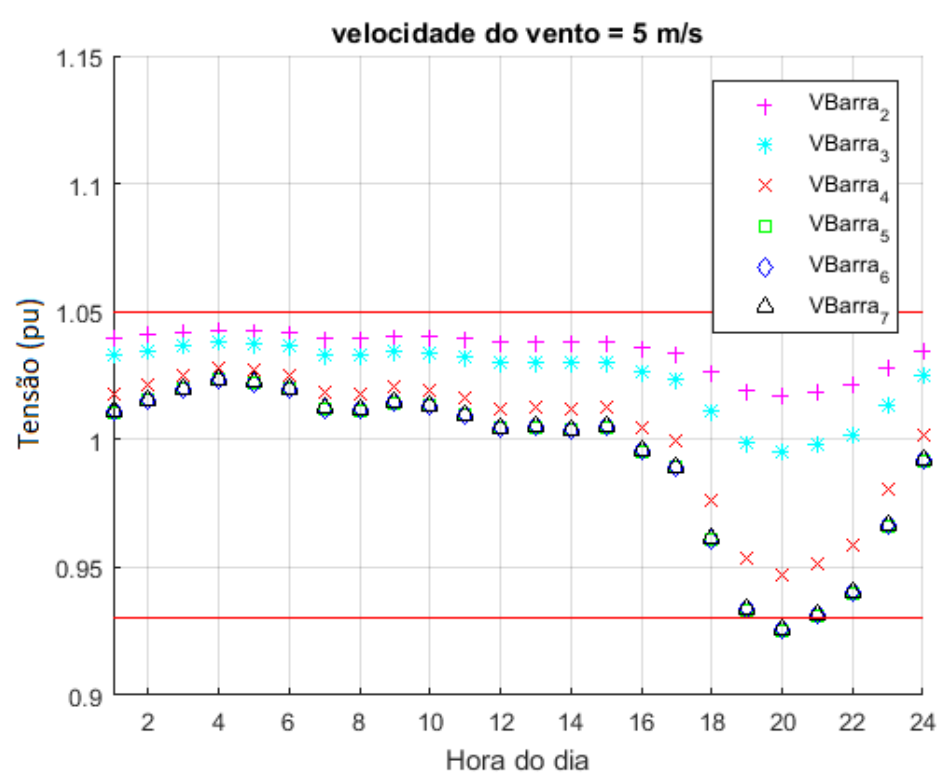


Com velocidade do vento de 16 m/s, ocorre violação de tensão na barra B7 para todos os patamares de carga, conforme ilustrado na Figura 33.

Figura 33: Tensão em função do horário do dia para cada barra do sistema (vento $=16 \mathrm{~m} / \mathrm{s}$ )

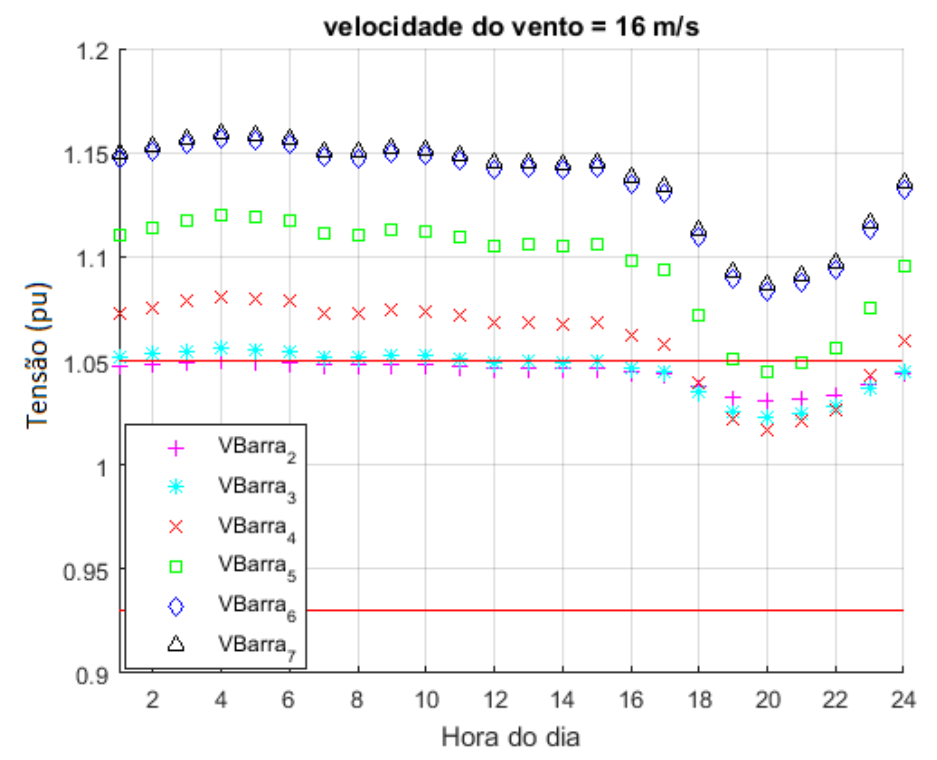

Com a utilização do controle de fator de potência 0,92 capacitivo, os valores de potência reativa medidos variam de acordo com a velocidade do vento e a potência ativa produzida pela máquina, como ilustrado na Figura 34. Quanto maior a velocidade do vento, maior o valor de potência reativa consumido pela planta eólica.

Figura 34: Potência reativa no ponto de conexão com a rede

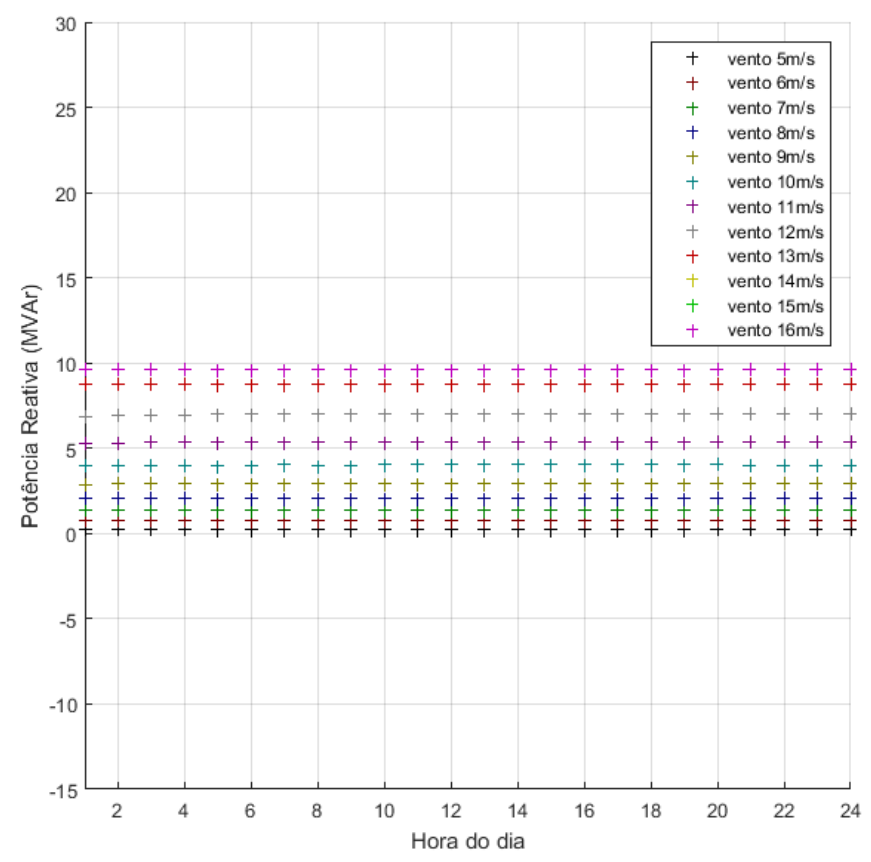


Em relação ao mapa operativo para o controle de fator de potência 0,92 capacitivo, para o patamar horário com menor carga, a tensão na barra B7 permanece dentro da faixa admissível apenas para velocidades do vento entre $6 \mathrm{~m} / \mathrm{s}$ e $7 \mathrm{~m} / \mathrm{s}$, conforme ilustrado na Figura 35. Nos demais cenários de velocidade do vento, ocorre violação de tensão em pelo menos um patamar horário.

Analisando todas as situações de carregamento e velocidade do vento, obteve-se o mapa operativo apresentado na Figura 36 para a estratégia de controle de fator de potência 0,92 capacitivo. Os problemas de tensão encontrados nas situações de carga elevada e velocidade baixa de vento são levemente atenuados, porém não resolvidos. Não é possível operar a planta eólica com esse controle para a condição de vento de $5 \mathrm{~m} / \mathrm{s}$ às $20 \mathrm{~h}$. Além disso, em situações de carga reduzida, o controle de fator de potência 0,92 capacitivo, em relação ao controle de fator de potência unitário, permite operação em menor número de pontos operativos.

Figura 35: Tensão nas barras no horário de menor carga

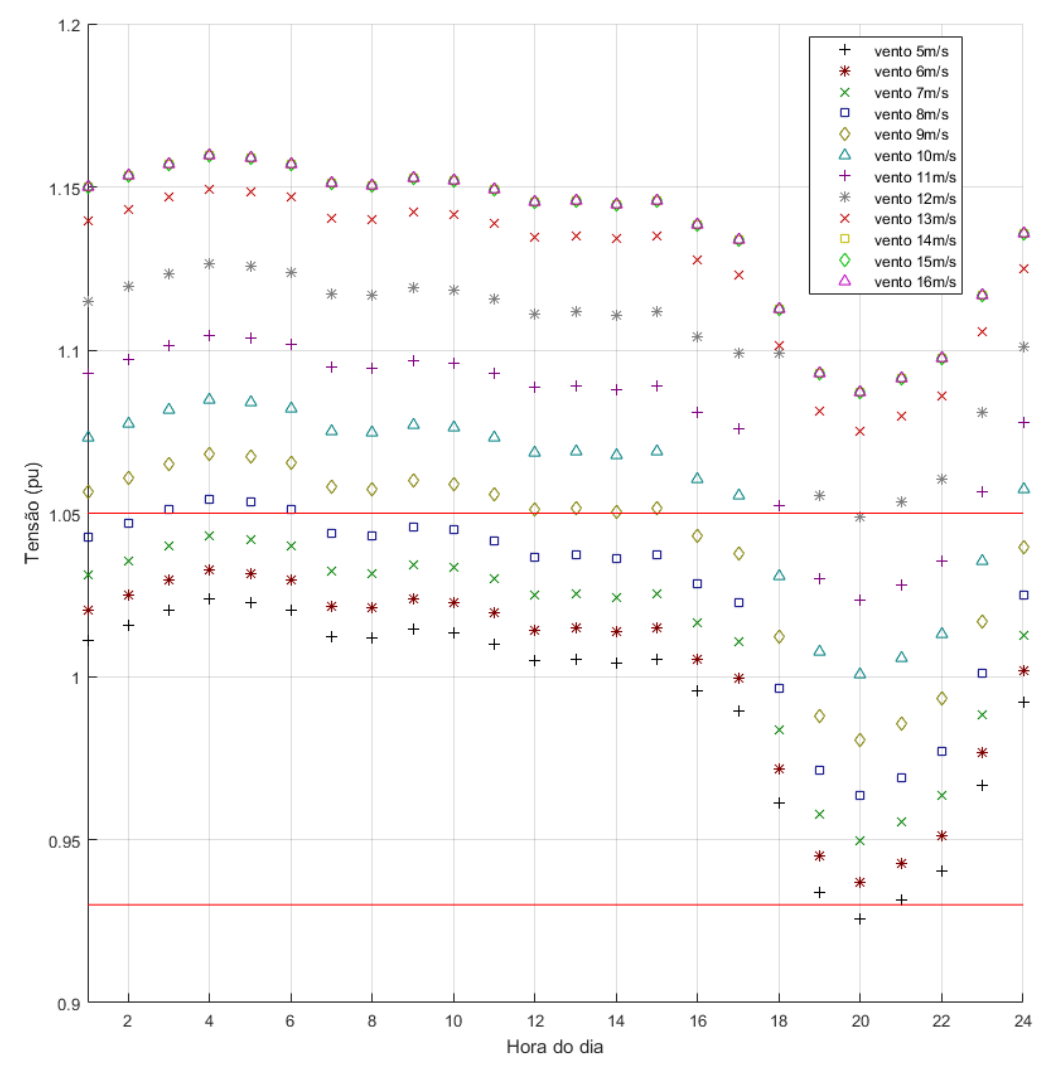


Figura 36: Mapa de operação para controle de fator de potência em 0,92 capacitivo

\begin{tabular}{|c|c|c|c|c|c|c|c|c|c|}
\hline & \multicolumn{8}{|c|}{ Velocidade do Vento $(\mathrm{m} / \mathrm{s})$} \\
\hline & & 5 & 6 & 7 & 8 & 9 & 10 & 11 & 12 \\
\hline \multirow{19}{*}{$\begin{array}{l}\text { 응 } \\
\text { 웅 } \\
\text { 윰 } \\
\text { 음 }\end{array}$} & 1 & & & & & & & & \\
\hline & $\frac{2}{3}$ & & & & & & & & \\
\hline & 4 & & & & & & & & \\
\hline & 5 & & & & & & & & \\
\hline & 6 & & & & & & & & \\
\hline & $\frac{1}{8}$ & & & & & & & & \\
\hline & 9 & & & & & & & & \\
\hline & 10 & & & & & & & & \\
\hline & 11 & & & & & & & & \\
\hline & $\frac{12}{13}$ & & & & & & & & \\
\hline & 14 & & & & & & & & \\
\hline & 15 & & & & & & & & \\
\hline & 16 & & & & & & & & \\
\hline & 18 & & & & & & & & \\
\hline & 19 & & & & & & & & \\
\hline & 20 & & & & & & & & \\
\hline & 21 & & & & & & & & \\
\hline & 22 & & & & & & & & \\
\hline & 24 & & & & & & & & \\
\hline & & & & & & nan & on $n$ & & \\
\hline & & & & & & a & rité & ope & \\
\hline
\end{tabular}

\subsubsection{Outras Possibilidades de Controle}

Conforme observado nos mapas operativos apresentados anteriormente, para a velocidade de $5 \mathrm{~m} / \mathrm{s}$, não é possível operar a planta eólica com um determinado tipo de controle em todas as situações de carga consideradas. Com a utilização de um fator de potência capacitivo baixo (0,92p.u), esperava-se que não houvesse esse tipo de violação de tensão. Entretanto, com o valor baixo da velocidade do vento, o valor de potência ativa gerado pela planta eólica também é baixo, o que limita a troca de potência reativa com a rede.

Para contornar essa situação, são propostas as seguintes alternativas de controle para a planta eólica:

\subsubsection{Controle de tensão em 1pu da planta eólica:}

A Figura 37 apresenta os valores de tensão obtidos na barra B7 para todas as condições de carga e velocidade do vento. Através desse controle, o valor da tensão no ponto de conexão da planta eólica é mantido próximo a 1pu, com a variação do valor de potência reativa trocada com a rede. 
Figura 37: Valores de tensão na barra B7 para todas as situações de carga e velocidade do vento

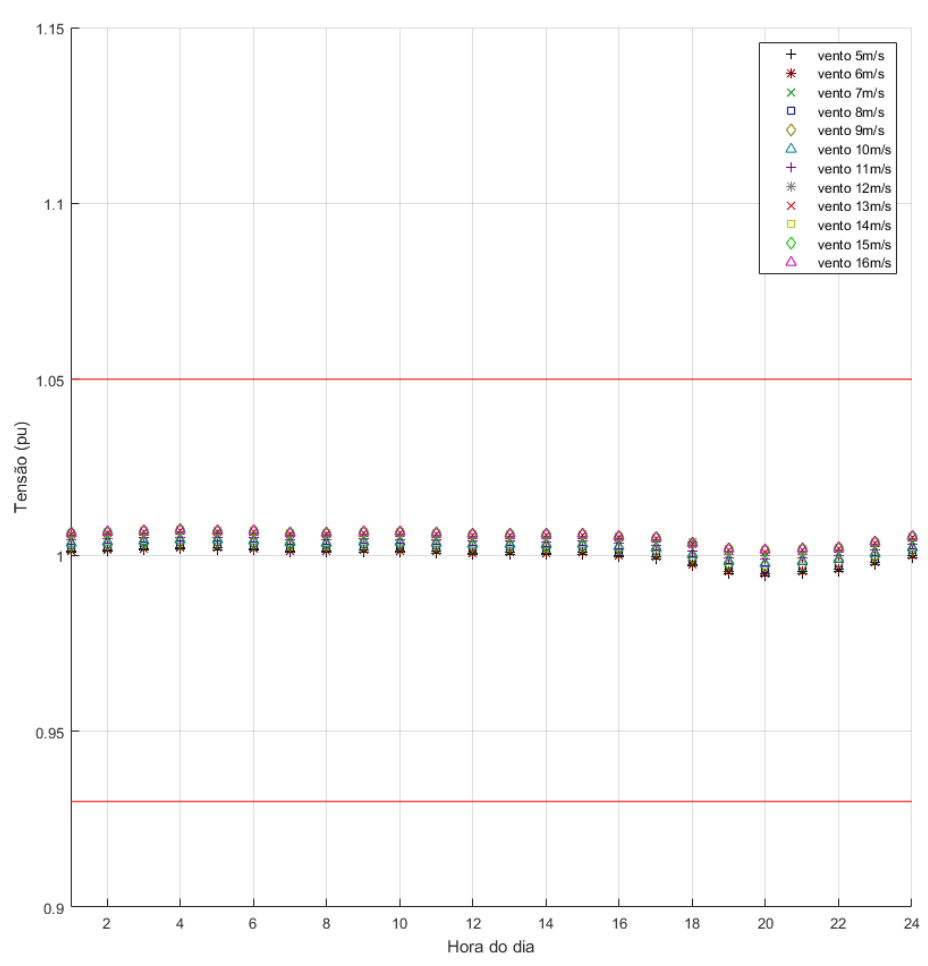

Em relação ao mapa operativo para o controle de tensão em 1p.u., não há condições em que ocorra violação dos critérios de tensão, conforme apresentado na Figura 38.

Figura 38: Mapa de operação para controle de tensão em 1p.u.

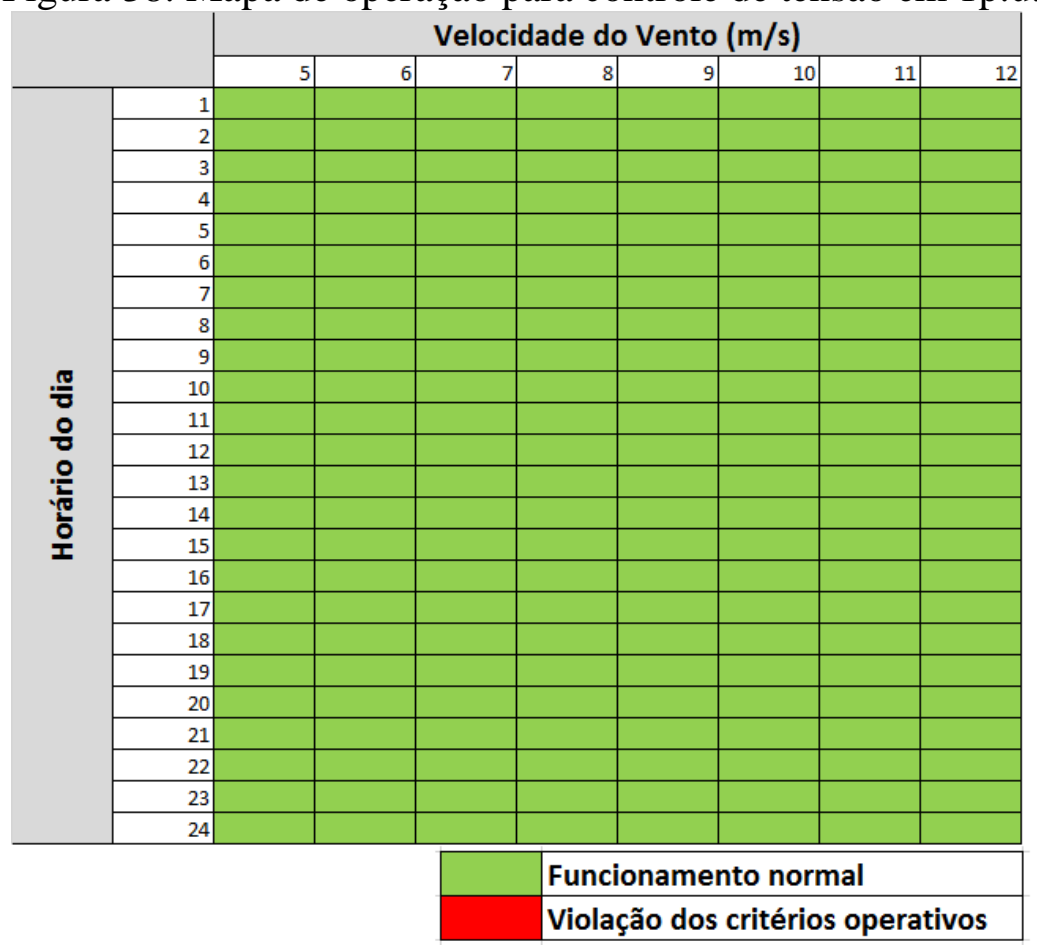


A estratégia de controle de tensão em 1p.u., conforme comprovado pelos resultados, apresenta vantagem em relação às demais por permitir a operação do sistema para quaisquer condições operativas.

Essa estratégia não foi considerada amplamente no trabalho devido à impossibilidade de implantação em determinadas plantas eólicas, pois normalmente demanda um controle integrado entre todos os geradores do parque eólico. Além disso, o modelo utilizado nas simulações no software Matlab equivale a apenas uma turbina, com os controle de tensão atuando apenas sobre essa turbina, o que difere bastante do que é encontrado na prática.

O modelo utilizado nas simulações poderia representar com mais precisão uma estratégia de controle utilizando um conversor do tipo STATCOM no ponto de conexão com a rede elétrica. Dessa maneira, esse equipamento faria o controle de tensão e potência reativa apenas no ponto de conexão, não sendo necessária a aquisição de dados e envio de comandos individuais para cada turbina.

\subsubsection{Injeção de valor fixo de potência reativa para velocidades reduzidas:}

Através dessa alternativa, para os casos em que o controle de fator de potência não é efetivo, é possível utilizar um controle que injete um valor fixo e mais elevado de potência reativa para velocidades do vento reduzidas.

A Figura 39 apresenta os valores de tensão na barra B7 para todas as condições de carga e velocidade do vento, para um controle injetando valor fixo de potência reativa de 0.05p.u. Observa-se que, para a velocidade do vento entre $5 \mathrm{~m} / \mathrm{s}$ e $7 \mathrm{~m} / \mathrm{s}$, não ocorre violação de tensão para qualquer situação de carga.

Ao mesmo tempo em que permite operação dentro dos limites de tensão para a faixa de velocidades citadas anteriormente, esse controle acarreta em violação dos limites admissíveis de fator de potência estabelecidos nos procedimentos de rede da ANEEL. Dessa maneira, poderia ser utilizado apenas em poucas condições operativas, que não causem punições por parte do órgão regulador do sistema elétrico. 
Figura 39: Tensão na barra B7 para todas as situações de carga e velocidade do vento

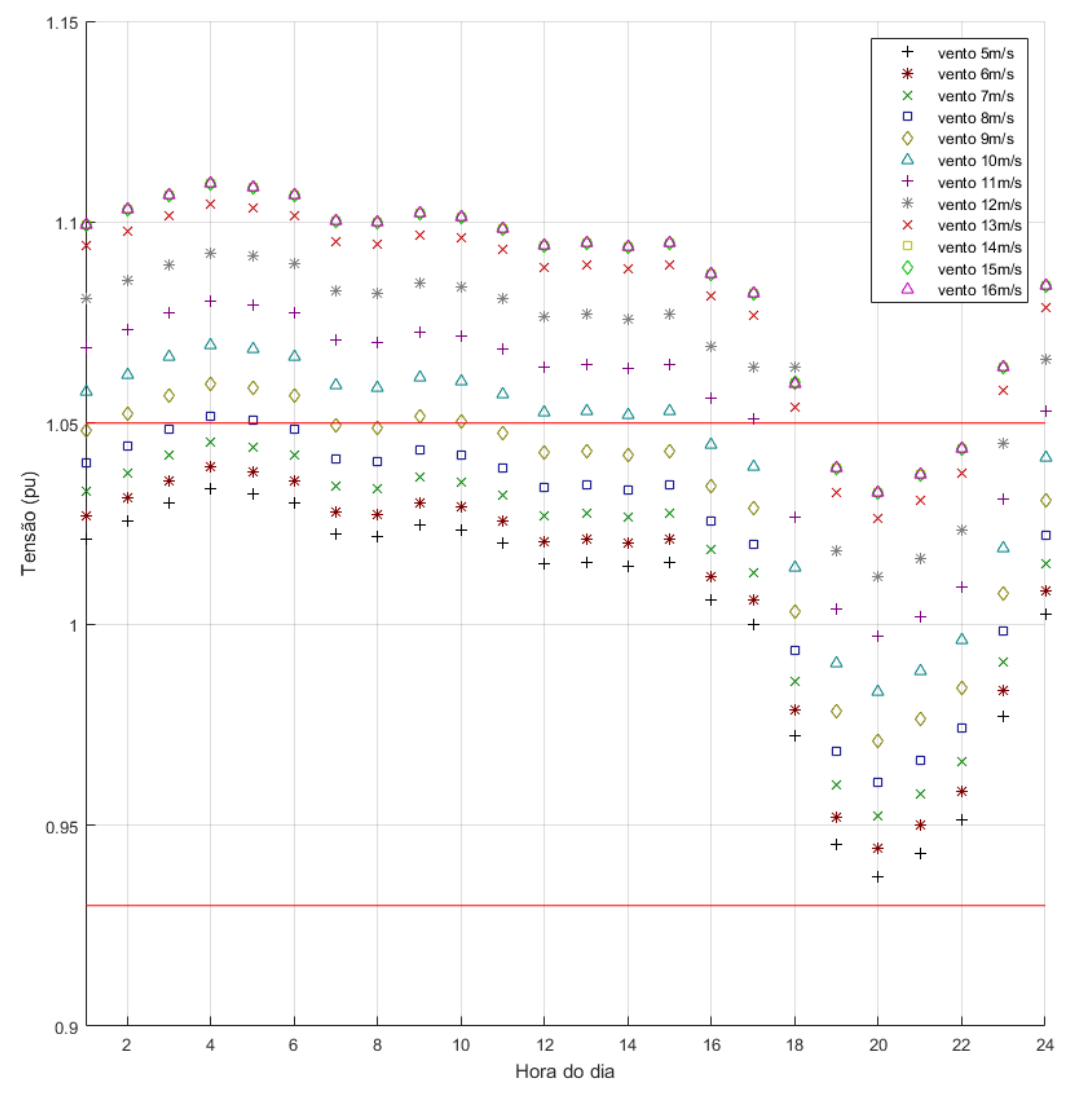

\subsubsection{Mapa Operativo Geral da Planta para a Rede com Consumidores Residenciais}

O objetivo desta subseção é apresentar um mapa operativo geral, utilizando diferentes tipos de controle, para todas as situações de velocidade do vento e carga. O mapa operativo geral pode ser entendido como uma estratégia de operação da planta eólica, combinando os tipos de controle estudados anteriormente, para que não haja violação dos critérios operativos nas condições estudadas de carga e velocidade do vento.

Existem diversas possibilidades para combinar os tipos de controle e obter um mapa operativo geral. Uma delas seria a combinação entre o controle de fator de potência 0,92 indutivo (para velocidades de vento entre $10 \mathrm{~m} / \mathrm{s} \mathrm{e} 12 \mathrm{~m} / \mathrm{s}$ ), controle de fator de potência unitário (velocidades entre $6 \mathrm{~m} / \mathrm{s}$ e $9 \mathrm{~m} / \mathrm{s}$ ) e controle de tensão em 1 p.u para velocidade de $5 \mathrm{~m} / \mathrm{s}$, conforme apresentado na Figura 40. 
Figura 40: Primeira alternativa para mapa operativo geral da planta eólica

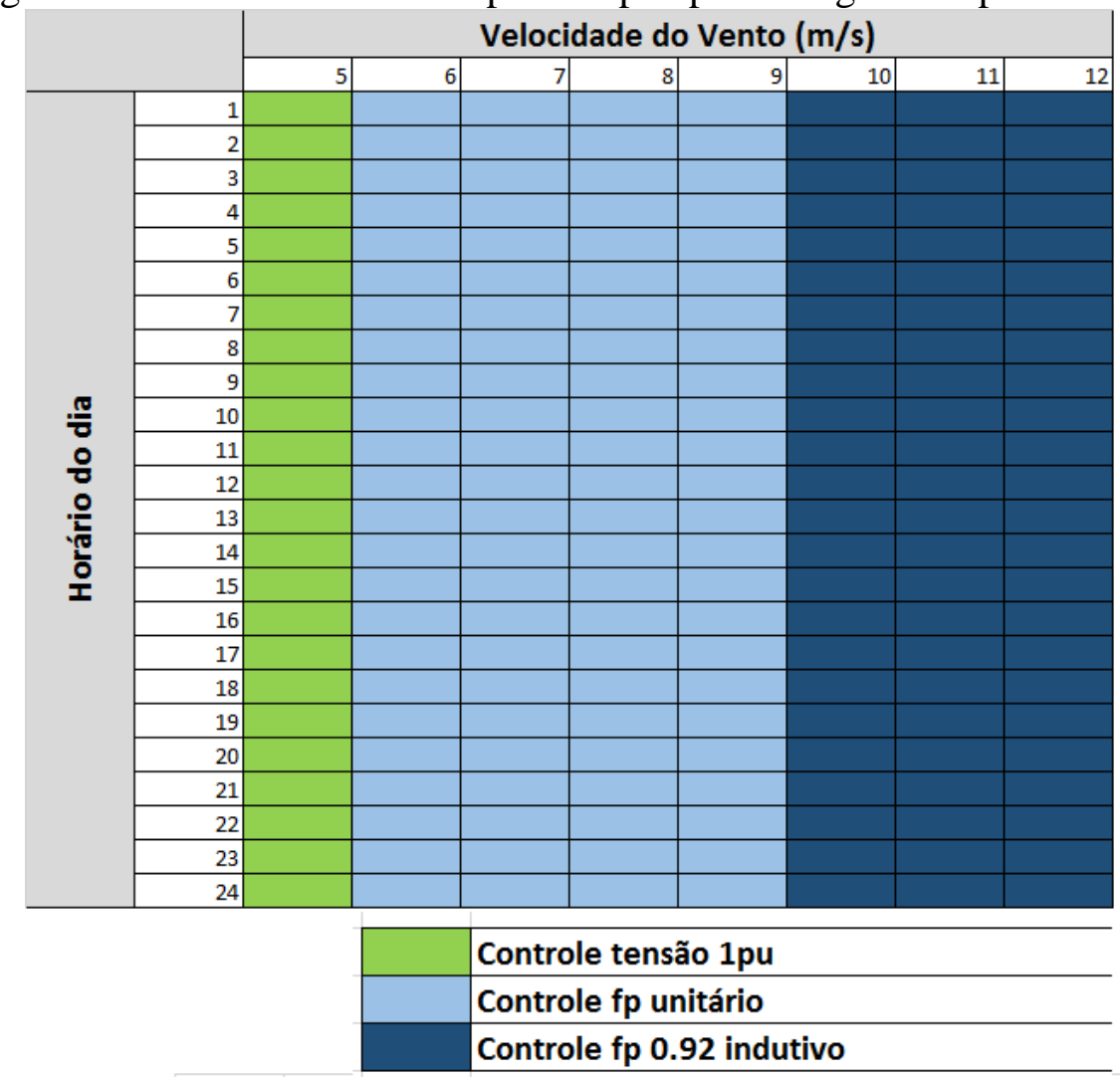

Outras possíveis alternativas:

- Operação com controle de tensão em 1p.u. para todas as condições de carga e velocidade do vento, caso seja possível implementar esse tipo de controle.

- Utilizar o controle de fator de potência 0,92 capacitivo na faixa de velocidades do vento entre $6 \mathrm{~m} / \mathrm{s}$ e $7 \mathrm{~m} / \mathrm{s}$, ao invés do controle de fator de potência unitário.

- Caso não seja possível utilizar o controle de tensão em 1p.u., utilizar controle de potência reativa para velocidade do vento de $5 \mathrm{~m} / \mathrm{s}$, o que provoca violação dos limites de fator de potência admissíveis, desde que isso não acarrete em penalidades por parte do órgão regulador;

- Utilizar um controle de fator de potência para velocidade do vento de $5 \mathrm{~m} / \mathrm{s}$, o que provoca violação do critério de tensão para determinados valores de carga, desde que isso não acarrete em penalidades por parte do órgão regulador. 


\subsection{Considerações Gerais}

Neste capítulo foram apresentados os resultados obtidos para o sistema elétrico com consumidores residenciais.

Inicialmente, foi realizado estudo da turbina eólica gerador com controle de fator de potência unitário. Os resultados obtidos mostram que esse controle é adequado para velocidades do vento entre $6 \mathrm{~m} / \mathrm{s}$ e $9 \mathrm{~m} / \mathrm{s}$. Para a velocidade de $5 \mathrm{~m} / \mathrm{s}$, existe violação de tensão nos dois patamares horários com carga mais elevada (20h e $21 \mathrm{~h}$ ). Para velocidades superiores a $9 \mathrm{~m} / \mathrm{s}$, existe violação de tensão nos patamares horários com menor carga.

Utilizando o controle de fator de potência 0,92 indutivo, observou-se melhor desempenho para velocidades elevadas de vento. Esse controle permite operação em todas as condições de carga para velocidades de vento superiores a $7 \mathrm{~m} / \mathrm{s}$. Para velocidades entre $5 \mathrm{~m} / \mathrm{s}$ e $7 \mathrm{~m} / \mathrm{s}$, existe violação de tensão na barra B7 nos patamares de carga mais elevada.

Com o controle de fator de potência 0,92 capacitivo, é possível operar a planta eólica sem restrições de carga para velocidades do vento entre $6 \mathrm{~m} / \mathrm{s}$ e $7 \mathrm{~m} / \mathrm{s}$. Para velocidade de 5 $\mathrm{m} / \mathrm{s}$, o desempenho desse controle é melhor em relação ao controle de fator de potência unitário, porém ainda ocorre violação de tensão para o patamar horário com maior carga (20h). Para velocidades de vento elevadas, esse controle apresenta desempenho inferior em relação aos anteriores.

Para a faixa de velocidades do vento entre $6 \mathrm{~m} / \mathrm{s}$ e $12 \mathrm{~m} / \mathrm{s}$, existe pelo menos um tipo de controle que permite operar o sistema elétrico sem violação dos critérios de tensão independentemente do valor do carregamento do sistema. Entretanto, para velocidade de $5 \mathrm{~m} / \mathrm{s}$, é necessário empregar um tipo de controle para que seja possível operar o sistema em qualquer situação de carga. Dessa maneira, foram testados dois tipos diferentes de controle:

- Controle de tensão no ponto de conexão com a rede em 1p.u.

- Controle de potência reativa em 0.05p.u.

Ambos as estratégias de controle permitem operação na velocidade de $5 \mathrm{~m} / \mathrm{s}$ sem violação de tensão, para qualquer valor de carregamento do sistema. Entretanto, ao passo que elimina possíveis violações dos critérios de tensão para essa velocidade, o controle de potência reativa acarreta em violação dos limites admissíveis de fator de potência para o sistema.

Apesar da vantagem em relação às demais estratégias, o controle de tensão em 1p.u. apresenta dificuldades de implantação, pois normalmente demanda um controle centralizado sobre todas as turbinas do parque eólico. 
Por fim, foram propostos mapas operativos gerais para a planta eólica, que combinam diferentes tipos de controle para a faixa de velocidades do vento considerada, que podem ser utilizados como estratégia de operação da planta para que não haja violação dos critérios operativos em quaisquer condições de carregamento e velocidade do vento. 


\section{Análise da Influência do Crescimento de Carga da Rede e Análise Considerando Diferentes Tipos de Consumidores}

Este capítulo inicia-se com a análise da influência do crescimento de carga, para a rede com consumidores residenciais, nos valores de tensão no ponto de conexão. São apresentados novos mapas operativos de acordo com o tipo de controle utilizado na planta eólica, além de um novo mapa operativo geral para a planta eólica.

Em seguida, foi realizado estudo semelhante ao apresentado no capítulo 4, porém considerando consumidores com diferentes perfis de carga (comerciais e residenciais) conectados à rede.

\subsection{Análise da Influência do Crescimento de Carga da Rede}

Para esta análise, foi considerado um crescimento de carga de $10 \%$ em relação aos casos estudados anteriormente. A Figura 41 mostra a rede elétrica com os novos valores das cargas (valores referentes ao patamar de carga máxima). Os resultados apresentados referem-se à rede com consumidores residenciais e a metodologia empregada é semelhante à que foi apresentada na Figura 18.

Figura 41: Rede elétrica e os novos valores das cargas

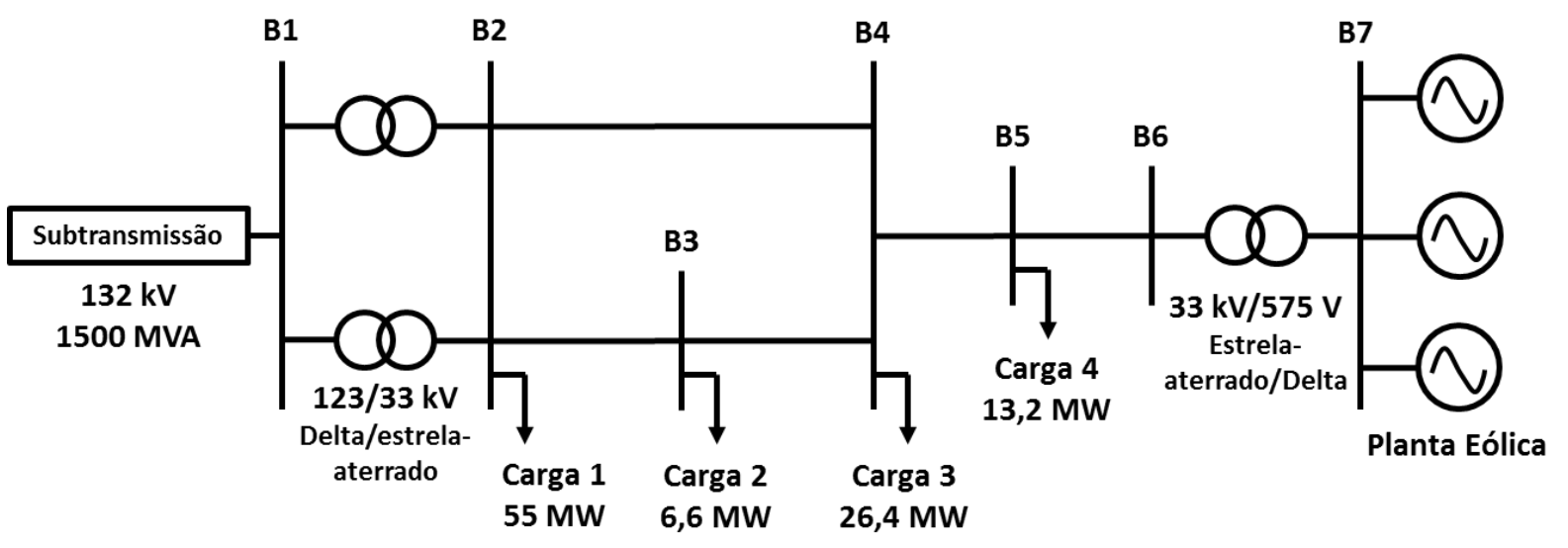

\subsubsection{Controle de Fator de Potência Unitário}

A Figura 42 apresenta os valores de tensão na barra B7 para todas as condições de carregamento e velocidade do vento. Observa-se que esse controle permite operação em todos os patamares horários apenas para velocidades do vento entre $8 \mathrm{~m} / \mathrm{s}$ e $9 \mathrm{~m} / \mathrm{s}$. 
Figura 42: Tensão na barra B7 para todas as condições de carga e velocidade do vento controle de fator de potência unitário

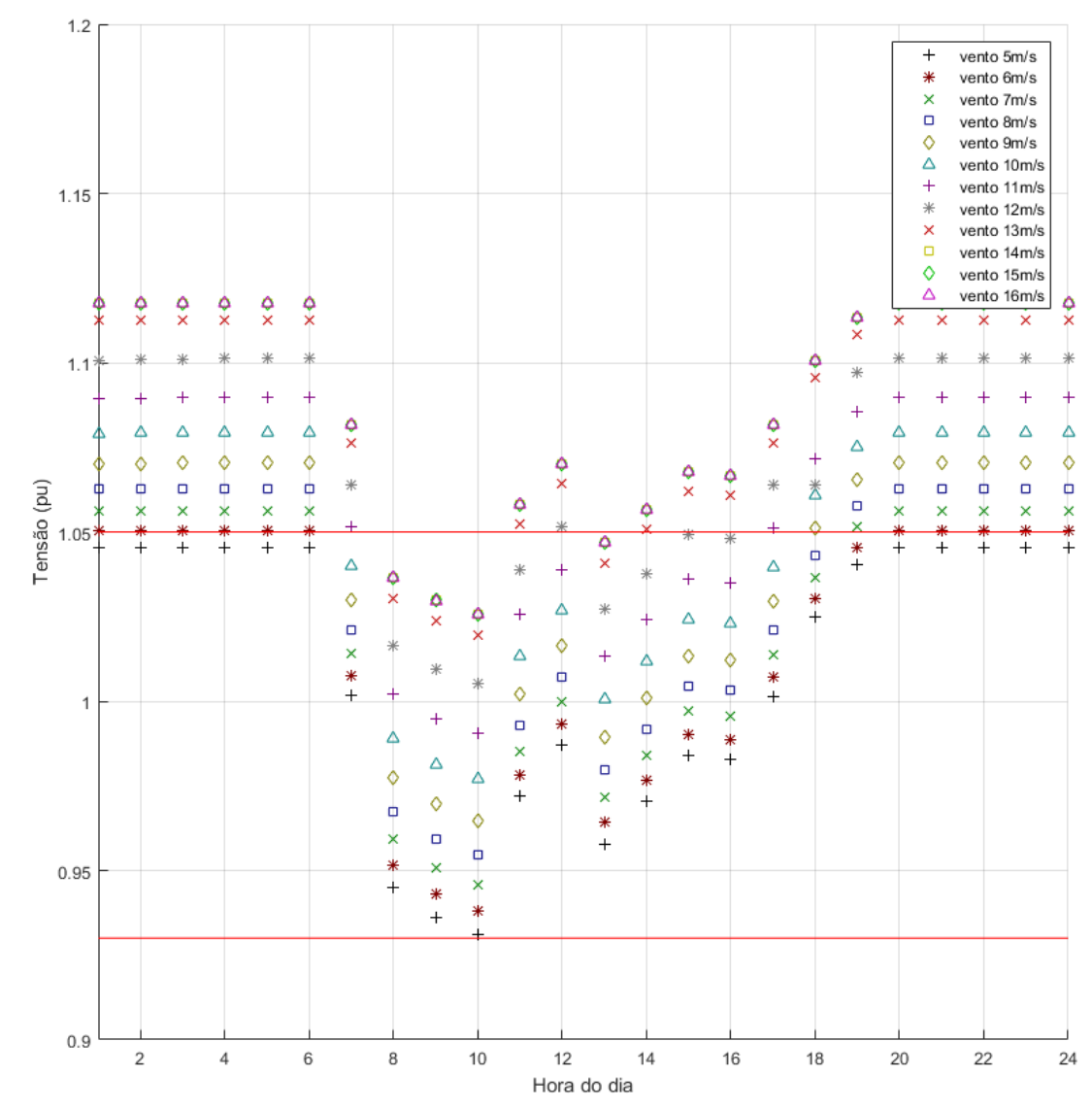

A Figura 43 apresenta os mapas operativos para controle de fator de potência unitário, considerando a rede original e a rede com crescimento de carga. Observa-se que, na situação sem crescimento de carga, é possível operar a planta eólica para velocidades entre $6 \mathrm{~m} / \mathrm{s}$ e 9 $\mathrm{m} / \mathrm{s}$. Para o novo cenário de carga, a operação da planta eólica é possível apenas para o intervalo entre $8 \mathrm{~m} / \mathrm{s}$ e $9 \mathrm{~m} / \mathrm{s}$. Para situações de carga elevada e velocidade do vento baixa, verificou-se aumento dos pontos operativos com violação de tensão. Já para cenários com carga reduzida e velocidade do vento elevada, nota-se diminuição do número de pontos operativos com violação de tensão. 
Figura 43: Mapas operativos para controle de fator de potência unitário considerando diferentes cenários de carga
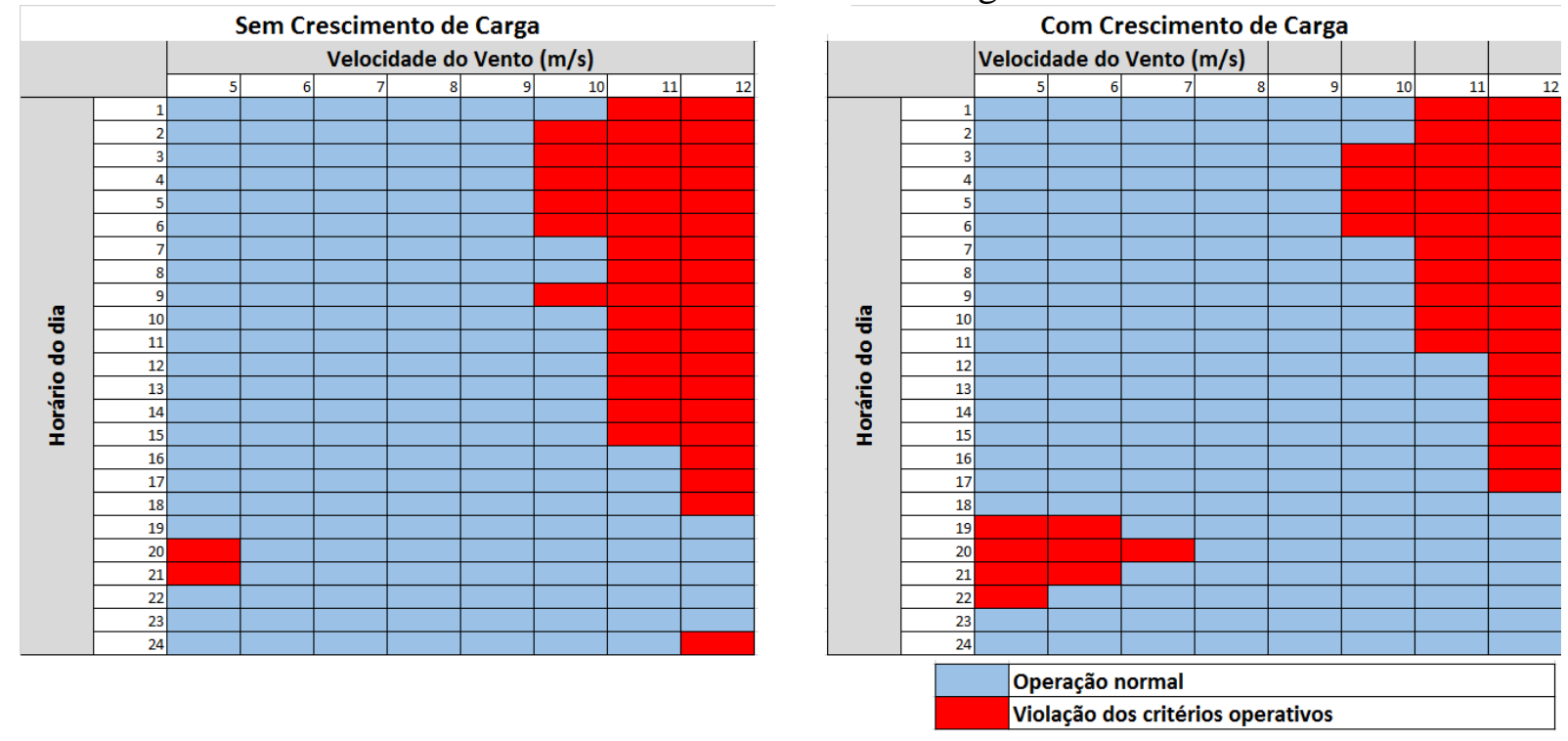

\subsubsection{Controle de Fator de Potência 0,92 Indutivo}

A Figura 44 apresenta os valores de tensão na barra B7 para todas as condições de carregamento e velocidade do vento, considerando controle de fator de potência 0,92 indutivo e crescimento de carga. Observa-se que, para cada valor de velocidade do vento entre $5 \mathrm{~m} / \mathrm{s}$ e $12 \mathrm{~m} / \mathrm{s}$, esse controle não permite mais a operação dentro dos limites de tensão para todos os valores de carga possíveis.

Através da Figura 45, é possível comparar os mapas operativos para o controle de fator de potência 0,92 indutivo com os dois cenários de carga. Os pontos operativos em que há violação de tensão, para o caso da rede sem crescimento de carga, concentravam-se na região de carregamento elevado e velocidade do vento baixa. Para a rede considerando crescimento de carga, os pontos com violação de tensão continuam na região de carga elevada, porém agora estendem-se para todos os valores de velocidade de vento considerados.

Considerando o resultado obtido, foi realizada simulação com controle de fator de potência 0,98 indutivo, buscando melhores resultados para a faixa de velocidades elevadas. 
Figura 44: Tensão na barra B7 para todas as condições de carga e velocidade do vento controle de fator de potência 0,92 indutivo

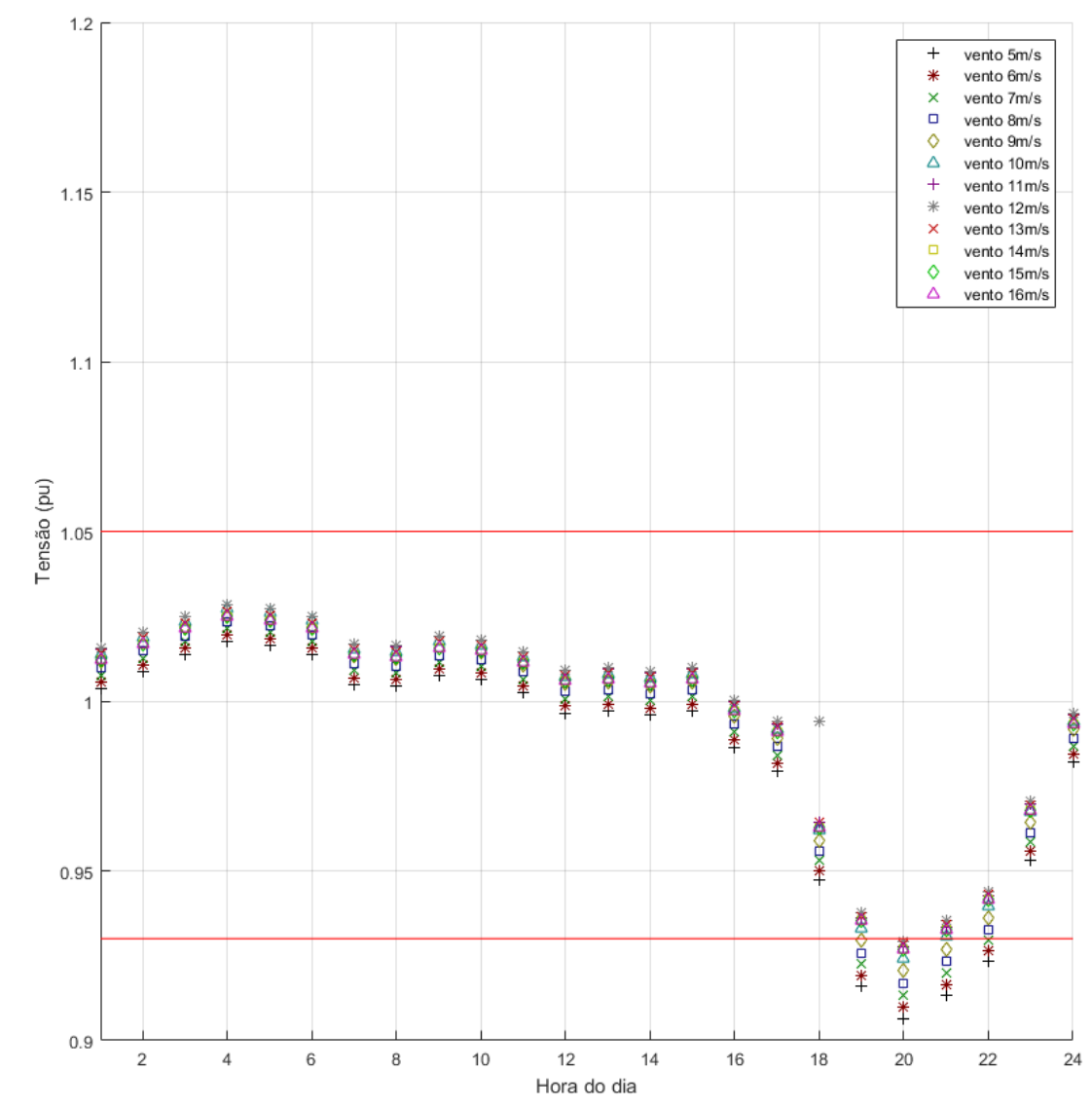

Figura 45: Mapas operativos para controle de fator de potência 0,92 indutivo considerando diferentes cenários de carga
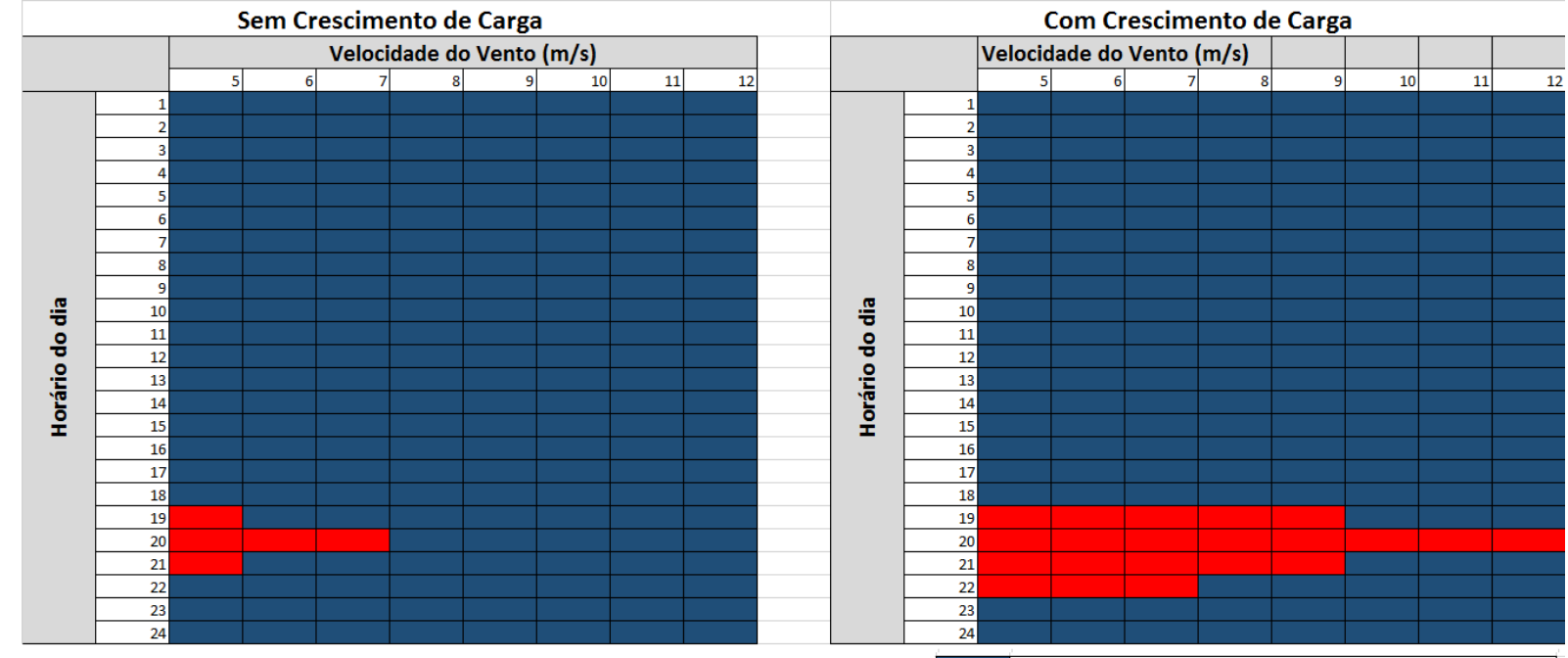

Operação normal

Violação dos critérios operativos 


\subsubsection{Controle de Fator de Potência em 0,98 indutivo}

A Figura 46 apresenta o mapa operativo obtido para o controle de fator de potência 0,98 indutivo. Observa-se que esse controle pode ser usado em todas as condições de carga para velocidades do vento entre $10 \mathrm{~m} / \mathrm{s}$ e $12 \mathrm{~m} / \mathrm{s}$, logo é mais adequado que o controle 0,92 indutivo nessas situações.

Figura 46: Mapa operativo para controle de fator de potência 0,98 indutivo considerando crescimento de carga

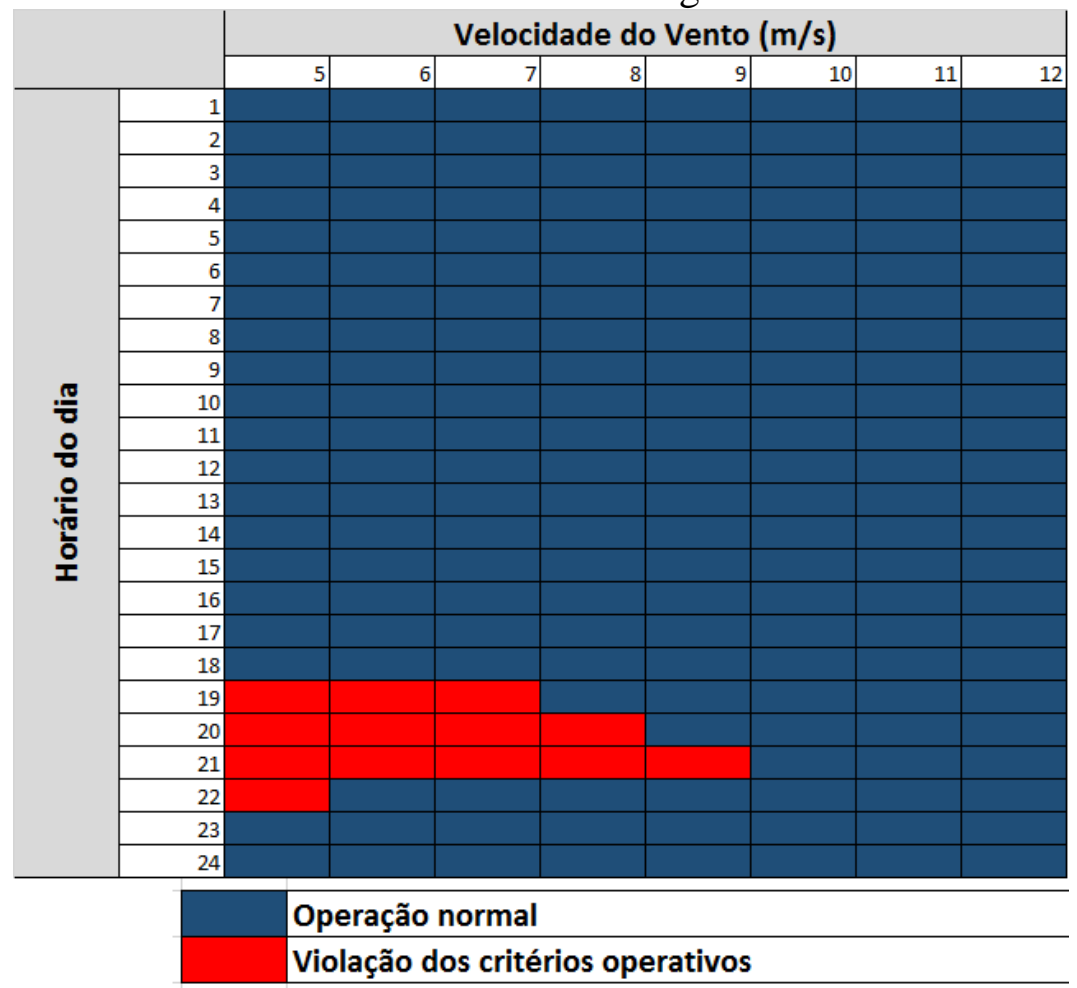

\subsubsection{Controle de Fator de Potência 0,92 Capacitivo}

A Figura 47 apresenta os valores de tensão na barra B7 para todas as condições de carregamento e velocidade do vento. Observa-se que, apenas para a velocidade do vento de 7 $\mathrm{m} / \mathrm{s}$, é possível operar a planta eólica para quaisquer valores de carga.

Através da Figura 48, que traz os mapas operativos considerando os dois cenários de carga, é possível notar o aumento de casos com violação de tensão em situações de carga elevada e a diminuição desses casos em situações com carga reduzida. No cenário sem crescimento de carga, era possível operar a rede para todos os cenários de carga para 
velocidades do vento entre $6 \mathrm{~m} / \mathrm{s} 7 \mathrm{~m} / \mathrm{s}$. Considerando crescimento de carga, é possível realizar essa operação apenas para velocidade de $7 \mathrm{~m} / \mathrm{s}$.

Figura 47: Tensão na barra B7 para todas as condições de carga e velocidade do vento controle de fator de potência 0,92 capacitivo

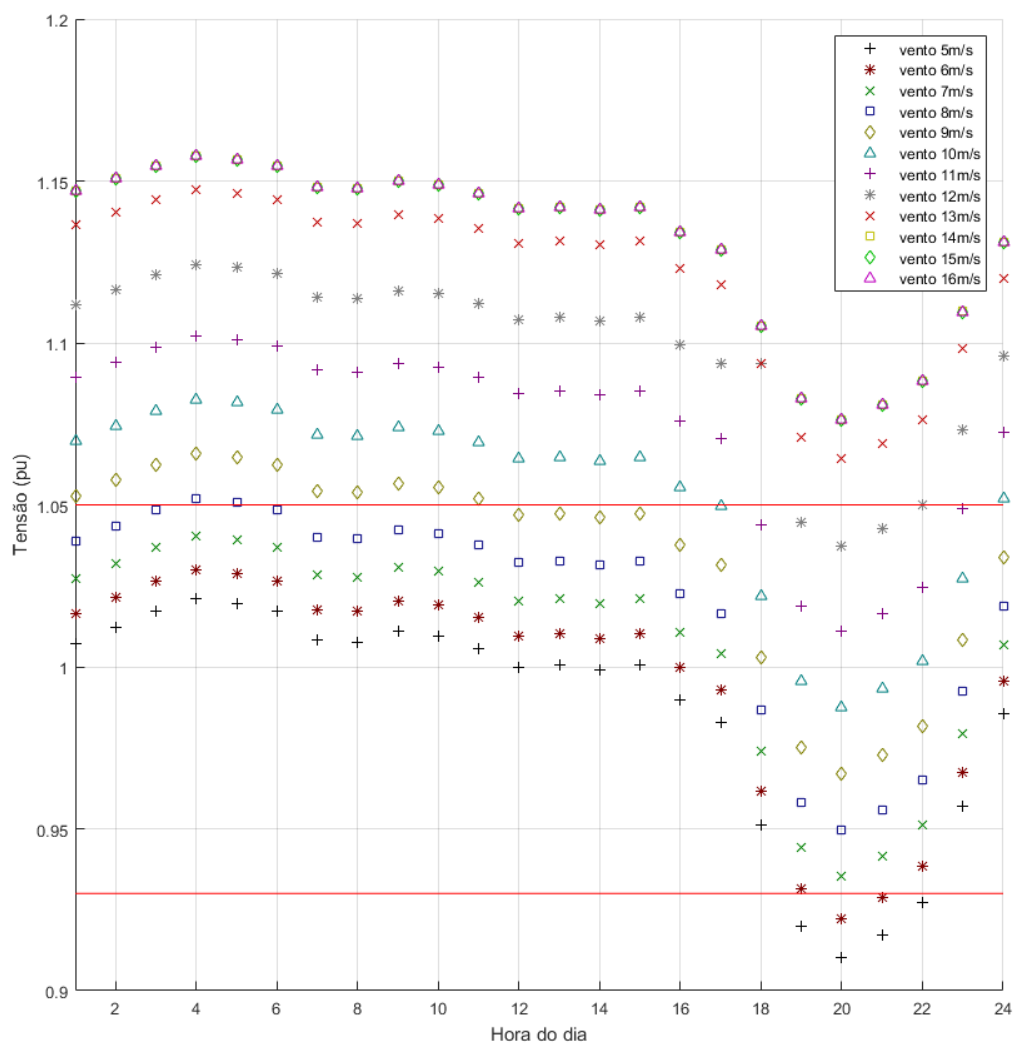

Figura 48: Mapas operativos para controle de fator de potência 0,92 capacitivo considerando diferentes cenários de carga
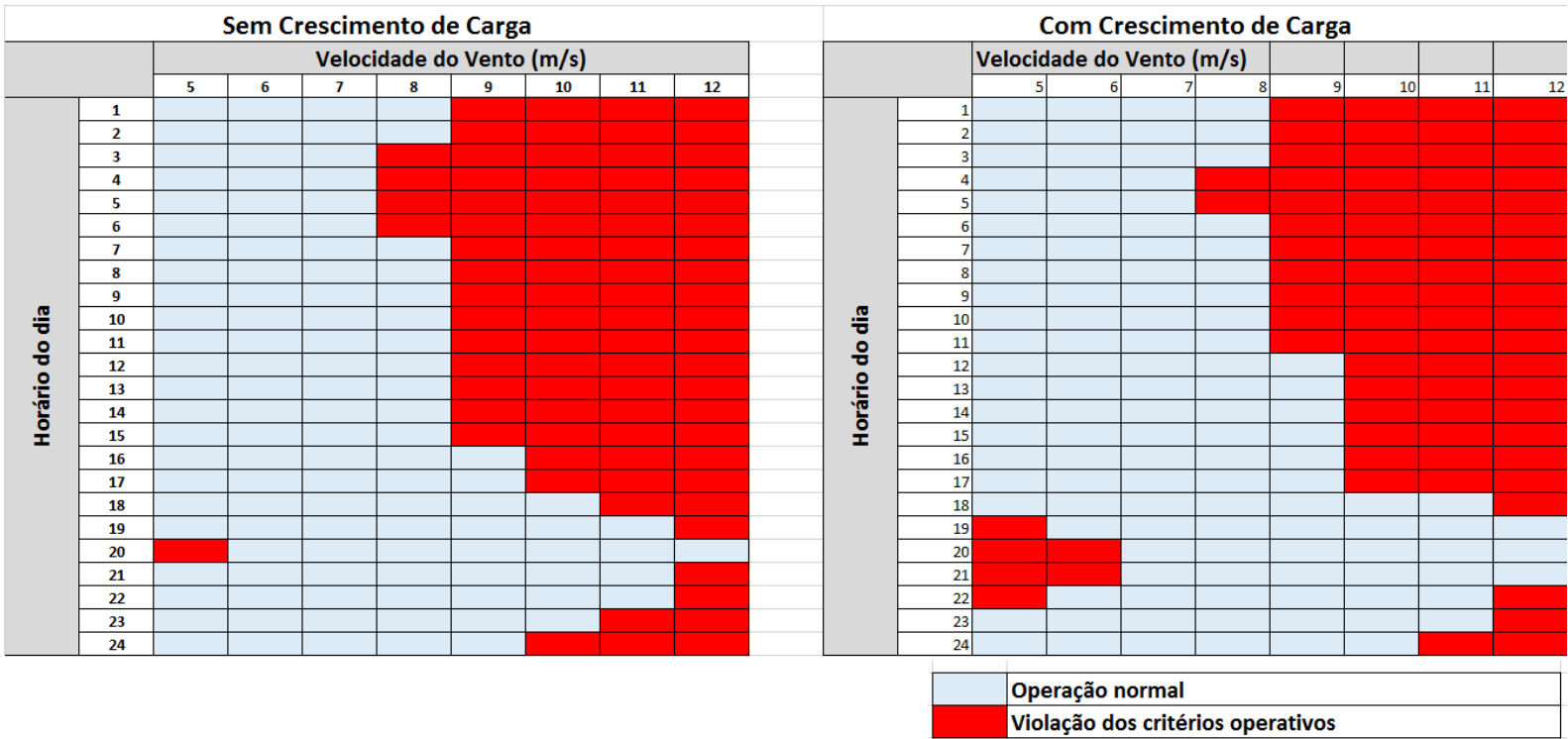


\subsubsection{Mapa Operativo Geral para a Rede Considerando Crescimento de Carga}

A Figura 49 apresenta o mapa operativo geral para operação da planta eólica na rede considerando crescimento de carga. Para o intervalo de velocidades do vento entre $10 \mathrm{~m} / \mathrm{s}$ e 12 $\mathrm{m} / \mathrm{s}$, é possível operar a planta eólica apenas com controle 0,98 indutivo, que se mostrou mais adequado que o controle 0,92 indutivo para situações de velocidade elevada. No intervalo entre $8 \mathrm{~m} / \mathrm{s}$ e $9 \mathrm{~m} / \mathrm{s}$, é possível somente operar a planta eólica com fator de potência unitário. Para velocidade de $7 \mathrm{~m} / \mathrm{s}$, a última alternativa possível de controle é de fator de potência 0,92 capacitivo. Por fim, para velocidades menores ou iguais a $6 \mathrm{~m} / \mathrm{s}$, para que não haja violação dos critérios de tensão ou fator de potência, é necessário utilizar o controle de tensão em 1p.u.

Em relação ao mapa operativo obtido para a rede sem crescimento de carga, foram notadas as seguintes diferenças:

- Controle de fator de potência unitário não é mais adequado para velocidades do vento entre $6 \mathrm{~m} / \mathrm{s}$ e $7 \mathrm{~m} / \mathrm{s}$. Para velocidade de $7 \mathrm{~m} / \mathrm{s}$, é possível utilizar o controle 0,92 capacitivo. Entretanto, para $6 \mathrm{~m} / \mathrm{s}$, a única opção possível estudada foi o controle de tensão em 1p.u.

- Para a faixa de velocidades do vento entre $10 \mathrm{~m} / \mathrm{s}$ e $12 \mathrm{~m} / \mathrm{s}$, o controle 0,92 indutivo não é mais adequado. Logo, foi adotado um controle de fator de potência 0,98 indutivo. 
Figura 49: Mapa operativo geral para a planta eólica considerando rede com crescimento de carga.

\begin{tabular}{l|r|r|r|r|r|r|r|r|r|r|r|}
\multicolumn{9}{|c|}{ Velocidade do Vento (m/s) } & & & \\
\hline
\end{tabular}

\subsection{Análise Considerando Perfil de Carga Comercial}

Conforme ilustrado na Figura 50, a rede com consumidores comerciais apresenta os menores valores de carga nos períodos da noite, madrugada e início da manhã, enquanto os maiores valores de carga são registrados no final da manhã e no período da tarde.

Como a metodologia empregada e grande parte das análises realizadas são as mesmas do estudo apresentado com consumidores residenciais, para as redes com consumidores comerciais, serão apresentados apenas os gráficos de tensão e os mapas operativos obtidos. 
Figura 50: Perfil de carga comercial

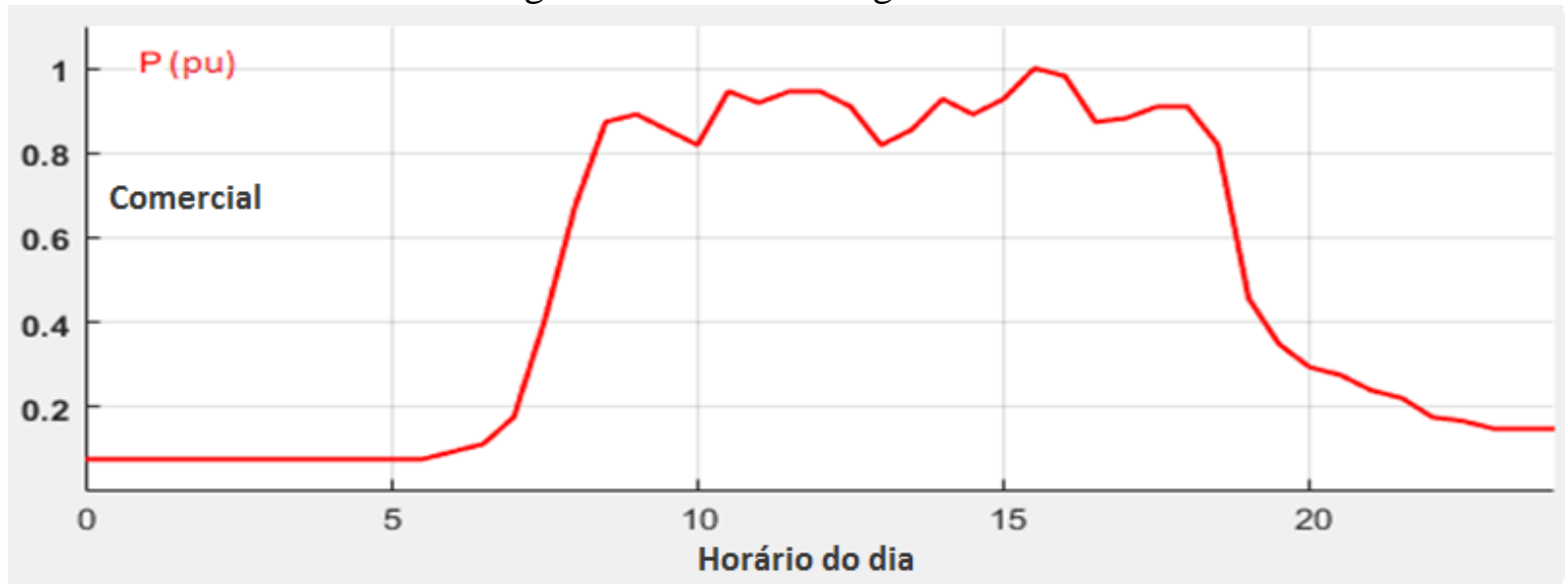

\subsubsection{Controle de Fator de Potência Unitário}

Para a rede com consumidores comerciais, observa-se na Figura 51 que existe violação de tensão no patamar de carga mais elevado (16h) para a velocidade do vento de $5 \mathrm{~m} / \mathrm{s}$. Para velocidades do vento entre $7 \mathrm{~m} / \mathrm{s}$ e $16 \mathrm{~m} / \mathrm{s}$, existe violação de tensão em pelo menos um patamar horário, em situações de carregamento reduzido do sistema. Existe apenas um valor de velocidade do vento $(6 \mathrm{~m} / \mathrm{s})$ em que é possível operar com esse controle para todos os valores de carga considerados.

Considerando o exposto anteriormente e os limites de potência reativa que podem ser supridos pela turbina, obteve-se o mapa operativo apresentado na Figura 52. 
Figura 51: Tensão na barra B7 para todas as condições de carga e velocidade do vento controle de fator de potência unitário

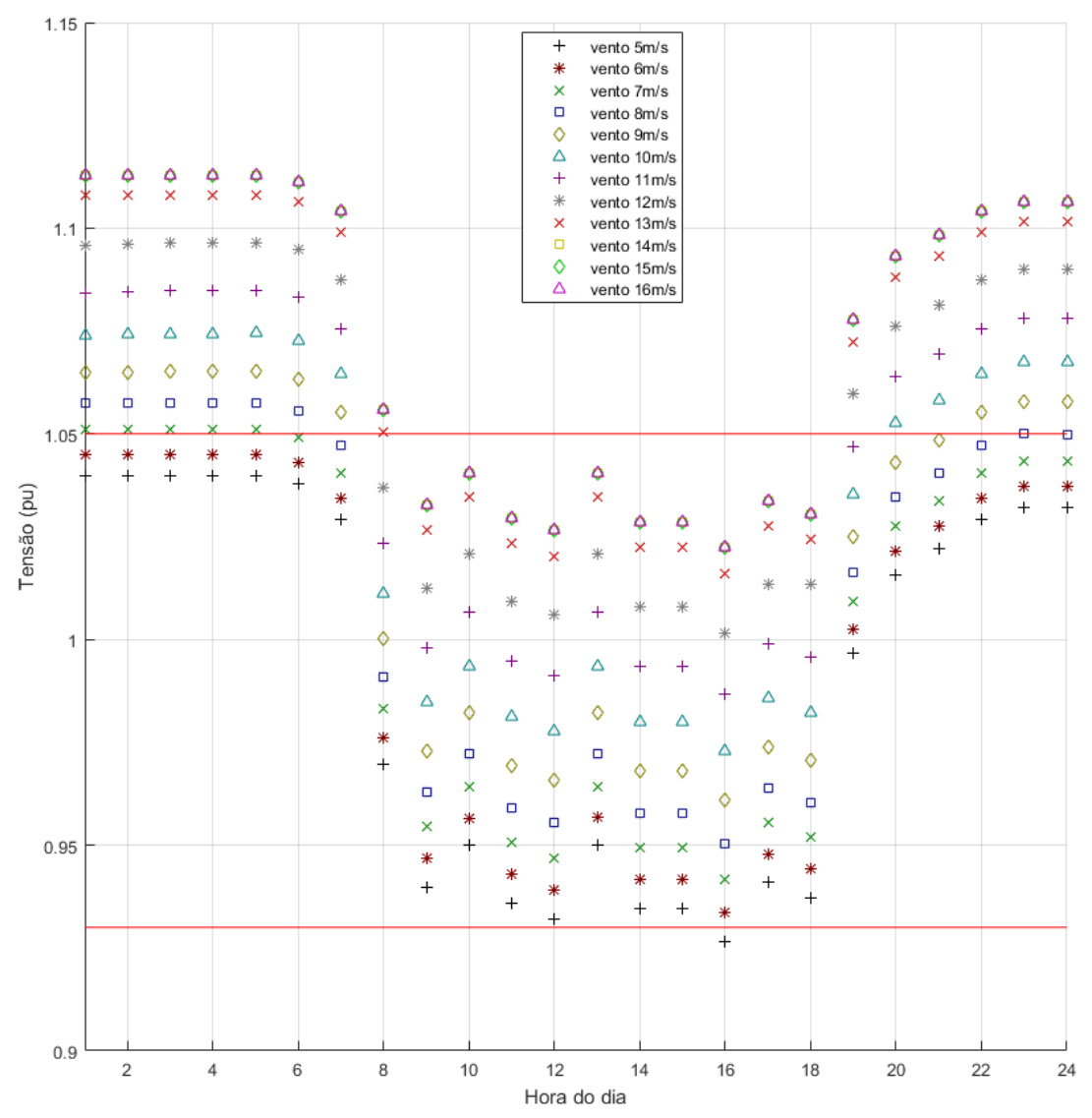

Figura 52: Mapa de operação para controle de fator de potência unitário

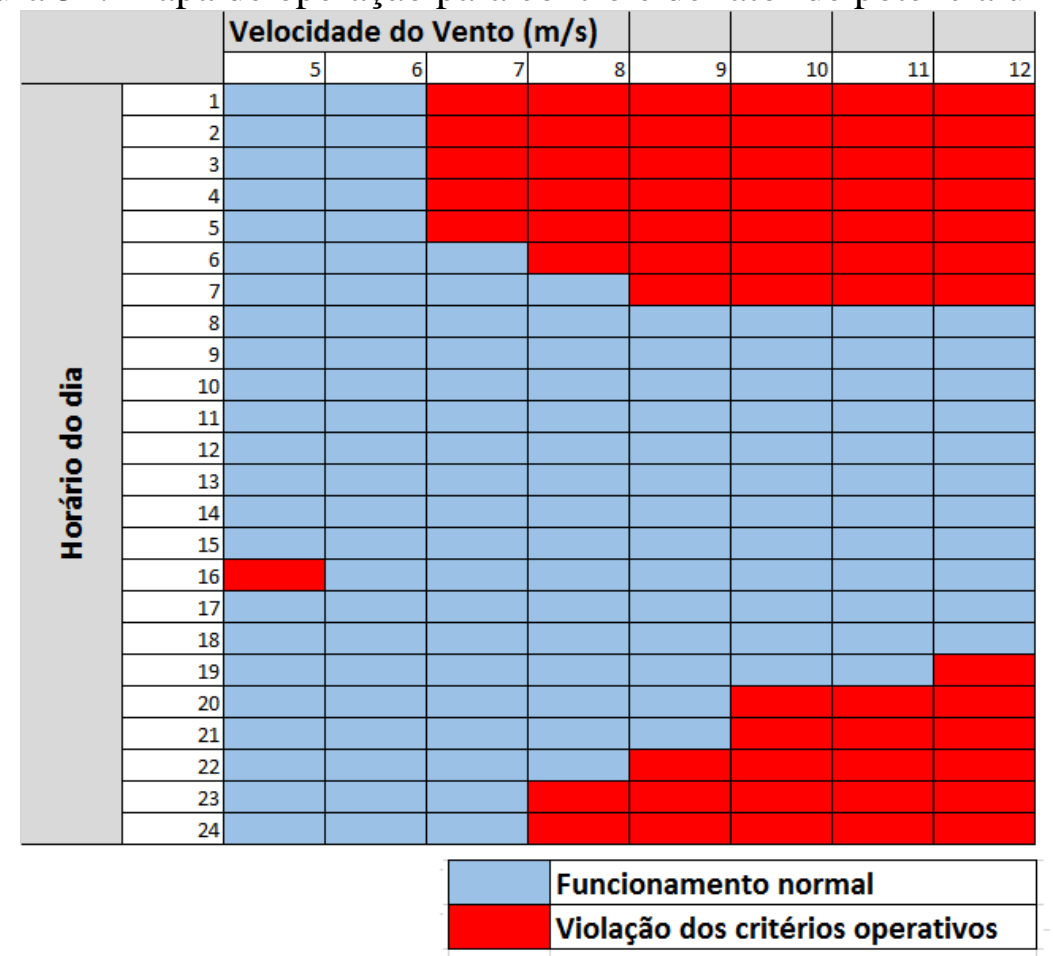




\subsubsection{Controle de Fator de Potência 0,92 indutivo}

Os valores de tensão obtidos na barra B7 para todas as condições de carregamento e velocidade do vento são apresentados na Figura 53. Para velocidades do vento entre $7 \mathrm{~m} / \mathrm{s}$ e 12 $\mathrm{m} / \mathrm{s}$, é possível operar a planta eólica com esse controle independente das condições de carga. Para velocidades entre $5 \mathrm{~m} / \mathrm{s}$ e $6 \mathrm{~m} / \mathrm{s}$, existe violação dos critérios de tensão em pelo menos um horário (nas situações de maior carregamento do sistema). Observa-se também que há menor variação nos valores de tensão em cada patamar horário, considerando a faixa de velocidades do vento estudadas.

Considerando os níveis de tensão e os limites de potência reativa que podem ser supridos pela turbina, obteve-se o mapa operativo apresentado na Figura 54.

Figura 53: Tensão na barra B7 para todas as condições de carga e velocidade do vento controle de fator de potência 0,92 indutivo

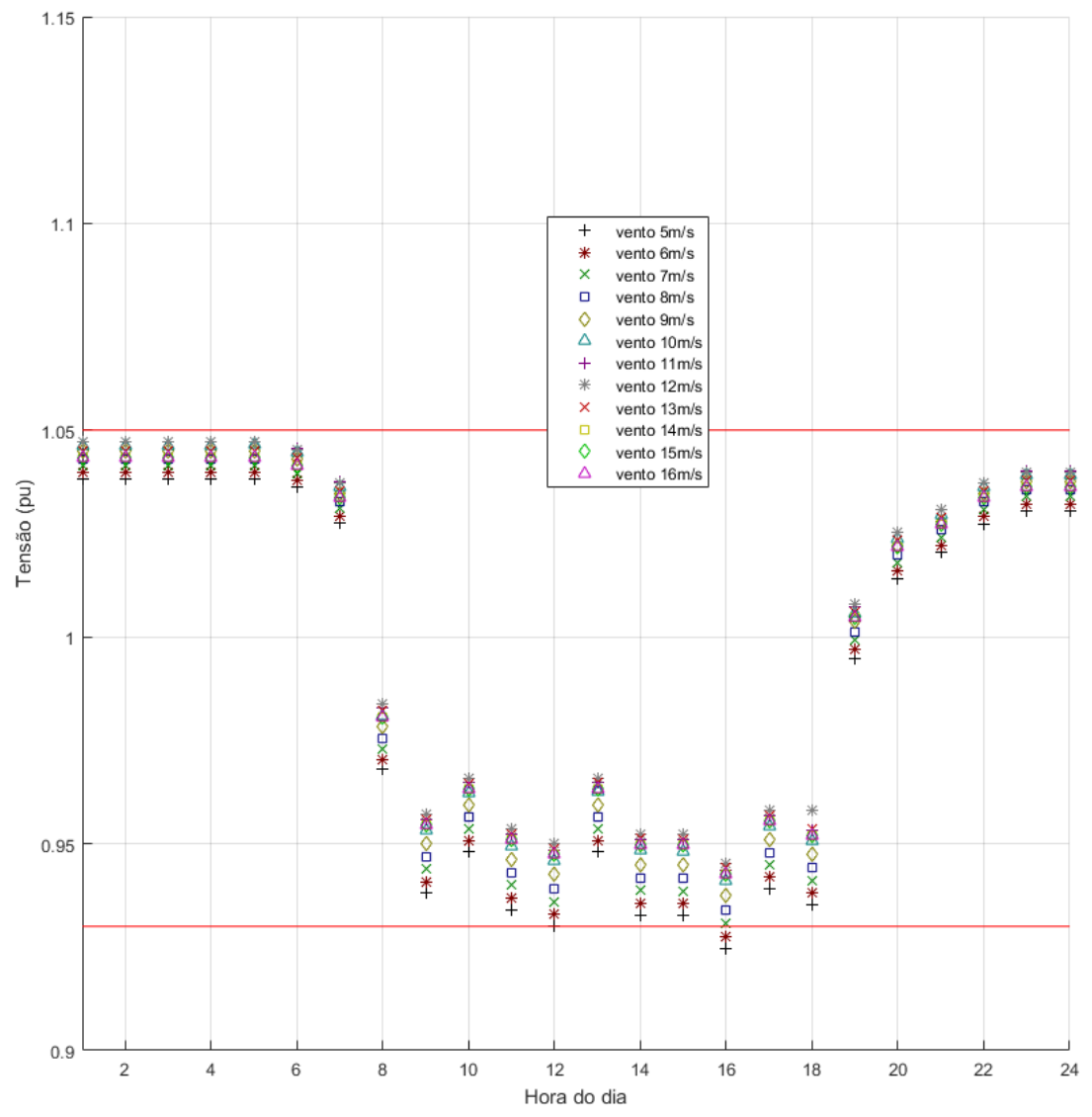


Figura 54: Mapa de operação para controle de fator de potência 0,92 indutivo

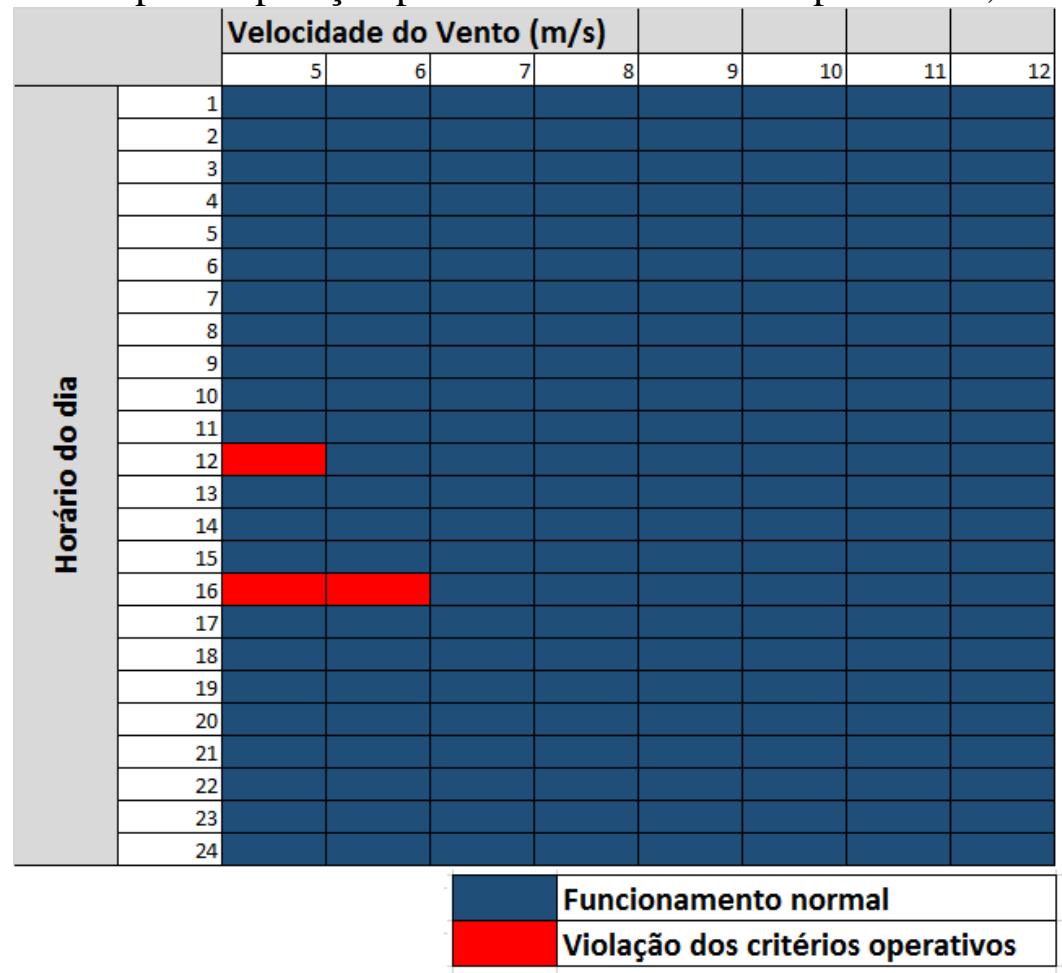

\subsubsection{Controle de Fator de Potência 0,92 capacitivo}

Os valores de tensão obtidos na barra B7 para todas as condições de carregamento e velocidade do vento são apresentados na Figura 55. Observa-se que, para todos os valores de velocidade do vento considerados, existe pelo menos um patamar horário com violação dos critérios de tensão. Para velocidade de $5 \mathrm{~m} / \mathrm{s}$, a violação ocorre no patamar com maior carga (16h). Para velocidades de $6 \mathrm{~m} / \mathrm{s}$ a $16 \mathrm{~m} / \mathrm{s}$, a violação ocorre nos patamares com menor carregamento.

Considerando os valores de tensão obtidos e a curva de capabilidade de potência reativa da turbina, obteve-se o mapa operativo da Figura 56. 
Figura 55: Tensão na barra B7 para todas as condições de carga e velocidade do vento controle de fator de potência 0,92 capacitivo

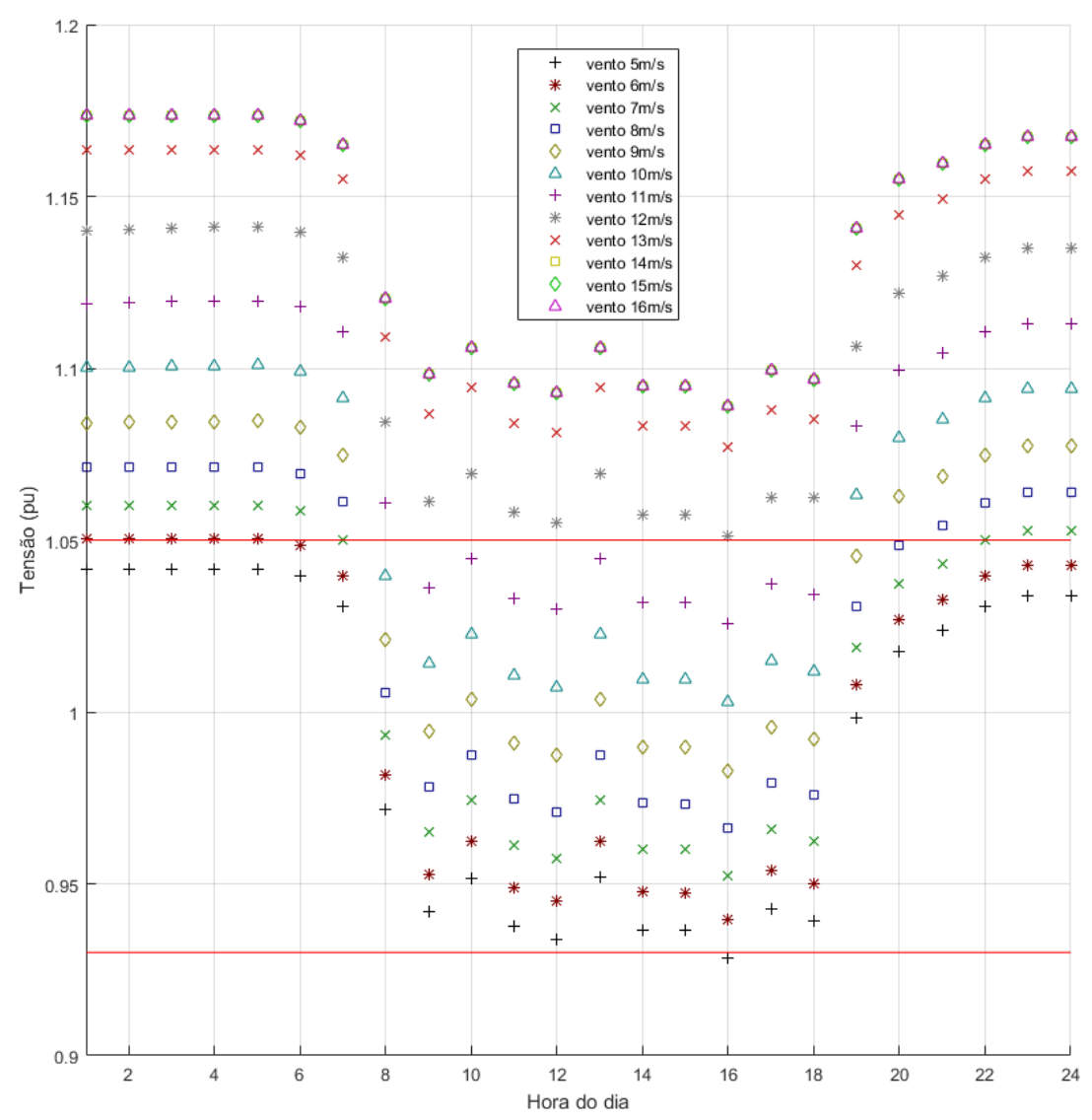

Figura 56: Mapa de operação para controle de fator de potência 0,95

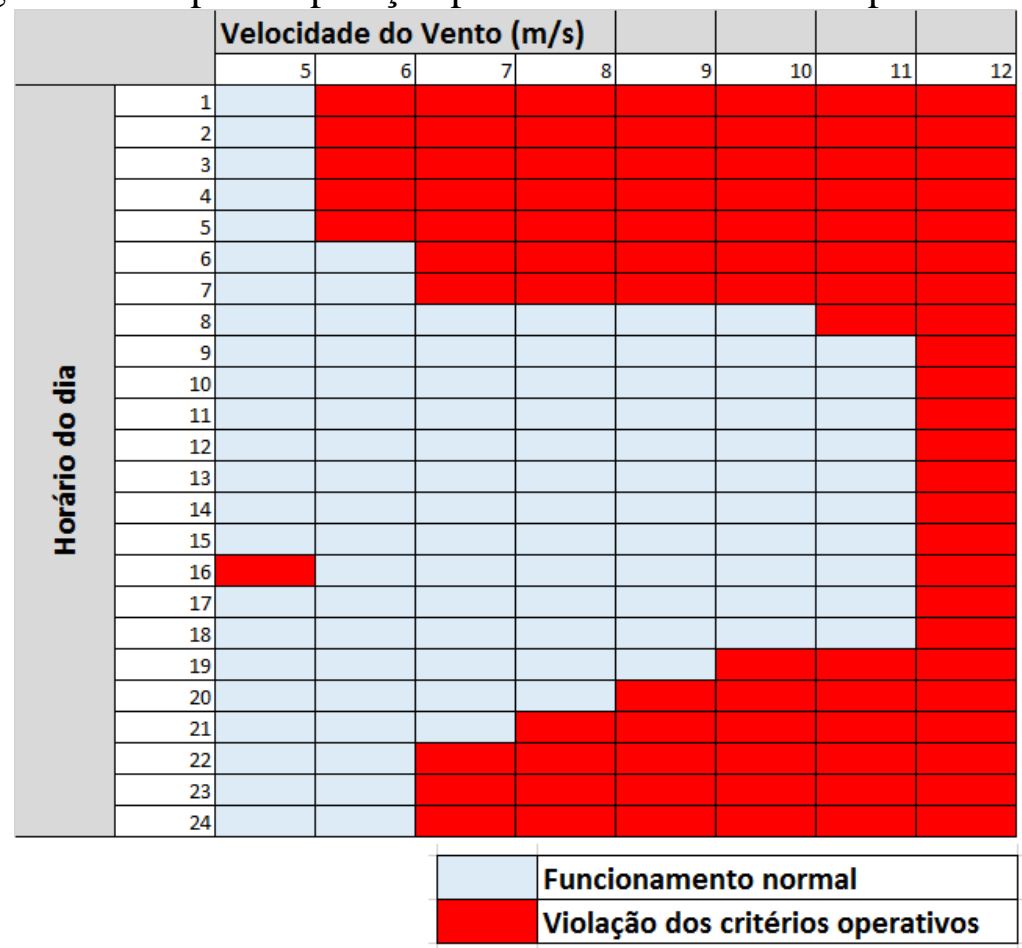




\subsubsection{Controle de Tensão em 1p.u.}

Os controles apresentados anteriormente não permitem operação em todas as condições de carga para velocidade do vento de $6 \mathrm{~m} / \mathrm{s}$. Dessa maneira, uma possível alternativa seria utilizar o controle de tensão em 1p.u. nessas condições. O mapa operativo da planta eólica para esse controle é apresentado na Figura 57.

Figura 57: Mapa de operação para controle de tensão em 1p.u.

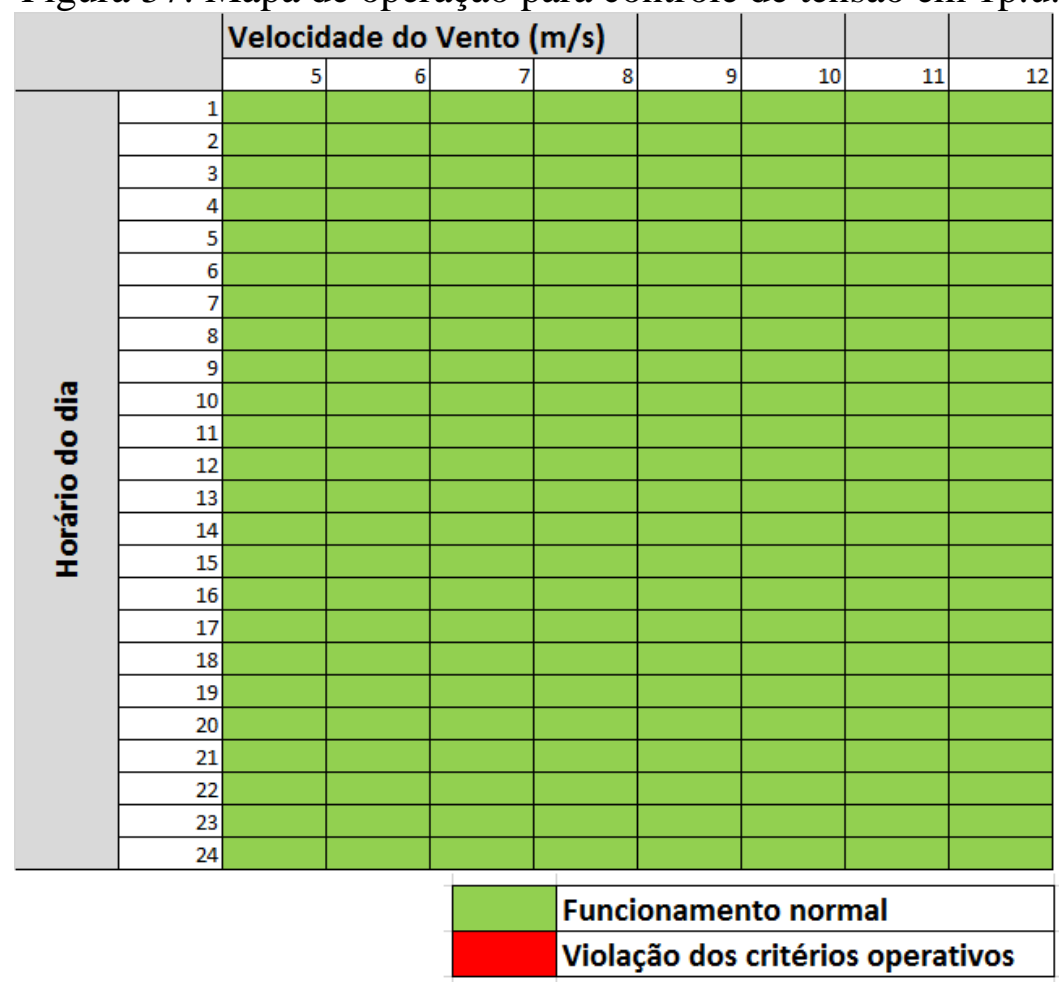

\subsubsection{Controle de Potência Reativa em 0.03p.u.}

Foi estudada também a operação da planta eólica com controle de fator de potência fixo em 0.03p.u. Os valores de tensão na barra B7 são apresentados na Figura 58. Observa-se que esse controle permite operação sem restrições para velocidade do vento de $5 \mathrm{~m} / \mathrm{s}$. Porém, para velocidades superiores, existe pelo menos uma condição de carga que inviabiliza a utilização dessa estratégia. Além disso, o valor proposto de potência reativa a ser injetado na rede provoca violação dos critérios de fator de potência admissíveis. 
Figura 58: Tensão na barra B7 para todas as condições de carga e velocidade do vento controle de potência reativa em 0.03 p.u.

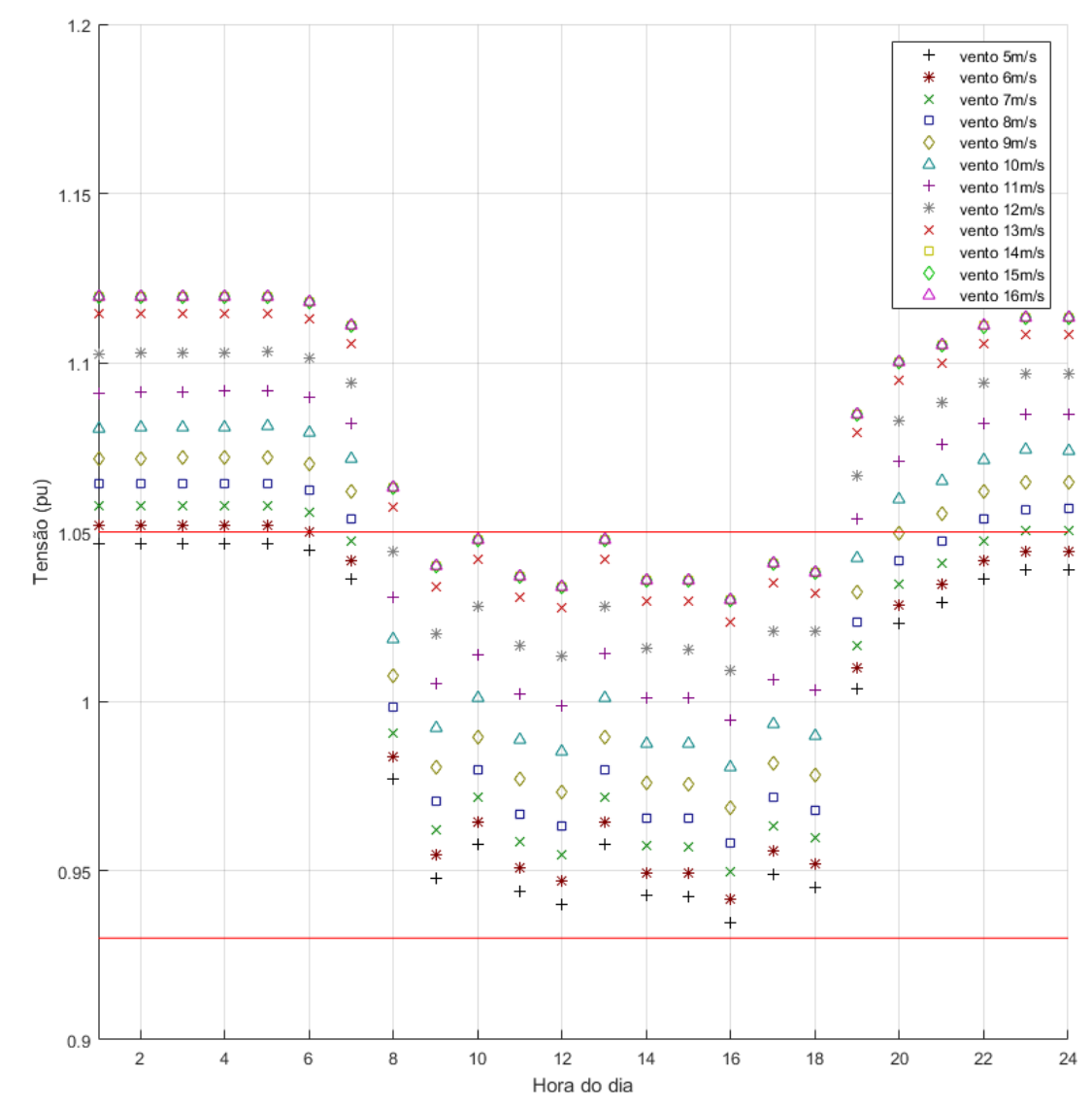

\subsubsection{Mapa Operativo Geral da Planta Eólica Considerando Consumidores Comerciais}

Caso seja viável operar a planta eólica com este controle, um possível mapa de operação geral é apresentado na Figura 59, combinando o controle de tensão em 1p.u. para velocidades de até $6 \mathrm{~m} / \mathrm{s}$ e o controle de fator de potência 0,92 indutivo para velocidades do vento superiores a $6 \mathrm{~m} / \mathrm{s}$.

Caso não seja viável operar a planta eólica com controle de tensão, uma opção seria utilizar o controle de potência reativa em 0.03p.u. para velocidade do vento de $5 \mathrm{~m} / \mathrm{s}$, e considerar a utilização do controle de potência reativa 0,92 indutivo nas demais situações, inclusive para velocidade de $6 \mathrm{~m} / \mathrm{s}$, que causa violação dos critérios de tensão. Para isso, seria necessário avaliar os valores de tensão e de potência reativa obtidos, para garantir que o total 
de situações em que o sistema operar fora dos critérios adequados não cause penalidades regulatórias ao operador da planta eólica.

Figura 59: Mapa operativo geral da planta eólica para a rede com consumidores comerciais

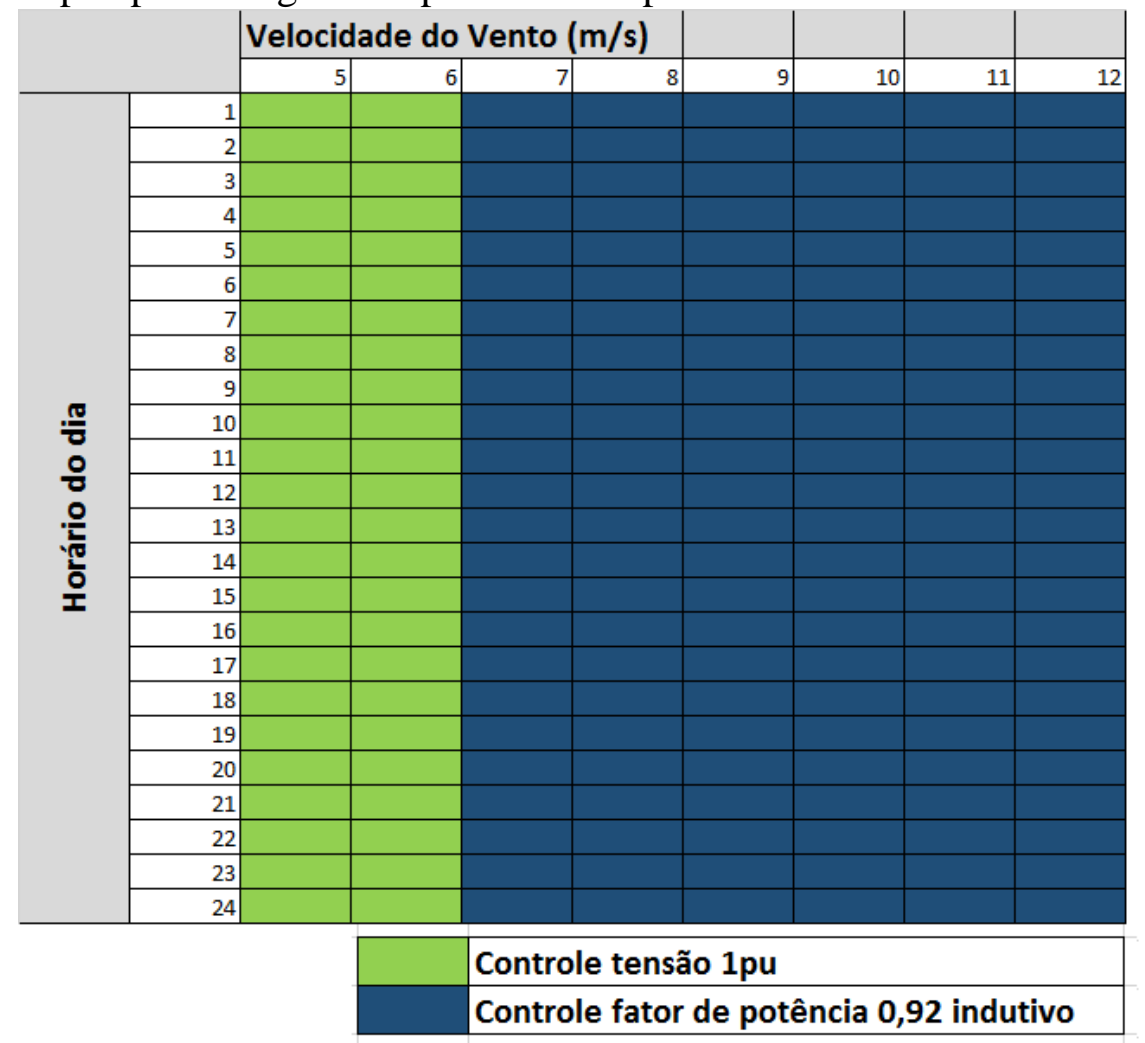

\subsection{Análise Considerando Perfil de Carga Industrial}

A rede com consumidores industriais, cujo perfil de carga é apresentado na Figura 60, apresenta os maiores valores de carga no período da manhã, uma queda acentuada na hora seguinte (período de almoço), seguido de valores altos novamente no período da tarde. Os valores patamares com carga mais baixa são inferiores aos patamares de menor carga dos perfis residencial e comercial.

Figura 60: Perfil de carga industrial

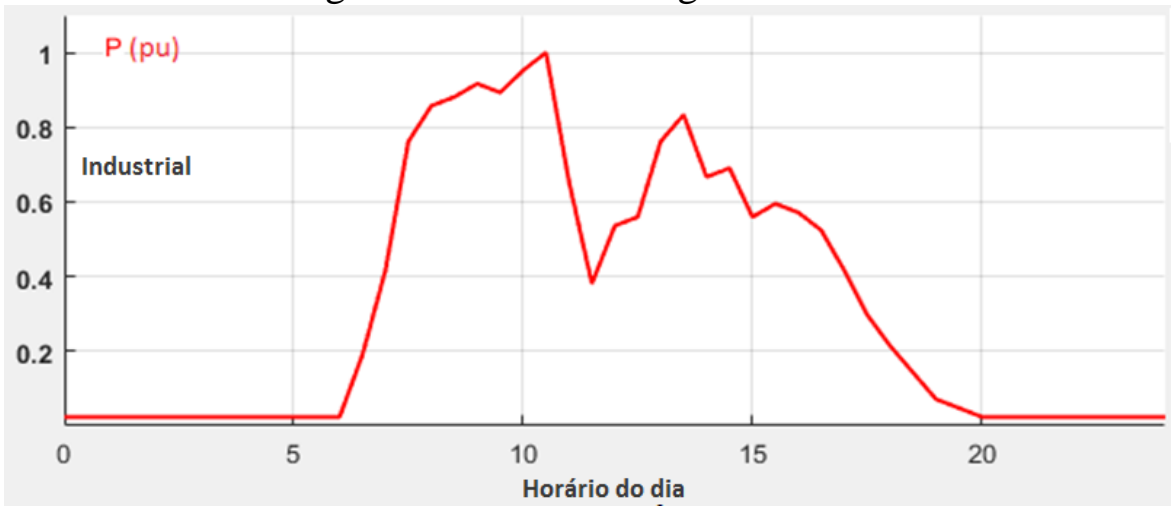




\subsubsection{Controle de Fator de Potência Unitário}

Os valores de tensão obtidos na barra B7 são apresentados na Figura 61. Para a velocidade do vento de $5 \mathrm{~m} / \mathrm{s}$, não há violação dos critérios de tensão para qualquer patamar horário. Para cada um dos demais valores de velocidade do vento, ocorre violação em pelo menos uma condição de carregamento do sistema.

Considerando os valores de tensão obtidos e os limites de potência reativa que podem ser supridos pelas turbinas eólicas, obteve-se o mapa operativo representado na Figura 62.

Figura 61: Tensões na barra B7 para todos os valores de carregamento e velocidade do vento controle de fp unitário

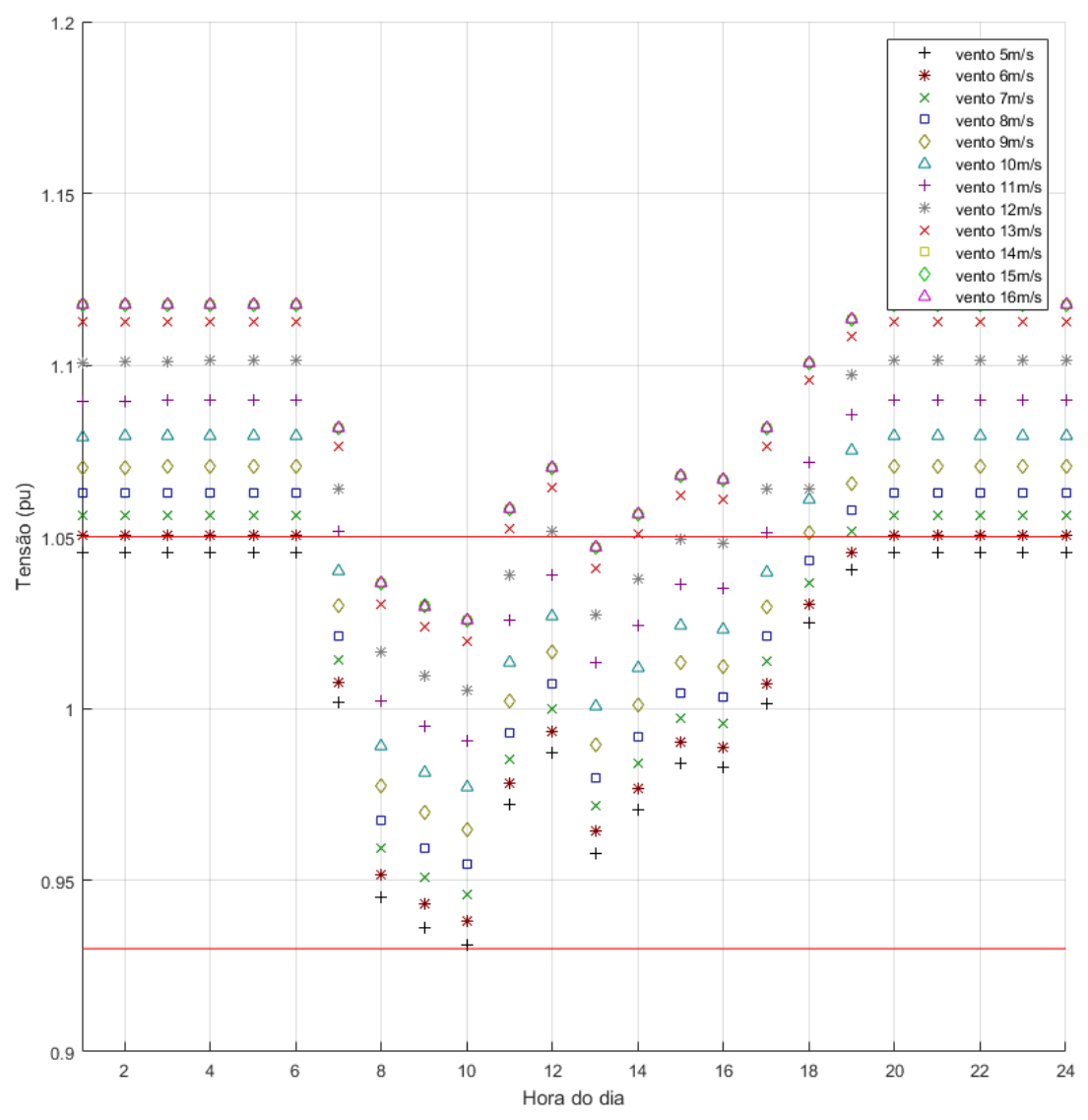


Figura 62: Mapa operativo para controle de fator de potência unitário

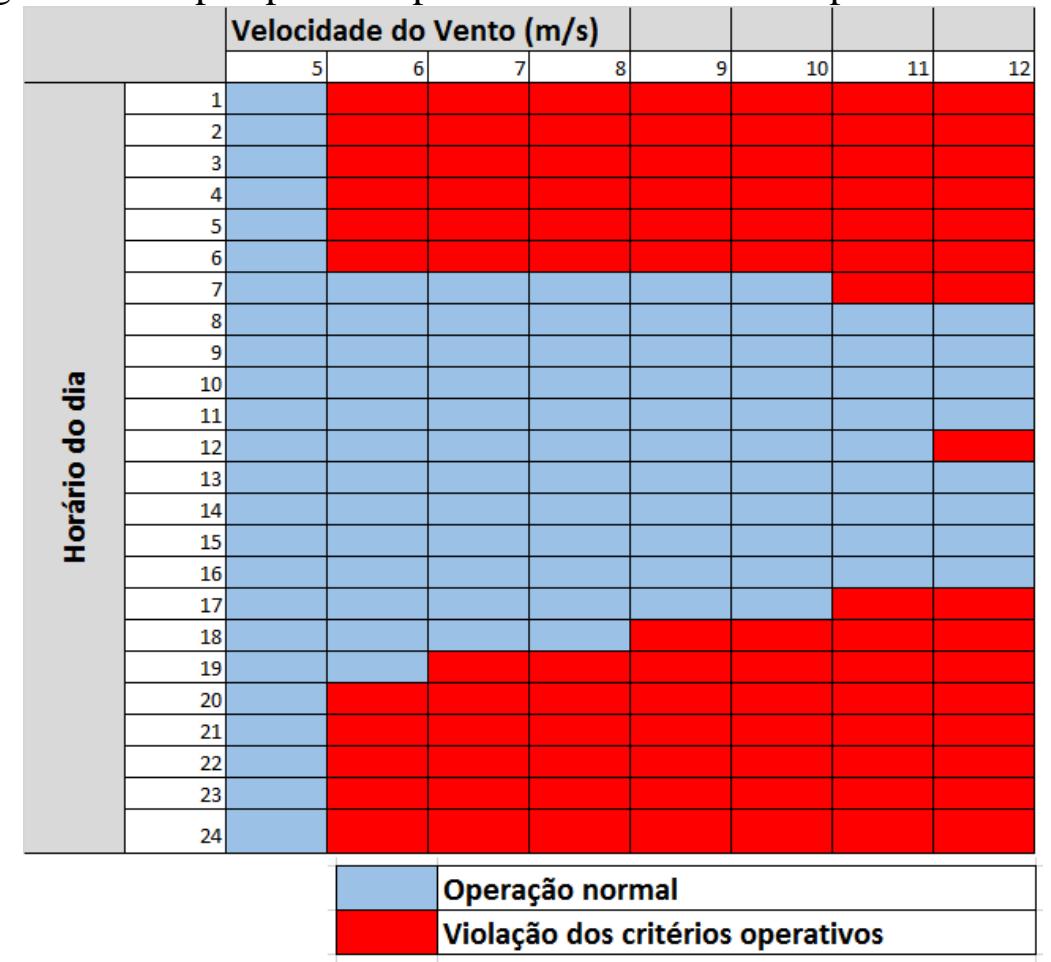

\subsubsection{Controle de Fator de Potência 0,92 Indutivo}

Os valores de tensão obtidos na barra B7 utilizando o controle de fator de potência 0,92 indutivo são apresentados na Figura 63. Para a velocidade do vento de $5 \mathrm{~m} / \mathrm{s}$, ocorre violação de tensão no patamar horário com carga mais elevada (10h). Observa-se também que, ao contrário dos resultados obtidos para os sistemas com consumidores residenciais e comerciais, essa estratégia de controle não é adequada para operação em condições de velocidade do vento elevada. Isso ocorre pois, nos patamares em que o carregamento é mais baixo no perfil de carga industrial, esses valores são inferiores em relação às mesmas condições nos perfis de carga residencial e comercial. 
Figura 63: Tensões na barra B7 para todos os valores de carregamento e velocidade do vento - controle de fp 0,92 indutivo

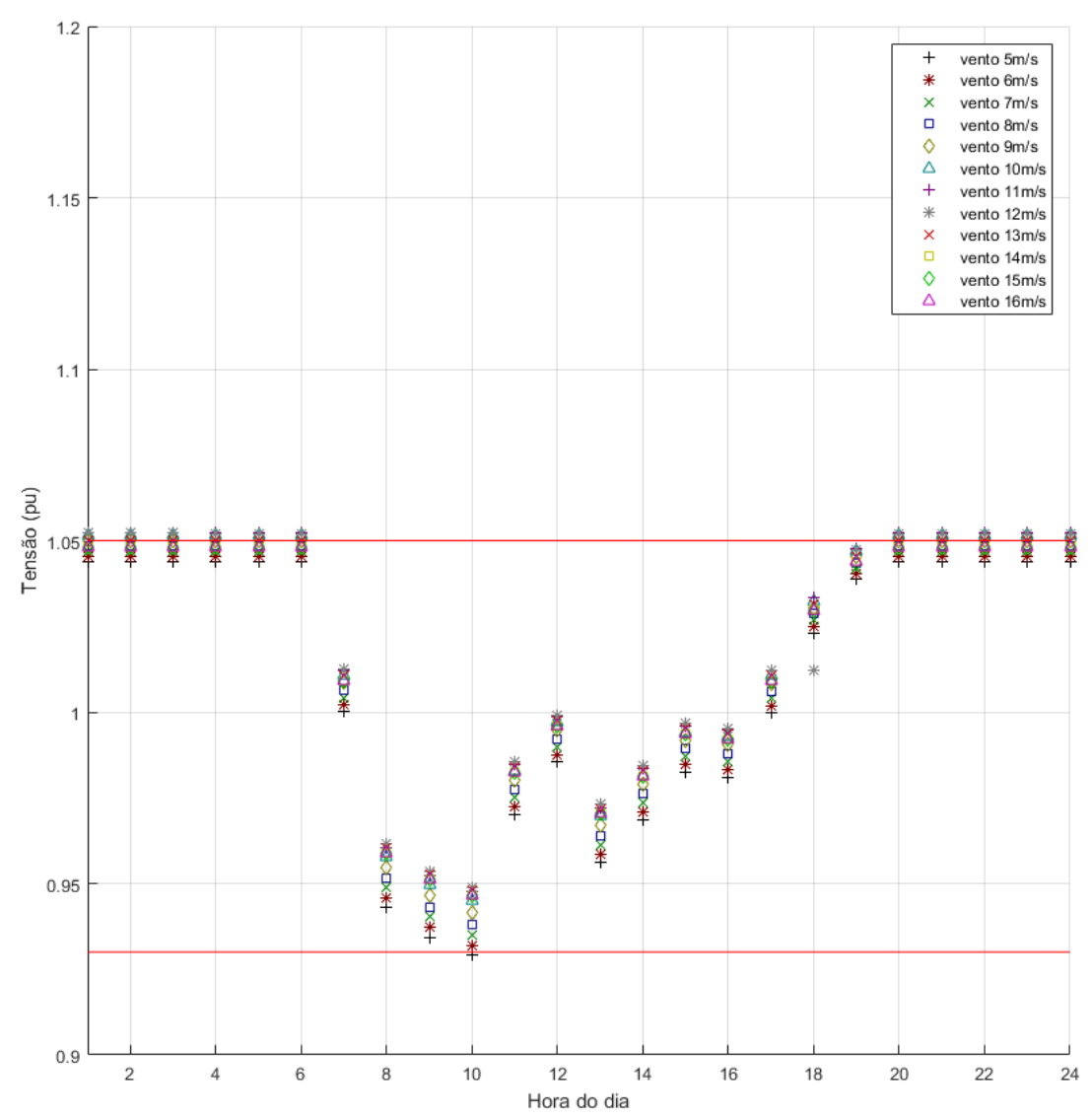

O mapa operativo obtido para o controle de fator de potência 0,92 unitário é apresentado na Figura 64. Observa-se que essa estratégia de controle é adequada apenas para a faixa de velocidades de vento entre $6 \mathrm{~m} / \mathrm{s}$ e $9 \mathrm{~m} / \mathrm{s}$. 
Figura 64: Mapa operativo para controle de fator de potência 0,92 indutivo

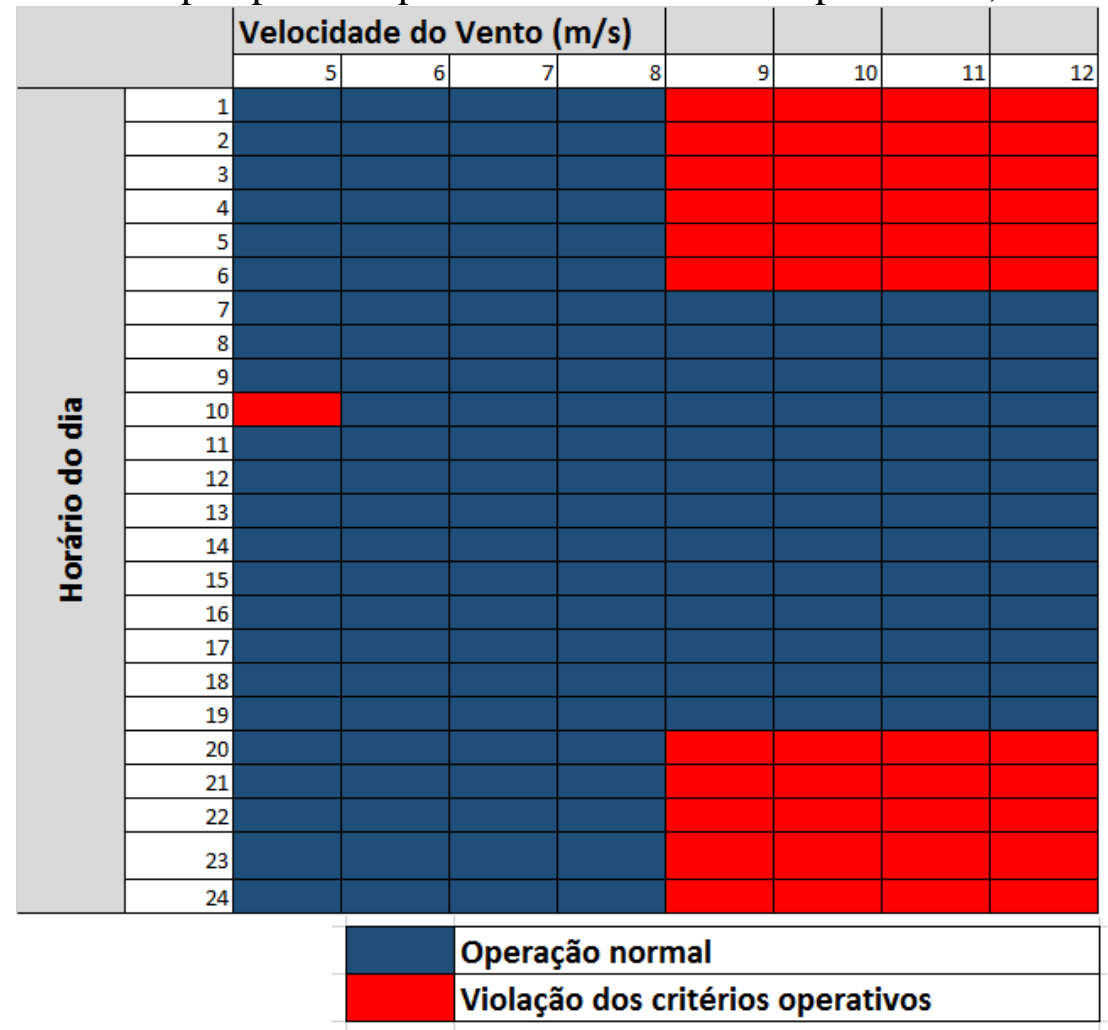

\subsubsection{Controle de Fator de Potência 0,92 capacitivo}

Na Figura 65, são apresentados os resultados obtidos de tensão na barra B7 para todas as condições de carregamento e velocidade do vento. Observa-se que esse controle é adequado apenas a velocidade do vento de $5 \mathrm{~m} / \mathrm{s}$. Para as demais velocidades, há pelo menos uma situação de carga que causa violação dos critérios de tensão.

Considerando-se os valores de tensão obitdos e o limite de potência reativa que podem ser suprido pela turbina, obteve-se o mapa operativo apresentado na Figura 66. 
Figura 65: Tensões na barra B7 para todas as condições de carregamento e velocidade do vento - Controle de fator de potência 0,92 capacitivo

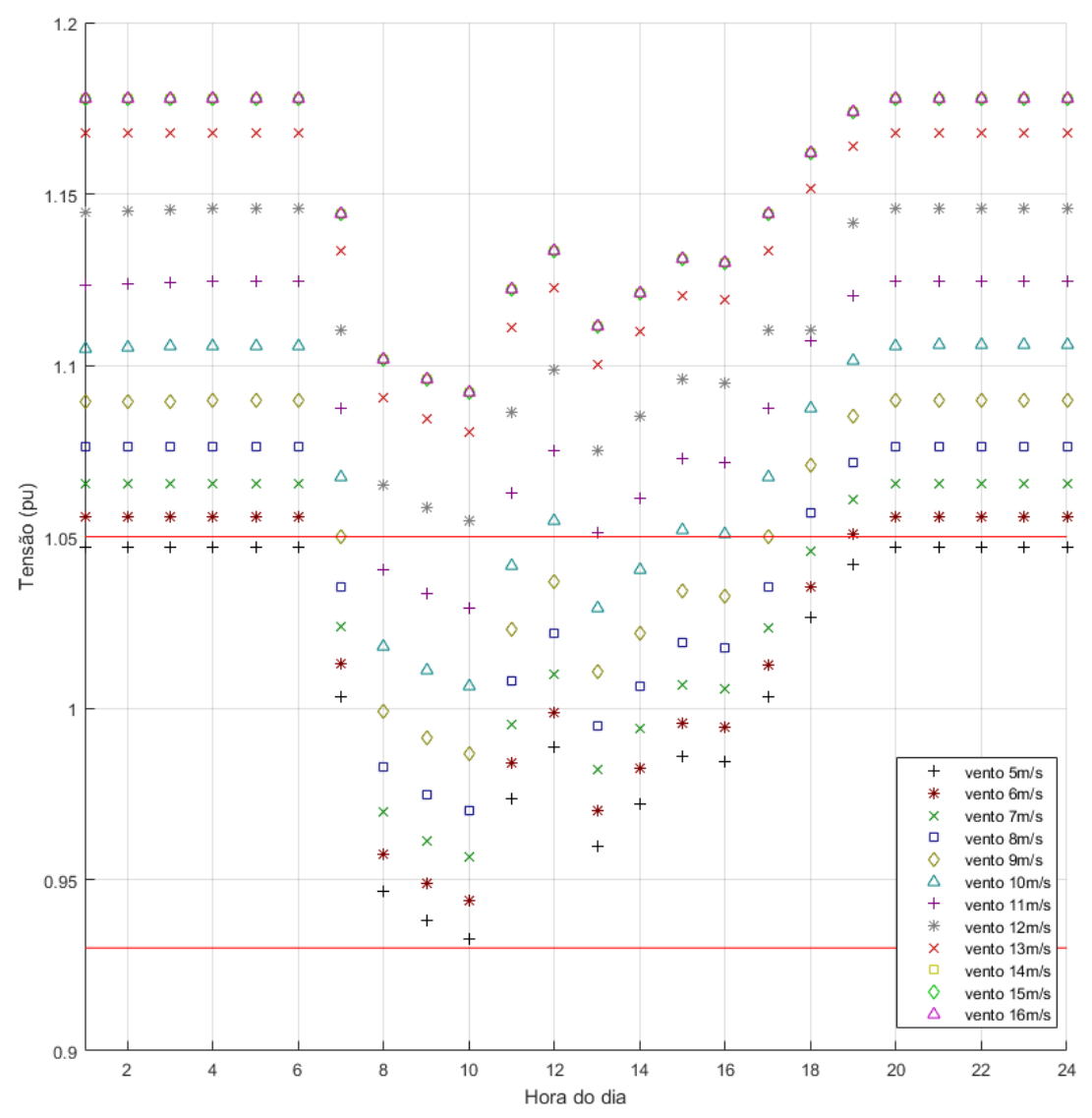

Figura 66: Mapa operativo para controle de fator de potência 0,92 capacitivo

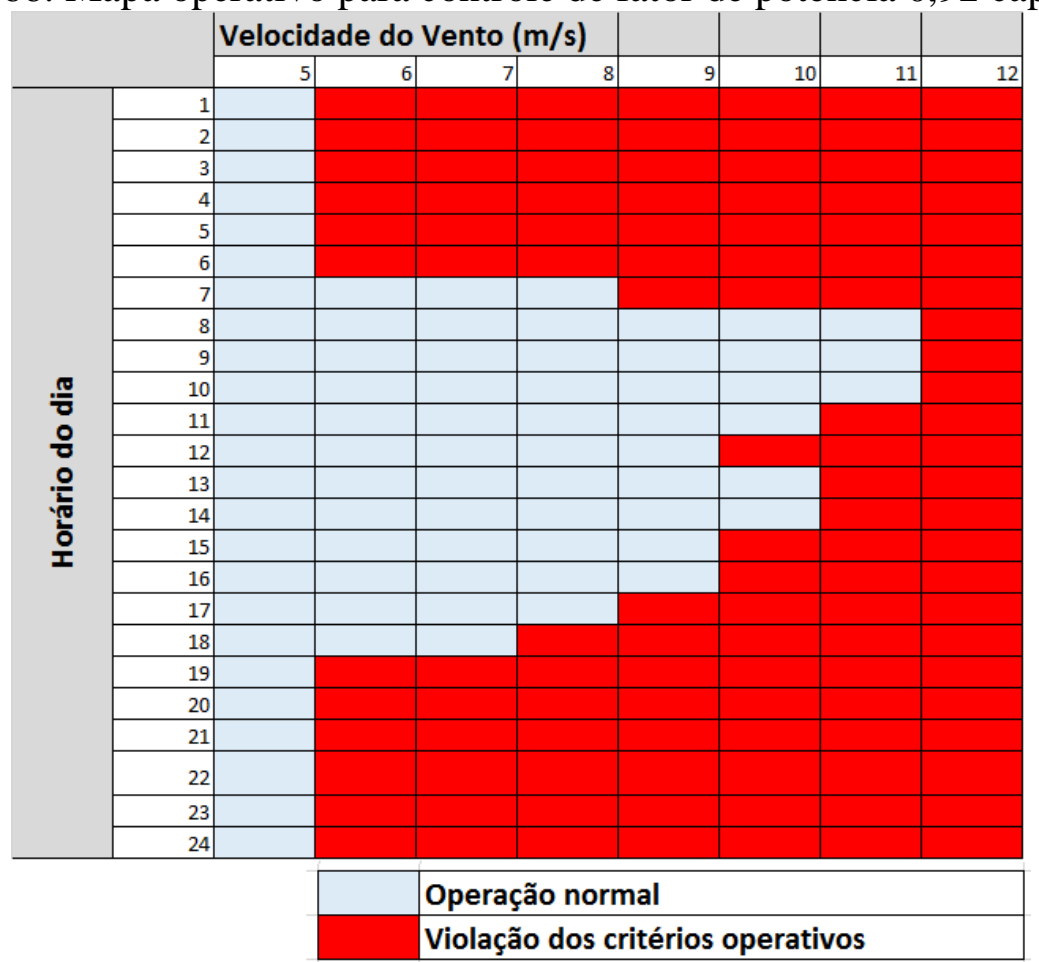




\subsubsection{Mapa Operativo Geral da Planta Eólica para a Rede com Consumidores Industriais}

O mapa operativo da planta para a rede com consumidores industriais é apresentado na Figura 67. Observa-se que, ao contrário das situações em que havia consumidores residências ou comerciais na rede, para o caso com consumidores industriais, é possível operar a rede com controle de fator de potência para a velocidade do vento de $5 \mathrm{~m} / \mathrm{s}$. Entretanto, para velocidades superiores a $9 \mathrm{~m} / \mathrm{s}$, torna-se necessário utilizar o controle de tensão.

Para este sistema, não é aconselhável utilizar controle de potência reativa ou controle de fator de potência na faixa de velocidades do vento acima de $8 \mathrm{~m} / \mathrm{s}$, que acarretariam em violação dos limites de tensão e potência reativa no ponto de conexão. Por ser uma faixa extensa de velocidades do vento, que envolvem muitos pontos operativos, possivelmente causariam violação dos indicadores e penalidades por parte do órgão regulador do setor.

Figura 67: Mapa operativo geral da planta com consumidores industriais

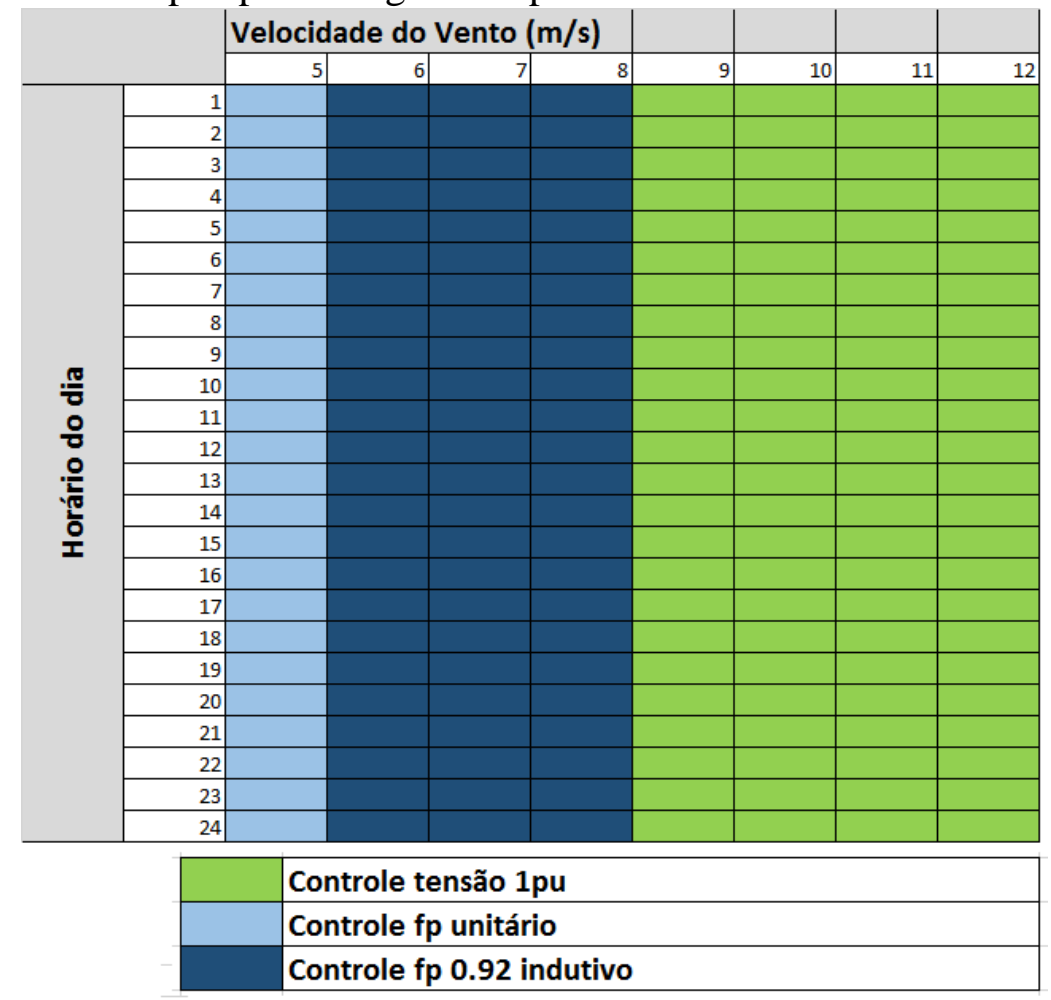

\subsection{Considerações Gerais}

Neste capítulo foram apresentados inicialmente os resultados obtidos para a rede com consumidores residenciais, considerando crescimento de carga de $10 \%$ em relação aos casos apresentados no capítulo 4. 
Em geral, os pontos operativos com violação dos critérios de tensão aumentaram em situações de carga elevada e diminuíram em cenários com carga reduzida. O controle de fator de potência 0,92 indutivo, que na rede original era adequado para operação em velocidades elevadas em quaisquer condições de carregamento, não é mais adequado em situações de carga elevada na nova rede estudada. Para contornar essa nova situação, utilizou-se controle de fator de potência 0,98 indutivo, que permite operação adequada no intervalo de velocidades do vento entre $10 \mathrm{~m} / \mathrm{s}$ e $12 \mathrm{~m} / \mathrm{s}$.

No intervalo entre $8 \mathrm{~m} / \mathrm{s}$ e $9 \mathrm{~m} / \mathrm{s}$, é possível operar a planta eólica apenas com controle de fator de potência unitário. Para velocidade de $7 \mathrm{~m} / \mathrm{s}$, apenas o controle 0,92 capacitivo mostrou-se adequado. Por fim, para velocidades do vento entre $6 \mathrm{~m} / \mathrm{s}$ e $7 \mathrm{~m} / \mathrm{s}$, a única alternativa para operação sem violação dos critérios de tensão e fator de potência é utilizar o controle de tensão em 1p.u. A partir desses resultados, foi montado o mapa operativo geral da planta eólica.

Em seguida, realizou-se estudo considerando consumidores com perfis de carga comercial e residencial. Em relação ao estudo considerado no capítulo 4, o estudo com consumidores comerciais apresentou análises e resultados semelhantes, com a alteração do perfil de carga refletindo apenas nos horários em que houve violação de tensão. Em relação ao mapa operativo geral da planta para essa rede, o controle de fator de potência 0,92 indutivo mostrou-se adequado para valores de velocidade do vento a partir de $7 \mathrm{~m} / \mathrm{s}$. Para valores inferiores, para que não haja violação dos critérios de tensão e fator de potência, foi necessário empregar o controle de tensão em 1p.u.

Para a rede considerando consumidores com perfil de carga industrial, pelo fato dessa rede apresentar carregamento inferior em relação às demais nos patamares de menor carga, o controle de fator de potência 0,92 indutivo não pode ser utilizado em todas as situações de carga para velocidades do vento a partir de $9 \mathrm{~m} / \mathrm{s}$. Para essa faixa de velocidades do vento, foi considerado o controle de tensão em 1p.u. Para velocidades do vento entre $6 \mathrm{~m} / \mathrm{s}$ e $8 \mathrm{~m} / \mathrm{s}$, o controle 0,92 indutivo mostrou-se adequado. Por fim, para velocidade do vento de $5 \mathrm{~m} / \mathrm{s}$, foi possível utilizar um dos controles de fator de potência (unitário), o que não foi viável nos casos com consumidores residenciais ou comerciais. Isso se deve ao fato dos maiores patamares de carga na rede com consumidores industriais serem superiores às duas outras redes estudadas. 


\section{Conclusões e Trabalhos Futuros}

As turbinas com geradores DFIG representam a tecnologia mais utilizada atualmente em plantas eólicas. Em relação às turbinas de velocidade fixa, apresentam como vantagens a possibilidade de controlar separadamente os valores de potência ativa e reativa, além de possibilitar melhor aproveitamento da energia eólica disponível. Em relação a outras tecnologias de velocidade variável, possui como uma das principais vantagens o fato de utilizar um conversor eletrônico não dimensionado para suportar a potência nominal do gerador, o que acarreta em custos reduzidos.

Através do desenvolvimento do presente trabalho, foi possível verificar os princípios de operação e de controle do gerador DFIG. Em relação à operação, observou-se a operação nos modos sub-síncrono e super-síncrono, além da atuação do sistema de controle aerodinâmico para limitação da potência ativa. Em relação ao controle, foi possível notar a regulação dos valores de tensão no ponto de conexão da rede através dos diferentes tipos de controle empregados na planta eólica e os diferentes valores de potência reativa consequentemente trocados com a rede.

No capítulo 4, foram utilizados diferentes tipos de controle da planta eólica para a rede com consumidores residenciais, observando-se a variação dos valores de tensão no ponto de conexão com a rede, de acordo com as condições de carregamento da rede e velocidade do vento. Para montar os mapas operativos referentes a cada tipo de controle, que mostram em quais situações de carga e velocidade do vento é possível operar a planta eólica sem violar os limites de tensão admissíveis, foram consideradas apenas as velocidades do vento (entre $5 \mathrm{~m} / \mathrm{s}$ e $12 \mathrm{~m} / \mathrm{s}$ ) que não violam os limites de capabilidade de potência reativa do modelo de turbina considerado nas simulações. Essa análise adicional foi necessária pois o modelo não considera os limites de potência reativa que podem ser supridas, que dependem das características do gerador e do conversor considerados.

O controle de fator de potência unitário permite operação para todos os cenários de carga apenas em uma determinada faixa de velocidades do vento (entre $6 \mathrm{~m} / \mathrm{s}$ e $9 \mathrm{~m} / \mathrm{s}$ ). Para velocidades superiores a $9 \mathrm{~m} / \mathrm{s}$, é possível operar a rede em todos os cenários de carga com o controle 0,92 indutivo. Para a velocidade do vento de $5 \mathrm{~m} / \mathrm{s}$, o controle de fator de potência 0,92 capacitivo, assim como os demais controles de fator de potência estudados, não permitem operação em todas as condições de carregamento. Logo, foi proposto utilizar o controle de tensão em 1p.u., sendo feitas considerações referentes à possíveis dificuldades de implantação dessa estratégia de controle em determinadas plantas eólicas. 
No capítulo 5, para a rede com consumidores industriais, notou-se uma diferença em relação aos demais casos estudados: o controle de fator de potência 0,92 indutivo não permite operação em todos os cenários de carga para velocidades mais elevadas (a partir de $9 \mathrm{~m} / \mathrm{s}$ ). Para essas situações, foi proposto utilizar o controle de tensão em 1p.u.

Ainda no capítulo 5, foram apresentados resultados considerando crescimento de carga de $10 \%$ na rede com consumidores residenciais. Comparando-se os mapas operativos obtidos para cada tipo de controle nas duas redes, observou-se em geral um aumento de pontos com violação de tensão em situações de carga elevada e diminuição de pontos com violação de tensão para situações de carga reduzida.

Com o controle 0,92 indutivo, existe pelo menos uma situação de carga com violação de tensão para todas as velocidades do vento consideradas. Pelo fato das violações de tensão ocorrerem em situações de carga elevada para as maiores velocidades do vento, foi possível contornar a parcialmente situação variando-se o valor do fator de potência para 0,98 indutivo. Com esse valor, foi possível operar no intervalo de velocidade do vento de $10 \mathrm{~m} / \mathrm{s}$ a $12 \mathrm{~m} / \mathrm{s}$.

Para a faixa de $8 \mathrm{~m} / \mathrm{s}$ a $9 \mathrm{~m} / \mathrm{s}$, é possível operar a rede apenas com o controle de fator de potência unitário. $\mathrm{O}$ controle de fator de potência 0,92 capacitivo permite melhor desempenho em situações de velocidade do vento reduzida e carga elevada, podendo ser utilizado em todos os patamares horários com velocidade do vento $7 \mathrm{~m} / \mathrm{s}$. Por fim, para velocidades entre $5 \mathrm{~m} / \mathrm{s} \mathrm{e}$ $6 \mathrm{~m} / \mathrm{s}$, para que não ocorra violação dos critérios de tensão ou fator de potência, foi sugerida operação com controle tensão em 1p.u.

Como sugestões de trabalhos futuros, podem ser abordados:

- Comparação de desempenho entre o gerador DFIG e outros modelos de geradores utilizado em turbinas eólicas. Caso seja utilizado um gerador síncrono de imã permanente, avaliar a influência nos valores de tensão da capacidade adicional de controle proporcionado por essa tecnologia, pelo fato de utilizar um conversor projetado para suportar a potência nominal da turbina.

- Avaliar os níveis de tensão em todas as barras do sistema e não apenas na barra de conexão com o sistema, modificando os mapas operativos obtidos para cada tipo de controle. Considerando todos os pontos operativos da rede, o número de pontos em que há violação dos níveis de tensão em pelo menos uma barra da rede deve aumentar consideravelmente, comparado ao número de pontos com violação na apenas barra de conexão com a rede. 
- Considerar a existência de equipamentos em determinados pontos da rede que possam trocar potência reativa e alternar os níveis de tensão nesses pontos, verificando assim a influência nos valores de tensão nas demais barras do sistema. Utilizando-se esses equipamentos, é possível diminuir as situações em que há violação dos limites de tensão. 


\section{Referências}

ABAD, Gonzalo et al. Doubly fed induction machine: modeling and control for wind energy generation. John Wiley \& Sons, 2011.

ABEEÓLICA. Boletim Anual de Geração Eólica 2016. [S.1.]. 2016.

ACKERMANN, Thomas (Ed.). Wind power in power systems. John Wiley \& Sons, 2005.

AKHMATOV, Vladislav. Variable-speed wind turbines with doubly-fed induction generators Part I: Modelling in dynamic simulation tools. Wind engineering, v. 26, n. 2, p. 85-108, 2002.

ALKANDARI, Ahmad M. et al. Steady state analysis of a doubly fed induction generator. Energy and Power Engineering, v. 3, n. 04, p. 393, 2011.

KUMAR, Ashwani; JAIN, Sanjay K. A Review on the Operation of Grid Integrated Doubly Fed Induction Generator. IJERSTE, v. 2, n. 6, p. 25-37, 2013.

ÁVILA, Manuel Ricardo Vargas. Modelagem dinâmica e controle de um gerador tipo DFIG em redes de distribuição. 2014.

ENGELHARDT, S., ERLICH, I., FELTES, C., KRETSCHMANN, J. Reactive Power Capability of Wind Turbines Based on Doubly Fed Induction Generators. IEE Transactions on Energy Conversion, v. 26, 2011.

CARDENAS, Roberto et al. Overview of control systems for the operation of DFIGs in wind energy applications. IEEE Transactions on Industrial Electronics, v. 60, n. 7, p. 27762798, 2013.

GONTIJO, Gustavo Figueiredo. Controles de um Sistema Eólico na Configuração DFIG com Funcionalidades de Condicionamento de Energia. Tese de Doutorado, Universidade Federal do Rio de Janeiro, 2016.

GWEC. Market Forecast for 2017-2021, 2016. Disponivel em: <http://www.gwec.net/wpcontent/uploads/2017/04/1_Market-Forecast-for-2017-2021.jpg>. Acesso em: 17 Maio 2016.

HANSEN, Anca D. et al. Review of contemporary wind turbine concepts and their market penetration. Wind Engineering, v. 28, n. 3, p. 247-263, 2004.

HANSEN, Anca D.; ALTIN, Müfit; IOV, Florin. Provision of enhanced ancillary services from wind power plants-Examples and challenges. Renewable Energy, v. 97, p. 8-18, 2016.

JACOB, Natália Moreira. Estudo do fluxo de potência de um gerador de indução de dupla alimentação atuando em um sistema de geração eólio-elétrica. Tese de Doutorado.

Universidade de São Paulo, 2013. 
MACDOWELL, Jason et al. Serving the Future: Advanced Wind Generation Technology Supports Ancillary Services. IEEE Power and Energy Magazine, v. 13, n. 6, p. 22-30, 2015.

MARQUES, Jeferson. Turbinas eólicas: modelo, análise e controle do gerador de indução com dupla alimentação. Universidade Federal de Santa Maria, 2004.

MOHSENI, Mansour; ISLAM, Syed M. Review of international grid codes for wind power integration: Diversity, technology and a case for global standard. Renewable and Sustainable Energy Reviews, v. 16, n. 6, p. 3876-3890, 2012.

MULLER, Set; DEICKE, M.; DE DONCKER, Rik W. Doubly fed induction generator systems for wind turbines. IEEE Industry applications magazine, v. 8, n. 3, p. 26-33, 2002.

NOVAK, Peter. On the modelling and partial-load control of variable-speed wind turbines. Chalmers University of Technology, 1995.

PETERSSON, Andreas. Analysis, modeling and control of doubly-fed induction generators for wind turbines. Chalmers University of Technology, 2005.

PHAN, Dinh-Chung; YAMAMOTO, Shigeru. Maximum energy output of a DFIG wind turbine using an improved MPPT-curve method. Energies, v. 8, n. 10, p. 11718-11736, 2015.

PINTO, M. D. O. Fundamentos de Energia Eólica. LTC, 2013.

RÊGO, Saulo Loiola et al. Um estudo das características dinâmicas elétrica e mecânica de um gerador de indução duplamente alimentado acoplado à rede elétrica. 2015.

SALLES, Maurício Barbosa de Camargo. Modelagem e análises de geradores eólicos de velocidade variável conectados em sistemas de energia elétrica. Tese de Doutorado.

Universidade de São Paulo, 2009.

SCHUBERT, Gerda. Modeling hourly electricity generation from PV and wind plants in Europe. European energy market (EEM), 2012 9th international conference on the. IEEE, 2012. p. 1-7.

SILVA, K, F., Estudo de Estabilidade de Sistemas Elétricos de Potência na Presença de Diversos Modelos de Unidades Eólicas. Tese de Mestrado. Escola Politécnica da Universidade de São Paulo, 2006.

SMITH, P., Question of the Week: Will permanent magnet generators replace DFIG? Disponivel em: < http://www.windpowermonthly.com/article/1315794/question-week-willpermanent-magnet-generators-replace-dfig > . Acesso em 03 Outubro 2017.

SOHN, Alexandre Prodóssimo. Estudos de estabilidade de sistemas elétricos de potência na presença de diferentes modelos de unidades eólicas. 2014. Tese de Doutorado. Universidade de São Paulo. 
TRIPATHY, S., ROURKELA, N., Different Generator Topologies used in Wind Turbine Applications. Indian institute of technology, Bhubanneswar, A case study, 2008.

VEERASATHIAN, Chanokwan; ONGSAKUL, Weerakorn; MITRA, Joydeep. Voltage stability assessment of DFIG wind turbine in different control modes. Green Energy for Sustainable Development (ICUE), 2014 International Conference and Utility Exhibition on. IEEE, 2014. p. 1-6.

VOLTOLINI, Helio et al. Modelagem e controle de geradores de indução duplamente alimentados com aplicação em sistemas eólicos. 2007.

VAN DE VYVER, Jan et al. Droop control as an alternative inertial response strategy for the synthetic inertia on wind turbines. IEEE Transactions on Power Systems, v. 31, n. 2, p. 1129-1138, 2016.

WU, Yuan-Kang; YANG, Wu-Han. Different Control Strategies on the Rotor Side Converter in DFIG-based Wind Turbines. Energy Procedia, v. 100, p. 551-555, 2016. 